\title{
ECOLOGICAL CONSCIOUSNESS AND THE LIMITS OF THE ACADEMY: A CASE STUDY APPROACH TO ECOHEALTH TRAINING AND RESEARCH
}

\author{
by \\ Mathieu Feagan \\ MA, Trent University, Peterborough, Ontario, Canada, 2007 \\ BA, McGill University, Montreal, Quebec, Canada, 2000
}

\author{
A dissertation \\ presented to Ryerson University and York University \\ in partial fulfillment of the \\ requirements for the degree of \\ Doctor of Philosophy \\ In the Program of \\ Communication and Culture
}

Toronto, Ontario, Canada, 2015

(C) Mathieu Feagan 2015 


\section{Author's Declaration}

I hereby declare that I am the sole author of this dissertation. This is a true copy of the dissertation, including any required final revisions, as accepted by my examiners.

I authorize Ryerson University to lend this dissertation to other institutions or individuals for the purpose of scholarly research.

I further authorize Ryerson University to reproduce this dissertation by photocopying or by other means, in total or in part, at the request of other institutions or individuals for the purpose of scholarly research.

I understand that my dissertation may be made electronically available to the public. 


\section{Abstract}

ECOLOGICAL CONSCIOUSNESS AND THE LIMITS OF THE ACADEMY: A CASE STUDY APPROACH TO ECOHEALTH TRAINING AND RESEARCH

Doctor of Philosophy, 2015

Mathieu Feagan

Joint Program in Communication and Culture

Ryerson University and York University

This dissertation explores the concept of ecological consciousness through a case study approach examining recent attempts to use graduate training and research to better address issues of ecological sustainability and human health. Since the 1970s, there has been a growing number of graduate training programs designed to equip a new generation of graduates with the kind of awareness necessary to address the global ecological crisis. Despite these efforts, the crisis on the whole continues to worsen. Although scholars have pointed to the challenges that ecological consciousness poses for graduate training and research, few studies have examined these challenges from the point of view of graduate students themselves. To better understand the opportunities and constraints of graduate training and research, this dissertation uses the framework of ecological consciousness to analyze the experiences of an international group of twenty-six graduate students and professionals trained in ecosystem approaches to human health (ecohealth) in Canada, West and Central Africa, and Central America. Drawing on systems thinking, Indigenous knowledges, and historical materialism, I argue that ecological consciousness means using different ways of knowing to challenge the disciplining tendency of academic knowledge 
production and open space for a wider ecology of knowledge to develop and express itself. Methodologically, this project is informed by institutional ethnography, building on the diverse experiences and insights of interviewees to make sense of the layered contextual frames of the university, the state, and international development research projects. Despite an orientation toward transformative practices, interviewee experiences reveal strong pressures to fit within top-down, disciplinary processes already governing the administration of training and research, thereby limiting the possibilities for ecological consciousness. I conclude by offering certain theoretical possibilities for how ecological consciousness can support collective action upon the disciplinary employment structures, which graduate students and professionals have a key role in transforming. 


\section{Acknowledgements}

I would like to thank my committee: Dr. Alan Sears (supervisor), Dr. Lila Pine, and Dr. Paul Moore. 


\section{Dedication}

To Marta, my beloved. 


\section{Table of Contents}

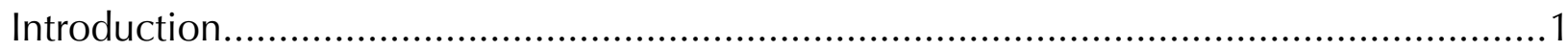

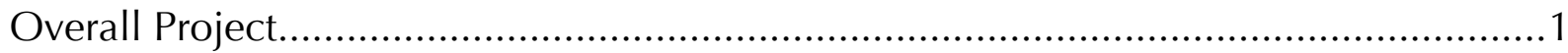

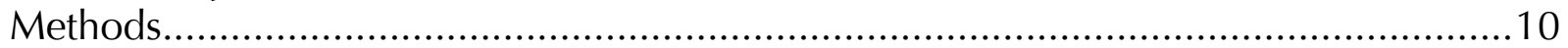

A Case Study: Ecosystem approaches to health, or ecohealth...................................21

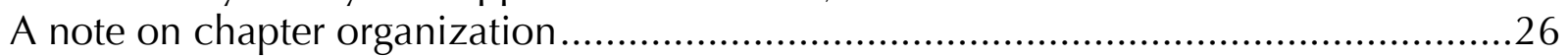

Chapter 1. Ecological Consciousness: Theoretical Foundations and Key Themes.............29

Navigating the contradictions of ecological consciousness in training and research......30

The university context as a case study for ecological consciousness.............................34

The university's relationship to a wider ecology of knowledge.....................................40

Another process of knowledge production is possible .............................................50

Systems thinking, Indigenous ways of knowing, and historical materialism as

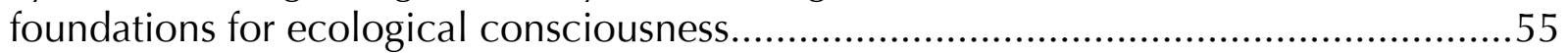

Pedagogical implications within an institutional and global development frame..........64

Chapter 2. Pathways to the Encounter with Ecohealth ................................................72

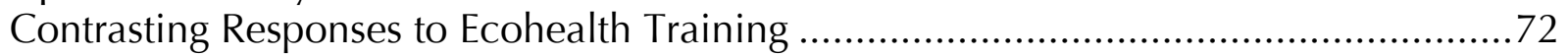

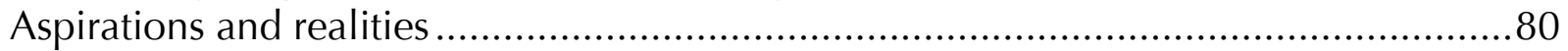

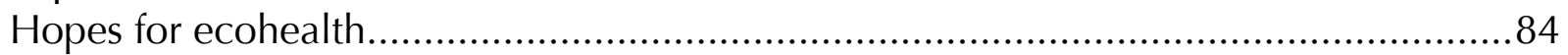

Chapter 3. Navigating the Institutional Frame of the University .......................................99

Finding a place within the university's disciplinary frame ........................................113

Chapter 4. From the University to the Field: Framing Relations with Communities .......124

The impact of the nation-state frame ......................................................................133

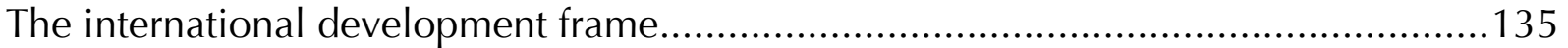

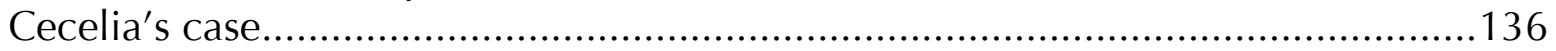

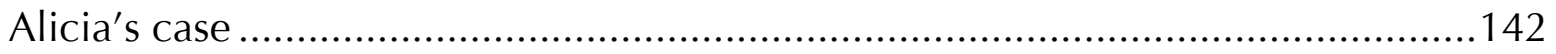

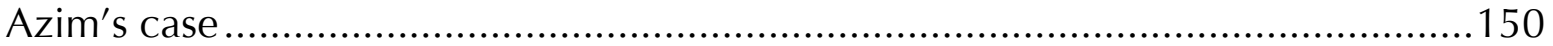

Chapter 5. Toward a Conclusion: Working Inside and Outside the Limits of Academic

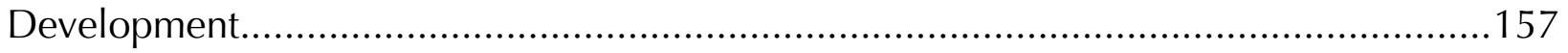

Navigation and Transformation: Confronting the backdrop of employment relations .168

The ambiguous potential of peer relations...........................................................174

General Implications for Ecological Consciousness, Graduate Training and Research 185

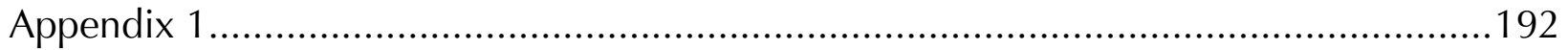

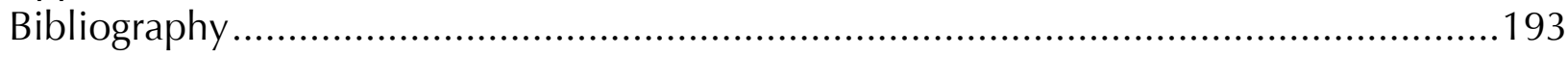




\section{Introduction}

\section{Overall Project}

This dissertation explores ecological consciousness through university-based attempts to address issues related to the global ecological crisis. Ecological consciousness is often presented as an awareness of humanity's dependency on ecosystems, with the assumption that this awareness is essential for steering humanity off of its current ecologically destructive path. In the context of university training and research, spreading this awareness has been associated with equipping the next generation of leaders with certain skills, knowledge, and competencies (Reynolds et al 2010; Orr 2004), especially around moving from single discipline to transdisciplinary and participatory approaches (Barnett 2011). In much of this activity, however, students' existing skills and awareness have tended to be overlooked. Furthermore, there has been little analysis of how the position of students as experts-in-the-making affects the development of their consciousness or their role in confronting the disciplinary model currently underlying the administrative structure of university-based approaches (Poteete, Janssen, \& Ostrom 2010). Overall, ecological consciousness has been limited to promoting a given set of ideas (values, principles, attributes) that allegedly give rise to ecological thinking and action, while leaving the material conditions of training and research largely in place, unchanged. Using a case study approach, I explore the tension experienced by those seeking to develop innovative approaches while obtaining university accreditation. 
The development of ecological consciousness through graduate training and research has attracted a wide range of contributions from systems thinkers, Indigenous scholars, educational practitioners and other theorists emphasizing the importance of bringing different ways of knowing together in a developmental process ( $\mathrm{O}^{\prime}$ Sullivan and Taylor 2004). Far from a fixed ecological worldview achieved by certain enlightened individuals (see for example, Esbjorn-Hargens and Zimmerman 2009; Uhl 2003 and 2013; Suzuki 2012), consciousness becomes a property of the relationship between a group and its surrounding context. Acknowledging this relational character is key for unlocking the transformative potential of consciousness, seeing it as both a product of context and an ability to direct action upon context, thus bringing into play both the context and the consciousness that exists in relationship to it. Rather than framing the specialists as those already in possession of ecological consciousness, thereby reducing their role to informing the rest, I suggest that specialists have a role in bringing different ways of knowing together in a collective inquiry into the norms, conventions, and structures of a given community form. Far from a standardized awareness transferred from the trainers to the trainees, ecological consciousness becomes part of a process of opening the boundaries that dominant approaches impose on the wider ecology of knowledge (Rosenberg 1997; Santos 2008). As an emergent property of the whole set of relationships through which thought and action are produced, ecological consciousness requires intervening in the ecology of knowledge production, including the institutional contexts of graduate training and research. The problem is to go beyond marketing new approaches, toward actually 
confronting the conditions in which they must be practiced—and I will argue that the experts-in-the-making are especially well positioned to help with this confrontation.

Methodologically, my analysis takes inspiration from institutional ethnography (Smith 2004), exploring the experiences of a group of graduate students and professionals trained in ecosystem approaches to health (ecohealth). While the notion that human health is tied to environmental conditions surely dates back to the beginning of humanity, ecohealth as an approach to university-based research and training only began to take on certain identifiable forms in the 1990s. Drawing on complexity theory, post-normal science, and systems thinking, James Kay and colleagues at the University of Waterloo began publishing articles under the title "ecosystem approach" (Kay et al 1994a; Kay et al 1994b; Kay et al 1999). In parallel, the International Development Research Centre (IDRC) in Ottawa - a Canadian crown corporation founded in 1970 to support the development of research capacity in the global South (Muirhead and Harpelle 2010) - began offering seed-funding to test the feasibility of an ecosystem approach to research about human health. The CARUSO project, a collaboration between Canadian and Brazilian researchers studying mercury contamination in the Amazon, became foundational for establishing the viability and parameters of at least one version of ecohealth research, resulting in dozens of publications, the earliest dating back to Jean Lebel et al (1996). There is now a growing global network of leaders in ecohealth research and training across Latin America, Asia, Africa, and Canada. Activities include multi-country and multi-partner research projects, a handful of graduate programs (Masters and $\mathrm{PhD}$ ), graduate and undergraduate course 
offerings, training modules and manuals, intensive field-school training courses, academic conferences and publications. ${ }^{1}$

Through interviews with people in Canada, West and Central Africa, and Central America, my research presents the struggles, hopes, and anxieties of ecohealth experts-inthe-making, with the aim of using their experiences to help understand how training and research might better support the development of new capacities - including practices, forms of community, and new types of awareness - leading to sustainable futures. Consider the following statements by Gilles and Beatrice, two of the interviewees whose experiences I will present in greater detail in Chapters 2, 3 and 4. Gilles, a graduate student in the social sciences trained in ecohealth in West Africa, remarked:

The ecohealth approach gives me the possibility to put in place sustainable solutions, and sustainable solutions are those that can be put in place by the populations themselves, even if the study that I conducted is completed, the solutions that I have been able to identify, they have to be capable of staying there and being valorized by the communities, and more precisely through their participation. So for me this is a fundamental element that motivates me in my day-to-day when I try to actualize work or to conduct investigations all the while valorizing the ecohealth approach.

There are subtle tensions in the passage, for example, between the role of the researcher and the role of the community, however the basic message is clear: the ecohealth approach makes it possible to implement sustainable solutions. Compare this to the following statement from Beatrice, a graduate student in the natural sciences trained in ecohealth in Canada:

One of the things I struggle with as a researcher is this feeling of extraction, and I know that participatory research is attempting to address this issue, what do they call, you know, parachute researchers, when they go in, take stuff, take knowledge and then leave and publish. But sometimes it still seems to me that participation is still extractive, and again it's just so context dependent, but I think that one of the experiences for me that has brought up this uneasy relationship is, ahh... [she cites an example of a so-called participatory research project in which she worked as a research assistant] but the problem was that [the populations supposed to participate in the study] were so

\footnotetext{
${ }^{1}$ More details on ecohealth are provided in in the next section on methods.
} 
overburdened [with their own daily work activities], but the problem was that on top of this, there was so many NGOs and so many research groups in this small geographic area, which is known for being one of the poorest of all of Latin America in poor health outcomes and that sort of thing, there was so many wanting to be participatory work that it was actually this humongous additional burden. And so it started to feel like participation wasn't doing what it was supposed to be doing and had become very extractive.

There are many contextual layers at play. On an affective dimension, there is the struggle around the role of the researcher in relation to community empowerment and change. There is the context of international development research projects funded with a focus on marginalized populations, which attract a lot of research traffic without any clear sense of coordination between the projects. And then there is the position of the young professional or graduate student hired as a research assistant to carry out a specific data collection task within a larger research project that s/he did not necessarily design. Gilles' and Beatrice's comments do not lead to an obvious determination about the value of new trends in graduate training and research; rather they begin to map some of the messiness within the terrain that must be navigated. It is this messiness that must be understood from the point of view of the group poised to take up these new training and research approaches - what do the trainees come to know, what options do they face, and how could this lead to a real change in how health and sustainability issues are addressed?

By mapping the contexts and patterns that frame interviewee experiences, I begin to theorize the hidden agency that graduate students and young professionals can bring to transforming their own training and research. However, the extent to which this agency is acted upon depends on a number of factors, including the room available for its development. For example, in Marlo's experience of the ecohealth training course, most of this room was already occupied: 
It sometimes felt like it was a bunch of people who all had different experiences but when they came together they kind of dumbed down some of what they actually felt to kind of fit it into this box. The first week was essentially lectures on the importance of the pillars, which again I thought was a bit redundant because we'd done all the readings on these sorts of things, I don't remember a ton of details about the individual lectures, I remember there was quite a few of them, they were long days.

By contrast, Caroline described the training course as "special" because "it br[ought] back

these human interactions" where people had the opportunity to "genuinely know each other":

What was really good about the course was how it was small enough that people actually worked together on solving problems and there was so much engagement so you had the chance to develop bonds, right, and literally were forced into situations where you had to work together, you had to plan together and it drew everyone closer, it put that intimacy back into things, which is awesome.

Caroline's and Marlo's experiences point to two entirely different kinds of space within the same course structure, and the resulting tension helps characterize the terrain of graduate training more generally. On the one hand, there is the expectation that the course instructors have some knowledge that must be imparted to the students—-part of the justification for the training process rests in this difference between the already acquired expertise of the trainers and the lack of this same expertise in the trainees. On the other hand, there is the reality that learning happens through the learner's own inquiry process, which means that what is in the heads of the trainers matters much less than how the activities of the trainees are organized to support their own discoveries. What starts to emerge is the possibility of a totally different model of graduate training and research, where the diverse experiences and existing skills of the trainees drive their own group inquiry, and the role of the teachers shifts from delivering content expertise to offering 
feedback, prompts, additional evidence, and theoretical guidance supporting the group's inquiry process. ${ }^{2}$

The general question about how to open space for the potential agency of the learners is not new; educational theorists whom I will discuss in Chapter 1 have already made important contributions. But there is a need to re-examine this question at the present juncture of at least two rising global tendencies. The first is the growth of higher education as a global industry (Lazerson 1998; Gibney 2014), especially in the areas of environmental training and research (Moeller et al 1979), sustainability (Sibbel 2009) and awareness-raising (see United Nations 1973, 1992, 1997, 2002, 2012; and see Brundtland 1987). The second is the decline of ecosystems on a global scale (Millennium Ecosystem Assessment 2005) as the global ecological crisis continues to worsen (IPCC 2013). How is it that more and more time, energy, and resources are being invested in the production of new expertise and awareness, yet the basic path of destruction remains, on the whole, firmly in place? Zizek (2007) has alluded to "ecology as new opium for the masses," and according to Kovel (2007: 3), "the era of environmental awareness, beginning roughly in 1970, has also been the era of greatest environmental breakdown." But when it comes to understanding what is actually going on within the channels of academic training and research, there is hardly a group better positioned to explore these questions than those moving through the training process themselves.

\footnotetext{
${ }^{2}$ In 2010, when I took the ecohealth training course in Montreal, one of the activities was called a "Rich Picture Map," which entailed walking through parts of the city snapping photos of examples of health or lack of health, and then in groups organizing the pictures to capture the group's insights-it was one of the course highlights for me.
} 
A third global tendency that coincides with the present growth in higher education and the escalation of ecological destruction, is the continued shift toward conditions of precarious labour as part of an ongoing "global slump" (McNally 2011; also see Readings 1996, and Giroux and Giroux 2008). While not the main focus of this dissertation, these conditions arise as a subtheme in interviewee experiences, thereby lending further importance to this question of how a new generation can gain greater steering capacity over the trends that define its time. If trainers and trainees continue to reproduce a model that does not unlock the full potential agency of the trainees (and, at worst, may systematically limit this capacity), it becomes imperative to find ways of counteracting this reproduction. Once again, posing the question from the point of view of the experts-inthe-making offers a unique window on the complexity of the situation. On the one hand, drawn to disassociate themselves (at least temporarily) from the roles that traditional researchers are set up to play, while, on the other hand, seeking accreditation and professional careers within existing institutional channels, how will these experts-in-themaking handle what remains a strong incentive to simply accept the existing channels of expertise in the form in which they present themselves?

My focus on young researchers moving through the official channels of academic and professional training goes beyond the convenience of working with a group to whom I have close access, toward an attempt to take seriously the aspirations and feelings of a group whose ability to form its own goals is always challenged by the norms imposed through the authority of established measures of success. Globally, young researchers are at the centre of the expansion of graduate and professional training in the North and the 
South, and many of these training programs - such as ecohealth - have direct ties to North-South global relations. Yet the extent to which trainees are encouraged by existing authorities to confront their own position within a history of unequal distribution of wealth deserves further attention. Graduate students and professionals may be, in general, a privileged group, but their struggle holds important clues in a world where, as Marcuse (1964) has argued, the process of politicization has become complicated by the rise of capitalism's technological capacity. Marcuse argues that the power of critique has diminished as the production of marginalization and wealth have become streamlined within the production of reality, which presents its own rationality as the norm to which everyone must conform. While there is a need for politicization everywhere, this need is confronted with the opposite tendency, that is, toward de-politicization and reaffirmation of the status quo.

Marcuse's analysis rests on a contrast between positive and negative thinking, where the former refers to thinking that takes for granted the parameters of the existing production process and its social organization, whereas the latter struggles to transcend those parameters and create the potential for new forms of organizing. Negative thought is thus critical for confronting inequities built into the established order, but Marcuse notes: "Even where the critical abstraction arrives at the negation of the established universe of discourse, the basis survives in the negation (subversion) and limits the possibilities of the new position" (1964: 134). In other words, thinking (whether positive or negative) does not by itself change the material base of the established order-this can only happen through action, and the possibilities for action are always limited by what is already in 
place. As I will show, this would seem to be particularly true in the case of graduate students and young professionals, who often start out with aspirations for making genuine change in the world but find the spaces provided for them contain their efforts within preset parameters, which are generally (though not without contradictions) suitable to the reproduction of the status quo. By examining how graduate students and professionals might politicize themselves, I take the struggle for ecological consciousness beyond choosing an "ecological" paradigm, toward transforming the structures that currently reinforce dominant, top-down forms of authority.

The two arches of this dissertation - one starting from the concrete experiences of interviewees, the other starting from the theoretical framework of ecological consciousness - intersect in such a way that leaves room for further contributions to what remains an open-ended inquiry. While I explore some of the challenges that graduate students and young professionals face, by no means can I offer a complete mapping of all of the dimensions and contexts that frame these efforts. The contribution of this dissertation focuses on the praxis of creating space for the experts-in-the-making to confront and take ownership over the predicaments of their own position.

\section{Methods}

My approach has elements of grounded theory (Corbin and Strauss 2008) in that I insist on listening carefully to the lived experiences of interviewees, which provide the core themes of the project. But my methodology fits better overall with the aims of institutional 
ethnography (Smith 1974; 2005), which explores the connections between concrete experiences and the inter-textual spaces that frame them.

Institutional ethnography means using ethnographic methods to explore the ways people's experiences are framed through institutional contexts organized around texts. I rely primarily on interview data and participant observation to uncover the underlying and interconnecting themes and contexts that connect the diversity of interviewee experiences. Unlike traditional ethnography, which emerged out of the anthropological study of the "other," institutional ethnography calls for a sociology for and by the people, meaning that it aims "to make visible as social relations the complex practices that coordinate people's actions across separations of time and space, often without their conscious knowledge" (Campbell and Gregor 2004: 31). Engaging with this mapping process can help mobilize a group's capacity to investigate its own situation and become subject of its own knowledge, within certain parameters of a given historical process. Thus, experience becomes a valuable source of knowledge for re-visiting certain theoretical concepts and questions.

The development of institutional ethnography as a method began with Dorothy E. Smith's own critique of sociology based on her experience as a graduate student: "how sociology is thought—its methods, conceptual schemes, and theories—-has been based on and built up within the male social universe (even when women have participated in its doing)" (Smith 2004: 22), and since the "world as it is constituted by men stands in authority over that of women," the effect is "to impose the concepts and terms in which the world of men is thought as the concepts and terms in which women must think their 
world." This unequal standing is reinforced through "governing or ruling" relations, which Smith defines as the "total complex of activities differentiated into many spheres," including the professions, government, "and also the activities of those who are selecting, training, and indoctrinating those who will be its governors" (Smith 2004: 23). She claims that the different disciplines make up the institutions "through which we are ruled and through which we, and I emphasize this we, participate in ruling." Disciplinary workers become alienated from the products of their labour since "the body of knowledge which its members accumulate is appropriated by the discipline as its body." In the case of sociology, she says "we find out how to treat the world as instances of a sociological body of knowledge," and she calls this procedure "a sort of conceptual imperialism" (24). The result, she argues, is "a bifurcation of consciousness" (25), since as a woman graduate student in sociology she must prove herself on the established terms of success, yet those terms implicitly or explicitly silence women's knowledge and experiences, such that "the harder she works the more she strengthens the order which oppresses her" (26).

Institutional ethnography and my approach to ecological consciousness come together in seeking to reverse the disciplining tendency of graduate education, turning it on its head, so that the actual range of subjective experiences of students becomes the starting point for learning how to confront a pre-existing institutional context that organizes thought and action. If research and training programs are going to contribute to social change, they cannot start by ignoring the knowledge and experiences of the students. On the contrary, students must empower themselves to redefine the structures of knowledge they are confronted with. In the context of ecohealth, institutional ethnography 
means uncovering a number of layers through which experiences are shaped: the pathways for encountering ecohealth training, the institutional frames of the university, the state, and international development work, and the norms and incentives that currently come with these frames. Rather than take this whole context for granted and thereby limit understanding to certain products that depend on this particular configuration of space, institutional ethnography makes use of experience to map the layered nature of the space itself, which then sets up the possibility for its transformation.

To collect these experiences and begin this mapping process, I conducted in total 44 interviews - 17 in person, 27 by Skype—with people involved in ecohealth research and/or training in Canada, West and Central Africa, and Latin America. Of the 44, 26 were in-depth interviews with graduate students, young professionals and recent $\mathrm{PhD}$ recipients. These people are the primary focus of my inquiry and I refer to them as "young researchers," the "interviewees," or the "experts-in-the-making." They have been involved with ecohealth in one or more of the following ways: as participants in ecohealth training, as employees working on ecohealth projects, or as newly emerging researchers and professionals attempting to incorporate ecohealth approaches into their own projects and practices. Interviews lasted approximately 1-1.5 hours each, they were recorded and transcribed by me, and they make up the core of the research data for this project. Although in some cases there were multiple affiliations, the primary affiliation of interviewees can be described as follows: 12 had been involved with ecohealth in Canada, 7 in West and Central Africa, and 7 Central America (see Appendix 1). Although limited in scope, the small sample size allows a depth of analysis that is hard to reach with 
larger samples. It is this depth that reaches the underlying themes and contexts at the heart of this study. The remaining 18 interviews were shorter (approximately 30-45 minutes), conducted with faculty members, staff of the EcoHealth Program at the International Development Research Centre (IDRC) in Ottawa, and other professionals lending support to ecohealth approaches. These interviews were not recorded (except through careful note-taking) and they serve to gather information about the history of the ecohealth approach and its surrounding context.

My focus on the experts-in-the-making, rather than the more established faculty and staff, was deliberate from the outset of my project: I wanted to find out what ecohealth meant to those coming through the channels of graduate and professional training since, as they are repeatedly told, the future of ecohealth would depend on them, and while some of their views had already been collected through surveys administered in relation to training courses and workshops, no comprehensive in-depth qualitative studies had been conducted from a near-peer perspective. Indeed, I believe that my position as a peer or near-peer gave rise to a different kind of interaction—and therefore a different kind of information —-than what might be collected through surveys or other means administered by the faculty or staff directly implicated with promoting or delivering ecohealth.

I recruited interviewees in two ways. Firstly, I circulated an open invitation in an email explaining my research project and inviting those interested to contact me: I distributed this email myself on a Canadian based ecohealth listserv; for West and Central Africa, I had the email distributed by one of my colleagues with access to the listserv there; and in Central America, I had another colleague distribute the email to those 
working in this node. I attempted to word my invitation in a language that would invite a diversity of people to participate regardless of their present level of involvement with ecohealth, my rationale being that outlier experiences may hold a key to understanding some of the dynamics within ecohealth training and research. Most of my interviewees responded to one of these emails. I also contacted certain potential interviewees directly by locating their email addresses online. For example, in Canada the list of participants in the ecohealth training course is available through the IDRC website. It may be worth noting that I did not interview my partner, Marta Berbés, and one of my closest friends, Ben Brisbois, both of whom had taken the ecohealth training course in Vancouver in 2008, as I did not want my study to reflect heavily the views of people I already interacted with on a regular basis. I finished conducting all of my interviews for this study by December 2011 (but for those interested in the views of the 2012 or 2013 ecohealth participants, see Yip (2013)).

Some of the limitations that come with this approach to recruiting interviewees include the fact that respondents tend to be those still actively interested in ecohealth, rather than those who may have been interested at one point but have since stopped participating in the listservs. Also, my own position within the ecohealth "communities of practice" (more on this below) may have affected how potential interviewees would respond to my invitation. For example, some people might be more inclined to respond if my name was already familiar to them. As it turned out, respondents included participants in ecohealth activities every year between 2008 and 2011, along with some experiences that extend even further back before 2008. 
Interviews were conducted in English, Spanish, or French, based on the preference of the interviewee. One challenge I encountered was when the Internet connection was not strong enough to sustain a clear discussion on Skype, which happened with many of my interviewees in Africa. Being in Canada and having never been to Cameroon, Burkina Faso, Benin, Ivory Coast or other countries where my African interviewees were located, it was difficult to understand the subtleties of the contexts and experiences they were describing. A choppy recording made transcription much more difficult, which in turn generated less quotable text from the African interviews. Still there was plenty of material to work with. I did not have this same problem in Canada or in Central America. Although I am less fluent in Spanish compared to French or English, most of the interviews in Spanish were conducted face-to-face, thanks to the several months I spent in Central America visiting certain ecohealth projects, which helped tremendously with my comprehension of the situations interviewees described. Also, I conducted the Central American interviews last, at which point my interview skills had improved significantly. For example, from having begun transcribing my Canadian and African interviews, I noticed my tendency at times to over-contextualize a question before asking it, which made it harder for the interviewee to focus on what I was really asking. In my Central American interviews I was better at asking the questions plainly and directly, and just listening to responses.

Since I am concerned with how interviewees encountered ecohealth, it is worth commenting a little further upon their encounter with me. In particular, I wish to note that it is possible that certain interviewees in Africa would have a much harder time knowing 
who I was or what my project was about. Even though I could explain these things in emails and over Skype, there is something quite different about a face-to-face encounter and, having my own encounter with ecohealth located largely in Canada, I was less familiar with how graduate students and young professionals in Africa might have come across the approach. Also those interested in ecohealth have been largely dependent upon funding coming from Canada's IDRC, and coming from Canada with a project focused on ecohealth I could have been seen as a way of accessing funding, as a way of accessing graduate programs in Canada, or as a way of collaborating on writing articles. I wonder, therefore, whether for some the interview felt in part like a test of their knowledge about ecohealth or a possible opportunity to make a good impression on someone who might turn out to be a good connection for promoting or funding the approach. I tried my best to avoid this interpretation by explaining up front that I was not paid by IDRC and the project was launched out of my own interest and initiative, simply because I wanted to pursue some of the lines of inquiry that I had begun in discussions with students when I took the training course myself in Montreal in June 2010.

I transcribed all the interviews myself, translating those in French and Spanish into English. Although there were times when I wished I had asked more spontaneous follow up questions to get more details about the context of the interviewee's experience, in the end I wound up with approximately 300 pages of single spaced transcripts—certainly a rich collection of data to organize and analyze. For the analysis, I began by selecting long quotes from all of the interviews and coding the key themes. I then organized these quotes 
as conversations between interviewees about related themes and issues, highlighting contrasting experiences (see chapters 2, 3, and 4).

Although my fieldwork officially began in June 2011, when I started my first interviews, I had already by then observed numerous ecohealth activities. For example, in June 2008 I met the participants in the ecohealth training course offered at the University of British Columbia, when my partner attended the course. Later that same year in December I went to the Ecohealth conference in Merida, Mexico, which allowed me to meet more students, staff and faculty. After taking the training course in Montreal in 2010, I attended the London 2010 Ecohealth conference, where I met more ecohealth students, many of whom were involved in the International Association for Ecology and Health (IAEH) Student Section. Following the conference, I attended a debrief and planning meeting, which led to my involvement with an international group of ecohealth practitioners writing about ecohealth in relation to policy questions (see Koné et al 2011 and Feagan et al 2014). The following year I organized a meeting for ecohealth "alumni" (previous participants in ecohealth training) to pool ideas for improving the training course, and we participated in helping deliver parts of the ecohealth training course offered at the University of Northern British Columbia in Prince George in June 2011. Being at the course for a second time - now as a facilitator - and having the benefit of talking to more alumni from previous years, I was able to take careful notes about the interactions I was witnessing.

I officially began my fieldwork at the end of the course in Prince George and by early August 2011 I had finished most of my Canadian and African (via Skype) interviews. 
I spent most of August, September, and early October observing ecohealth related activities (meetings, presentations, workshops) in Latin America, while also making fieldtrips to the sites of ecohealth projects in Costa Rica. I attended a one-week symposium of PhD student presentations on research proposals on topics of environment and health at the Universidad Andina Simón Bolívar in Quito, Ecuador, where some students had received IDRC funding to support their research and training. After returning to Canada, I finished transcribing interviews and started my data analysis in December 2011. Since then, I have continued to be involved ecohealth activities. I participated in workshops and planning meetings to develop the ecohealth teaching manual (McCullagh et al 2012). In March 2012, I co-planned an ecohealth student retreat near Kingston, Ontario, where a group of past participants in ecohealth training came together to discuss their research, methods for analyzing fieldwork data, and broader philosophical issues pertaining to the challenge of bringing ecohealth principles into practice. While this is not an exhaustive account of my involvement with ecohealth activities, it nonetheless shows the main opportunities I have had for observing and contributing to this work; careful note-taking, journaling, and reflection have helped with the development of my understanding throughout these experiences. ${ }^{3}$

Working with those involved in ecohealth has allowed me to pool insights from a group already attempting to find a community form that would facilitate a more collective approach to intervening in socio-ecological issues. However, it is worth reflecting a little

\footnotetext{
${ }^{3}$ From January to December 2014, I was hired full-time as a Research Award Recipient with the IDRC's Ecohealth program, where I developed an action-research project entitled, Exploring a New Model With the Next Generation of Transdisciplinary Researchers: Peer-to-Peer Action Research. This project allowed me to pursue one of the avenues emerging from this dissertation, which was already in draft form when I started the IDRC contract.
} 
more on the challenge of conducting research with a community in which I am myself embedded. One challenge that arises, particularly in investigating formal educational contexts, is "making the familiar strange," or not taking for granted the norms of educational practices with which I am already familiar (Gordon 2001). Different levels of submergence come with different opportunities and challenges. For example, the "insider" point of view may facilitate greater empathy, but this can also blind the observer to other possible perspectives; the "outsider" position may sharpen empirical observation but it is also shaped by assumptions about what is normal (see Geertz 1973; see Garfinkel 1967). I am both an insider and outsider to the ecohealth communities, a position that comes with the ongoing responsibility of making ethical judgments about interactions with community members at different times. This is complex dilemma faced in anthropology, in actionresearch, and community-based projects (see L.T. Smith 1999). The main challenge lies in negotiating multiple roles within a set of institutional power relations. Since there is no "uninterested" relationship to these power relations and all participants in the communities of practice are embedded in different ways, my goal has been to make clear to myself and to those around me the role I am playing at a given time. The complexity of multiple relations is a source of richness that speaks directly to the central question of this research, and I acknowledge my own position within this complexity. I have found being involved with people in ecohealth projects incredibly rewarding in the sense that it has given me opportunities to act on much of what I have been learning throughout my research. My project is not only about efforts to intervene in the process of community formation, but also is itself an attempt to do so. Ecohealth training and research offer a rich 
context in which to pursue this inquiry because of the different layers involved: there is the layer of the course itself and the funding and labour that support it; the layer of the wider graduate and professional programs from which course participants are drawn; and there is the layer of the larger non-academic community beyond the course or the university context where it is offered—the places where much ecohealth fieldwork occurs. The power-relations between those involved depends in part on where they are located within these different layers, for example students occupy a different position than their supervisors. The intent of any training is to offer some kind of specialized conditioning; this dissertation helps understand that conditioning in the context of ecohealth and ecological consciousness.

\section{A Case Study: Ecosystem approaches to health, or ecohealth ${ }^{4}$}

The official start of IDRC's Ecohealth programming in 1997 was in part an outcome of massive funding cuts in the early 1990s under then Prime Minister Mulroney. With its programming budget cut nearly in half, previously separate IDRC programs were rolled into one, which turned into an opportunity to support a new kind of space for transdisciplinary research. Lebel (2003) outlined the three pillars of ecohealth transdisciplinarity, participation, and social/gender equity - in his seminal book launched in Montreal at the International Forum on Ecosystem Approaches to Human Health. This would be the beginning of a flurry of ecohealth activities backed by the institutional

\footnotetext{
${ }^{4}$ There are significant tensions within and across various approaches to ecohealth, as some groups of practitioners and scholars adhere more to certain theoretical and methodological assumptions compared to others. For further details see Nguyen 2011, Charron 2012; also see Spiegel et al 2011.
} 
support of the IDRC. By the mid-2000s, the International Association for Ecology and Health was born, launching a new journal, EcoHealth. Ecohealth would go on to become the IDRC's longest standing program, and Jean Lebel would become the centre's president. $^{5}$

Given the Centre's mission to support the development of scientific and technological skills in the global South (Cole et al 2006; Muirhead and Harpelle 2010), there has always been a focus on training young researchers, and so from the beginning the Ecohealth program has included a research and training awards component (White 2006). Initially, graduate students were flown from their home countries to take part in a week-long set of workshops and presentations at headquarters in Ottawa. From there, trainees might join a research team working on an ecohealth project or return to their home institutions where they might continue developing their use of ecohealth approaches. By the mid-2000s, IDRC began supporting the development of ecohealth communities of practice, and these communities have since taken on the responsibility of delivering ecohealth training. The first community of practice in ecosystem approaches to health (COPEH) started in Latin America in 2004 with CoPEH-LAC; in 2006 CoPES-AOC began in West and Central Africa (Bénin, Burkina-Faso, Cameroon and Côte-d'Ivoire); and CoPEH-Canada was started in 2007. CoPEH-ACC (America Central y Caribe) is one of the sub-nodes of CoPEH-LAC, with the purpose of institutionalizing the ecohealth approach in universities and government ministries specifically in Panama, Costa Rica, Nicaragua, Cuba, and Dominican Republic.

\footnotetext{
${ }^{5}$ Under Lebel's presidency, IDRC's Ecohealth programming is now scheduled to formally end in March 2015.
} 
All of the interviewees I spoke to in Canada and West and Central Africa had encountered ecohealth through the ecohealth training course. Although there is some variation in the how the course is taught from one year to the next, the basic commonalities are that it consists of approximately two-weeks of presentations and activities for a select group of about twenty graduate students and professionals with an interest in the relationship between environment and health. Typically, participants hear about the course through their program's listserv or directly through the recommendation of a professor or supervisor. Applying to the course involves sending a short biography, a statement of research and interest in the course, and a letter of recommendation from your supervisor.

In Canada, the course has rotated every year since 2008 between the Western, Ontario, Quebec and Maritime nodes of CoPEH-Canada. Successful applicants to the course will prepare core readings and attend the full schedule of presentations and activities led by a multidisciplinary team of professors, usually planned around a specific case study in the local area. Initially, funding was available to cover travel and lodging costs, with an additional competition at the end of the course for a limited number of research grants. By 2010, the value and number of these grants had diminished and since 2011 they have not been offered. Also, since 2011 greater emphasis has been placed on offering the course for credit, which involves submitting a reflective essay as well as some smaller tasks throughout the course to be graded by the CoPEH-Canada team.

In Africa, the ecohealth training course has been running since 2003 involving students primarily from Benin, Ivory Coast, Cameroon, and Burkina Faso. Successful 
applicants are also encouraged to participate at the end of the course in a competition for research grants to develop a project in relation to an ongoing ecohealth research in the field (Akpo and Baba-Moussa 2010).

In Central America, there is no annual ecohealth training course offered. Instead, the principal investigators familiar with the approach may include ecohealth as a theme in courses taught at the university or hire graduate students as research assistants to work on funded ecohealth projects in the field. The encounter with ecohealth happens, therefore, much more through employment relations, while students are completing their degree requirements (courses, thesis, etc.) in night classes and on weekends. As employees, some of the Latin American interviewees (but not all) had participated in ecohealth training, primarily through attending informal workshops within the workplace or more formal workshops organized by faculty for building partnerships, for example with the Ministry of Health, to help promote the institutionalization of ecohealth within current government and university infrastructure.

Hundreds of people have now been trained in ecohealth around the world, working in different professional fields and coming from different disciplines. To be sure, the reasons for becoming involved in ecohealth may include gaining access to research funding, for example in the form of IDRC research grants, however what really attracted interviewees to ecohealth (as opposed to other training, research or funding programs) was the possibility of realizing certain aspirations for doing meaningful research about the relationship between environment and health, often with an emphasis on community participation and the integration of different kinds of knowledge. As the following chapters 
make clear, there remain pressing questions about the effectiveness of the model in place as well as concerns about the future development of the ecohealth field. Some of the challenges discussed in this thesis have been confronted in part by others. For example, Cole et al (2006) have pointed to the challenges of dwindling public resources along with the pervasive penetration of market capitalism into remote agricultural communities, raising the question: to what extent is ecohealth capable of addressing the global politicaleconomic dimensions driving environmental and health problems? And while acknowledging the need for - and potential of - a participatory approach to research (Dakubo 2004), Dakubo (2010) also raises the challenge of intervening in a world in which power-structures shape the dynamics of academic research teams, communities, and the interactions between the two. Against the backdrop of the economic downturn of 2008 and the new global climate of austerity (McNally 2011), my dissertation expands on these works by uncovering the underlying patterns and contexts that connect young researcher experiences together, creating certain opportunities and constraints.

There are a number of reasons why ecohealth offers a good case study for testing the ecological consciousness framework. First, within ecohealth there is a specific focus on what it means to think ecologically, tied to systems theory. Secondly, ecohealth comprises an attempt to bring together different kinds of expertise in confronting the complexity of issues of ecological sustainability and human health. As such, ecohealth is concerned with different ways of knowing and how they can work together to transform reality (see De Plaen and Kilelu 2004; and see Webb et al 2010). Third, as part of realizing the aims of ecohealth, one of the fundamental achievements has been the development of 
communities of practice in various parts of the world (see Parkes et al 2012). While still largely limited to university personnel, graduate students, and some professionals, these communities have opened up new kinds of spaces for collective thinking and action outside traditional disciplinary lines. I aim to draw lessons from these important experiments that help flesh out the ecological consciousness framework while at the same time using ecological consciousness as a lens to understand the experiences of young researcher within ecohealth training and research.

\section{A note on chapter organization}

While this dissertation follows a fairly traditional structure - with an emphasis on theoretical concepts in the first chapter, a set of core data chapters in the middle, followed by an integrated discussion/conclusion chapter - the ethnographic quality of the project necessarily blurs the lines between theory, method, data analysis, and discussion, and the conclusions remain open-ended. Each chapter contributes to the analysis as a whole, but remains incomplete as a standalone piece. In Chapter 1, I discuss the theoretical foundations and key themes that I am using to define the framework of ecological consciousness. I start with a few sample snippets from the interview data, and then discuss emerging themes in relation to the university as a case study for ecological consciousness. Through a review of the literature on the relationship between the university and different ways of knowing - especially women's and Indigenous knowledges - I show the ongoing history of struggle between dominant approaches and the wider ecology of knowledge that exists in the world, suggesting that different models of community and leadership are 
not only possible, but also necessary for supporting the actual range of ways of knowing. I then point to systems thinking, Indigenous knowledges, and historical materialism as foundations for a new approach to ecological consciousness - one that avoids indoctrination into a single mode of knowledge production - and I discuss some pedagogical implications for participatory approaches to global development research.

Chapter 2 launches into the ethnographic data, starting with interviewee encounters with ecohealth training. Interviewee experiences point to contrasting perspectives about the hopes and realities faced at different stages of their encounter, revealing a pattern tied to a tension between career advancement and the realization of wider aspirations associated with ecohealth. In Chapter 3, I explore interviewee experiences of the institutional contexts framing the relationship to ecohealth research more generally, starting with the university frame and relations of disciplinary authority. Interviewees talk about their relationship to science and research, as they struggle to make sense of the opportunities and constraints that come with an approach committed to concepts of transdisciplinarity, participation, and social/gender equity, while working within an institutional context that does not always embody those concepts. Chapter 4 moves the discussion of institutional frames into the context of researcher relations with researched communities, where interviewees grapple with what it means to apply ecohealth principles in the field. Here I examine three case studies, showing that the arising issues are in fact part of a larger interconnected set of pre-designed relations, which at once allow attempts at ecohealth to occur while constraining the extent of their development. 
Having now presented all of the interviewee experiences and comments, Chapter 5 offers reflections on the lessons learned and the challenges for bringing research efforts closer in line with movements for social change. On the whole, there is a strong tendency to perpetuate the status quo relations that dominate the university. However, I also point to an untapped theoretical potential residing in peer relations among graduate students and professionals, which I suggest can lead to a more collective confrontation with existing employment structures that enforce the status quo. Indeed, the development of ecological consciousness within university-based expertise ultimately depends on this confrontation. 


\section{Chapter 1. Ecological Consciousness: Theoretical Foundations and Key Themes}

Attempts at genuinely new approaches to graduate training and research often produce tensions with the given institutional context that frames these efforts. The ecological consciousness framework that I am proposing in this chapter helps make sense of these tensions by drawing attention to the relationship between experience and knowledge as framed by the academy's disciplinary structure. Taking the university as a case study, I look at how different ways of knowing are allowed to take shape - or not - and I suggest that changing consciousness means changing the channels of expertise themselves, opening them up to the wider ecology of knowledge that exists in the world. I begin with some comments from my interviews with graduate students and young professionals trained in ecohealth, showing how they at once reveal a wider institutional context and a tendency to limit the understanding of that context to certain personality traits. I then look at the literature on ecological consciousness and the university, arguing that while there are important conceptual insights about the relationship between consciousness and context, there remains a tendency to seek a conceptual fix that fails to acknowledge the ongoing material struggles for confronting the university's colonial and patriarchal heritage. I propose that ecological consciousness is not about a fixed understanding but rather it is about allowing space for the tensions between different ways of knowing to produce their own interactions and new forms of community. I finish by discussing some pedagogical implications that the ecological consciousness framework poses for research taking place within a global development frame. 


\section{Navigating the contradictions of ecological consciousness in training and research}

Comments from Daniel, Julian, Vincella, and François - just some of the interviewees whom you will meet in more depth in Chapters 2, 3, and 4 - help introduce key issues that the ecological consciousness framework can help address. Daniel, a graduate student working in Central America, explained to me that the "huge challenge" for ecohealth was to help some experts get beyond their disciplinary allegiance:

There are people who don't believe in the [ecohealth] approach as such because they say that the pillars of the approach were taken from biology, I've heard this from biologists. And the biologists are a bit reactionary, they don't want to engage with this topic because they feel that health sciences is taking over the parts that used to belong to biology, so it's as if health belonged to them. So they feel that what's happened is that people have started stepping into their field, into the field of biology, and they say no, all of this was already here since 1950, you're not bringing anything new. And we agree, nothing new. What the approach is trying to do is systematize, consolidate what ecological understandings we have, and put it all together.

Although Daniel's comments make clear that tensions arise in relation to disciplinary turf, he characterizes the problem primarily as originating in the personalities of the experts themselves, as he asks, "I'm sorry, but can't we work together to strengthen our capacity, so that we can see the issue differently?" Likewise, the solution presents itself as already contained in the personality, as Daniel goes on to describe those already part of the Latin American ecohealth community of practice as "humble" people: "we're not going to get our ideas caught up with our egos." Part of the mission of those dedicated to ecohealth is this: "From a very disciplinary world, we have to transform it into a multi- and then transdisciplinary world," which he adds means having "to work hard together, to make [specialists] a little bit more sensitive, but that's not easy."

There are key insights in Daniel's comments about the relationship between this 
sensitivity training and the disciplinary turf of expertise, which I think Julian's comments below can help develop further. Despite a good relationship with his committee members on a one-on-one basis, Julian found it "awkward" that they did not "have that intention to work with one another." Instead, he said, "they came to the meeting, they all said 'yes' to their individual piece and then they all said 'no we don't understand what the other two are talking about, but if they're okay with it, we're okay with it'." Julian found it difficult to put into practice a "holistic perspective" integrating different kinds of knowledge when, "by these three committee members I really mean them and the discipline or the department that they stand for." In other words, even though Julian could see how his project fit well conceptually with ecohealth, materially the disciplinary structure behind his committee was blind by design to a more holistic approach. Julian's example shows how individual personalities take on particular roles in relation to the disciplinary contexts of work. This helps explain Daniel's situation too: it is not the individual personality alone that determines an expert's open or closed-mindedness, but rather the relationship between the personality and the institutional context in which s/he is working. To bring about meaningful change in consciousness, therefore, graduate training and research must intervene in this relationship between the mind and the surrounding setting, not just in the mind itself.

Yet the problem does not present itself in this relational or dialectical way. Instead, on the surface the problem tends to be reduced to an individual personality trait, whereby the solution becomes some kind of training to fix individual minds, to make them more like some other individual minds deemed to be more open-minded or more capable in 
some specialized way. Consider two more examples. Vincella starts describing her strong affinity for the ecohealth approach:

I felt ecohealth was trying to explore problems in a broader way and I just felt that made so much sense. I guess in research I've been always quite frustrated that we tend to focus into very specific aspects of problems, and yeah yeah you might find a solution for something but it doesn't really look at the whole problem.

Vincella's frustration points to existing research practices that fragment issues into tiny pieces for analysis within very narrow parameters, which is why she felt that a broader approach like ecohealth "fit so much with my own way of thinking." Yet, she also sensed a tension with her disciplinary training: "my mental approach is too natural scientist driven, and that doesn't match very well with what ecohealth needs." So while she explained that she was "very open minded" and she tried "to look at problems from a very broad perspective," she also said that she always tried

to rationalize things and understand things very deeply, and probably when you really try to do ecohealth and put it into practice that's something that sometimes you have to put aside a bit and try to be a bit more capable of improvisation and capable of understanding, because some things really escape rationality. Yeah, like, for example, social behaviour and culture, these kinds of things, it's very hard for me to incorporate that into my actions or my look into reality or into the problem.

In essence, while the ecohealth approach made sense to her, Vincella nonetheless felt that her personality was still missing something that an ecohealth researcher ought to be able to do.

One last example for now: François is currently employed as a young professional working on development projects in West Africa, but as a former graduate student, he noted, "the ecohealth approach is a transdisciplinary approach, yet today transdisciplinarity, at a certain moment, is not, if I may say it like this, something easily shared." He explained: 
One of the main challenges is when you choose people, for example from a particular discipline, and when I was working on my ecohealth project, you have to in effect prepare them. It's bit like a training to explain to them where we're going so that they can appreciate and understand exactly what you want to do. Without this, at a certain point it becomes difficult for them to follow you. There was a point in the project where each person had to contribute a piece. We needed a sociologist, then a technician, etc. And once again, each one stays within his or her own personal specialization, so the major difficulty is that we don't actually succeed in really defining this transdisciplinary language where everyone has the same grasp and can work together on the project.

François' and Vincella's comments - like Daniel's and Julian's before - describe parts of a whole context of training and research in which particular disciplinary ideas and practices have already established themselves, making it very difficult to introduce new innovative approaches, even if the outcomes of the established ideas and practices are highly limited and unsatisfying. In Vincella's case, it seems she may write herself off as a potential ecohealth practitioner because her disciplinary training has not adequately prepared her for what ecohealth needs; in François' case, it seems that only those specialists trained in ecohealth can have the possibility of developing a transdisciplinary project together, suggesting that the ecohealth approach itself caters to those already speaking its language.

These examples raise a central problem: how to introduce new approaches to graduate training and research while continuing to work within the same basic contexts where more established disciplinary assumptions dominate? To address this question I am proposing not just to name the elephant in the room but to look at the room itself and its effect on the ideas and practices contained therein. In other words, what the examples make clear is that the development of a new approach cannot be adequately understood without closely examining how the surrounding context imposes certain constraints—it is these constraints - in all of their conceptual and material forms - that must be dealt with as part of the development of a new approach. Yet this surrounding context, while 
continuously present in the interviewees' descriptions, becomes lost in the tendency to limit the problem to the individual level, i.e. to a question of changing individual minds. At the level of graduate training and research, this tendency can unfortunately get scaled up, as efforts become centered on fitting more people into what the new approach requires rather than demonstrating how a range of different people can work together to transform a given context. Put another way, even though the comments and experiences presented so far show that the challenge of developing new approaches to training and research has a fundamentally structural dimension, there is a strong tendency for it to quickly become reduced to a problem at the individual level (egos, personalities, personal capacities, training) such that problems of a structural nature are only worked on at a level that can have little effect on the structures themselves.

\section{The university context as a case study for ecological consciousness}

There is a growing body of literature looking at the university context as a case study for the development of ecological consciousness. While universities are often portrayed as centres for the development of expert knowledge capable of addressing problems in the world, within the context of graduate training and research these problems can become framed in terms of a lack of (a particular type of) training and research. More training and research - using more advanced theoretical concepts - becomes a perpetual problem and solution that amount to basically the same thing: how to impose a pre-given set of concepts onto other people's consciousness. This type of framing turns the question of ecological consciousness into a simplistic (and yet impossible) quest to convince others to 
adopt a so-called "new" paradigm. But rather than start from the assumption that the problem originates in a lack of a specific type of specialized training, I am suggesting that the problem needs to be posed as a more open-ended question to which the experts-inthe-making and a range of others can contribute. Let us look at some examples from the literature.

In their critical review of a wide range of approaches to sustainable development and learning, Scott and Gough (2003: xiv) present the typical narrative summarizing the role that universities portray themselves as playing:

The argument goes: through schooling, further and higher education, professional training and development, and more informal awareness raising and capacity building, people can both be helped to begin to understand emerging ideas about the need for change, and be helped to engage in debate and critique of the issues, thus making meaning for themselves and developing personal and social action plans. In addition, it is now widely accepted by institutions of all kinds that there is a need for: (i) new ways of conceiving and operationalising learning with shifts in curriculum, pedagogy, and in institutional management practice; and (ii) novel approaches to the professional development of teachers, trainers and non-formal educators across the field.

Notice how this narrative locates the problem in people's lack of training and awareness, a problem that institutional leaders supposedly recognize and are already working to fix. But while better training for more people may seem like a no-brainer, this tendency to assume that the problem originates in people's lack of training leads to a cyclical response of offering endless forms of "new" training, without necessarily digging deeper into how the problems that need addressing came to be in the first place.

The tendency is to justify the need for a new approach to training based on an argument about the deficiencies of a previous training or research. For example, discussions framed by the university as training grounds for addressing issues of ecological sustainability and human health often point to the fact that environmental problems cut 
across disciplinary boundaries, which immediately raises the problem of how training

within a disciplinary institution can integrate different kinds of knowledge to address

complex issues. One response is to call for some form of inter-, trans-, or multi-

disciplinarity as a way of overcoming the blinding effects of disciplinary silos while

maintaining a sense that, given the right methodological tools and resources, university-

based training and research can contribute to solving problems. For example, Esbjorn-

Hargens and Zimmerman suggest that:

Growing recognition of the complexity of environmental problems has led leaders in environmental organizations, regulatory agencies, corporate offices, and academia to call for greater interdisciplinary, multidisciplinary, and even transdisciplinary models to describe, address, and resolve environmental problems. We agree-we need a more comprehensive map to understand and solve our most intransigent problems. (Esbjorn-Hargens and Zimmerman 2009: 5)

But while institutional leaders may agree that the problem can be understood largely as a mismatch between the complexity of environmental issues and the inadequacy of current research and training models, calls for inter-, multi-, and transdisciplinarity may not be enough to address the structural dimension of the problem. For example, Dirlik (2006) argues that the university's disciplinary structure remains intact and continues to fragment how university-based knowledge production happens, even when promoting the language of interdisciplinarity:

There is a clue in this mode of reasoning to why "interdisciplinarity" should be the preferred term within the university, and why the goal expressed by that term continues to be elusive in spite of all efforts on the parts of faculty like ourselves. The ideology of disciplines comes together in this reasoning with the organization of the university in departments based on the disciplines, so that "interdisciplinarity" is as much an organizational as it is a conceptual term. Departments are not only productive of knowledge, but also play a policing function over intellectual activity in the university. They also provide limits, if not obstacles, to the goals of communication across disciplinary boundaries. This is to say, somewhat pessimistically, that goals expressed by terms such as interdisciplinarity or transdisciplinarity may be impossible to achieve within the university as it is presently constituted, because they clash with established organized interests that rear their heads every time these goals are put in practice. The best we may hope for, short of a revolution in the present organization of learning, is to create new spaces for alternative practices. (Dirlik 2006: 10). 
Although universities portray themselves as the centres of innovative leadership, institutionally there is tremendous inertia built into their structure, which according to Dirlik (2006: 10) "implies, also, that any effort to realize transdisciplinarity is not just an academic but a broadly political effort." Without this political dimension, much of the buzz about inter- or trans-disciplinary innovation may turn out to be part of an institutionally acceptable response that ultimately supports - rather than challenges - the disciplinary structure of the university.

Another perhaps more robust response pushes further toward a fundamental reorganization of the university's structure itself, as De Guerre and Taylor (2004: 69-70) argue that, "systemic leadership education is a disturbance on many levels—logistical, administrative, intellectual, and political—in a conventional university." Their call for "a fundamental shift from hierarchical leadership and organizational structures to increasing decentralization of decision-making responsibility and self-organization" (De Guerre and Taylor 2004: 65) means moving away from "instrumental individualism," where "[k]nowledge is assumed to be stable, enduring, and applicable regardless of context" and where "it [is] the responsibility of the leader to maintain expert control through applying his/her received knowledge" (66-67), toward "a systemic leadership approach that, designed for a dynamic changing world, obviates the gaps of conventional leadership education" (67). By following certain basic principles of systems thinking, the authors argue that "these fundamentally new forms of leadership and organizational [structures] are also likely to be schools for a socio-ecological or systemic consciousness," (de Guerre and Taylor 2004: 66, original emphasis) where "systemic consciousness includes at least, 
awareness of self, awareness of the awareness, and awareness of social and ecological aspects of the global environment" (de Guerre and Taylor 2004: Notes, page 81).

Similarly, in their investigation into ecological consciousness and graduate learning, O'Sullivan and Taylor (2004: 6) make the point that there is a "profound co-constitutive relationship between ourselves and our world," which means that learning toward greater ecological consciousness entails a shift in the structure of that relationship:

Just as social organizations and cultural institutions impact constituent members with their consciousness demands, so too, do wider environments impact social organizations and institutions, calling forth fundamental structural and normative shifts. (O'Sullivan and Taylor 2004:17)

Since consciousness develops in relationship to the surrounding context, greater ecological consciousness would require changes in "conceptions of knowledge and education; social configurations (organizations, communities, and institutions) and leadership; and conceptions of ourselves" (O'Sullivan and Taylor 2004: 6). The authors suggest that organizations will need to become more like "fluid systems" with "evolving purposes" and "multidirectional" communication with "diffused" authority, where diversity and learning are highly valued (O'Sullivan and Taylor 2004: 17). Moreover, in comparing the contexts of training (school) and employment (work), Laiken (2004) contrasts an ideal model for ecological consciousness with what is currently offered:

Authentic learning environments and authentic workplaces have much in common. They tend to be ones in which collaborative partnerships prevail over hierarchical power relationships; leadership is enabling rather than controlling; differences are viewed as rich resources for learning rather than challenges to be "managed"; reflection and critical thinking are encouraged through the development of vibrant communities of practice; conflicting ideas are surfaced through genuine dialogue, often leading to expanded thinking and revised worldviews; and "wholeness" is valuedboth in the individual as a whole person (body, mind, emotions) and in the understanding of groups and organizations as living systems.

Probably the most important characteristic of these environments is the prizing congruence between beliefs and behavior. However this rarely describes the reality. Rather, an authentic learning or working environment is one in which participants may see themselves in a process of continuously striving for such congruence. This involves being clear at the outset about one's values and vision of an ideal, and then being willing to acknowledge honestly instances in which the 
reality may be out of sync with that vision. The task then is to conscientiously work toward closing the gap.

Graduate education programs in traditional universities are challenging places in which to create authentic learning environments that fit this description. Like the traditional workplace, they are generally hierarchically structured and tend to create power-over positions for those in leadership roles, encourage competition as opposed to collaboration through their funding and reward (i.e., grading) systems, use adversarial approaches such as collective bargaining or appeals procedures to resolve conflicts, and often implicitly allow and support critique that is judgmental and silencing as opposed to exploratory and inviting. Most significantly, genuine dialogue, honest expression of feelings, and the opportunity to focus on process as well as content are clearly devalued, making it difficult, if not impossible to close the gap between espoused values and practiced behavior.

And yet, we learn what we live. If our students are to help create transformative environments in their own work organizations, we believe that they must first experience such environments in their graduate education. (Laiken 2004: 85-86)

These calls for less hierarchy and more collaboration go part of the way in understanding what the production of ecological consciousness might look like in the university.

Yet, even in these calls, the core of the problem gets reduced to a question of valuing the right things, such as genuine dialogue, honesty, diffused authority, multidirectional communication and other concepts, the supposed lack of which becomes framed as the problem and, correspondingly, a new conceptual solution emerges. But without some explanation for how existing conceptual frameworks came to be (not just arguments about why they are deficient), any newly proposed concept or approach is unlikely to be able to deal with the material conditions surrounding its application. While there is discussion of power relations and the need to model spaces where students can exercise greater democratic control, the history that gave rise to the existing hierarchies is largely missing, making the presentation of the current situation seem almost accidental or the result of a failure to hold the right values, rather than part of an ongoing struggle. As a result, despite much lip service to the need to move away from top-down decision-making toward a more de-centralized and democratic process, the role of the students often remains that of consumers of what current institutional leaders have to offer (Johnson 2008). Thus there is 
a conceptual trap that, despite certain strengths, the literature on ecological consciousness is prone to fall into. It becomes necessary, therefore, to look past the presentation of new conceptual labels to see the relationship between the structure of training and research and the process of knowledge production.

\section{The university's relationship to a wider ecology of knowledge}

Learning does not only happen in universities, but rather across all experiences of life, yet universities do not usually recognize this broader context of learning. This poses the problem of working out which kinds of knowledge production does the university allow and why. Charles E. Rosenberg's "ecology of knowledge" is particularly useful for understanding part of the history of the structural relationship between knowledge and the context of its production. There is, he suggests, a "fine structure of interaction between knowledge and the society that supports its accumulators and practitioners" (228), which includes the "interaction of discipline and context," "the internal organization of academic disciplines and learned professions," and the role of knowledge "in defining identities appropriate to new social realities" (228). Rosenberg argues that "Such rubrics as the humanities, life sciences, or social sciences mask diversity as much as they imply unity" (230, original italics), but what they do have in common is a departmental structure:

Yet it is the discipline that ultimately shapes the scholar's vocational identity, and it is the department that constitutes the institutional form in which that identity finds its day-to-day meaning and support. The confraternity of his or her acknowledged peers defines the scholar's aspirations, sets of appropriate problems, and provides the intellectual tools with which to address them; finally, it is the discipline that rewards intellectual achievement. At the same time, disciplinary identity helps structure the scholar or scientist's relationship to a particular institutional context. Professional 
life becomes then a compromise defined by the sometimes consistent and sometimes conflicting demands of discipline or subdiscipline and the particular conditions of an individual's employment.

Knowledge production thus happens in relation to particular working conditions, but Rosenberg reminds the reader that, "there are no simple cases," since "universities vary widely" and "a diversity at least equal characterizes the professions" (231-232). What is needed, he argues, is an approach that balances general context against the richness of unique experiences:

Like the ethnological field-worker, historians of knowledge must integrate formal intellectual content with social and institutional organization, systems of economic support, and finally, the values that sanction and reward the career choice of members of a particular intellectual subculture. Like ethnology itself at the beginning of this century, we must free ourselves from the domination of overschematized developmental models and seek to understand the specific texture of particular scientific lives. (Rosenberg 1997: 233)

Despite enthusiasm for social change, Rosenberg argues that leaders in academic fields

have historically been subjected to high levels of discipline:

Though some of the most prominent leaders in the formative decades of American social science were imbued with an almost evangelical desire to intervene righteously in society, it soon became clear that such intervention could be dangerous, not only to the individuals involved but to the disciplinary needs of the nascent social sciences. Certainly one of the characteristic themes in all of the social sciences in the last quarter of the nineteenth century and the first quarter of the twentieth was this very conflict between social consciousness and academic cautiousness. And most social scientists did proceed with a growing caution in the twentieth century-or at least caution in expressing opinions potentially offensive to those who wielded social and economic power. (236)

What emerges from Rosenberg's analysis is a complex tension between specialization and the need to be relevant to the world outside of a specialized field, as experts-in-themaking feel pressure to define themselves both in relation to the more immediate institutional context of work as well as the world outside the workplace. Although Rosenberg also briefly mentions the importance of race, class, and gender (238), these elements are not well developed in his analysis of the university's ecology of knowledge, 
yet they remain fundamental to understanding the ongoing history of the structure of knowledge production.

Indeed, in the case of Indigenous knowledges, there is an ongoing history of struggle to have Indigenous ways of knowing recognized by the university (Alfred 2009; Simpson 2008; Battiste 2001; Smith 1999; Armstrong 1998; Cajete 1994). Indigenous people have sought to use their own methods based on an Indigenous paradigm, but profound tensions arise when a new generation of Indigenous researchers remains subjected to nonIndigenous processes of accreditation. Shawn Wilson argues that "These new Indigenous scholars have introduced Indigenous beliefs, values and customs into the research process, and this in turn has helped research to become much more culturally sensitive to Indigenous peoples" (2008: 15), but at the same time he notes:

We have tried to include our cultures, traditional protocols and practices into the research process through adapting and adopting suitable methods. The problem with that is that we can never really remove the tools from their underlying beliefs. Since these beliefs are not always compatible with our own, we will always face problems in trying to adapt dominant system tools to our use. (Wilson 2008: 13)

Thus Wilson wants to "develop our own criteria for judging the usefulness, validity or worth of Indigenous research and writing" (14), but he was struck by "how pervasive dominant system academics have been in guiding Indigenous research and the teaching of Indigenous knowledge" (17). In starting his doctoral research in Australia, Wilson says: I wanted to look at how Indigenous people could be successful in both worlds. I was looking at people who had high academic achievements (graduate students) while maintaining a strong and healthy Indigenous identity. What I really wanted out of this was to be able to form an understanding of an Indigenous epistemology through those who I thought would be able to explain it the best to dominant system academics: Indigenous graduate students. (Wilson 2008: 29)

Although he was impressed by some of his peers' abilities to conduct doctoral research in such a way that seemed to bring benefits to Indigenous communities, he also made a 
discovery: "A major obstacle that we were all facing revolved around having to justify our use of Indigenous methodologies in our research" (30). Indeed, in presenting his proposed research, "One panel member went so far as to insist that no Indigenous people be allowed to serve as examiners, as they would be too biased." Wilson says, "I doubt that White students at QUT are told that they are not allowed to have any White examiners! It was only the fact that I could justify my methods through the citing of western researchers that saved $\mathrm{me}^{\prime \prime}(30-31)$.

In the context of African education, evidence suggests that while the university is deeply implicated in the language of development, it remains far away from confronting this challenge in a participatory way, that is, in a way that empowers local actors to know themselves and take ownership over the future of local communities. Instead, the tendency has been to continue past traditions of imposing top-down authority from well outside the experiences of learners, as George Dei explains, drawing on his own experiences in Ghana:

From curricula to pedagogies, dominant knowledge systems have been organized and inscribed through governing Eurocentric paradigms historically augured within colonial specificities. Education systems and processes, as well as ideas about what counts as education, have been entrenched in the reproduction of colonial ways of knowing which concomitantly limit possibilities for many learners. By way of my own personal educational experience, I have written how my colonial education in Ghana taught me less about my own communities than other distant places, which made it difficult to relate education to my lived experiences. Cultural community knowledges were not affirmed in my education and it has taken many years of struggle to shed the Eurocentric gaze and interpretations that have been ingrained in my thinking. Many of us, whether as Indigenous, colonized or racially minoritized scholars/learners, continue to struggle to convey liberatory ways of understanding for/in different socio-cultural, economical and political spaces. For education to facilitate rather than limit learning possibilities and educational transformation, it is crucial that we develop and apply liberatory conceptual frameworks that are accessible to learners. (Dei 2012: 103)

While Dei does not use the words "ecological consciousness," his search for new inclusive practices is largely compatible with how I am using the term. The main 
difference, however, is that Dei argues that "No doubt culture as a social system is at the roots of coming to know" (Dei 2012: 104), whereas I am putting more emphasis on the relationship between knowledge and community form, such that culture is not a root cause but rather part of an ongoing development. In any case, Dei's contribution is critical:

We must resist colonizing knowledge if 'fulfilling education' is ever going to be a reality. Our education must make a difference and create space for our learners to work with [in] communities. The affirmation of the anti-colonial intellectuality is to address the major problems that oppressed and marginalized learners have to deal with: a) negation of historical experiences and collective and cultural memories; b) negation of our subjectivities; c) the denial of the embodiment of knowledge; d) the persistent and continuing struggles against our dehumanization; e) the 'spirit injury' of perpetual resistance; $f$ ) the often times easy and seductive slippage into the form, logic and implicit assumptions of the very things we are contesting, as well as g) the lack of mental/bodily/spiritual nourishment and accommodation (including food, shelter, clothing, and so on) that often accompany the systemic oppressions many of our people experience. (Dei 2012: 111)

Given this history of continued negation of other knowledges, how could the university assume a leadership position in the production of ecological consciousness?

Francis Nyamnjoh's argument may help answer this question in that he offers both a strong critique of the university and a possible opportunity for making use of its international development frame. In his critique he claims:

In Africa, the colonial conquest of Africans - body, mind and soul - has led to real or attempted epistemicide - the decimation or near complete killing and replacement of endogenous epistemologies with the epistemological paradigm of the conqueror. The result has been education through schools and other formal institutions of learning in Africa largely as a process of making infinite concessions to the outside - mainly the western world. Such education has tended to emphasize mimicry over creativity, and the idea that little worth learning about, even by Africans, can come from Africa. It champions static dichotomies and boundedness of cultural worlds and knowledge systems. It privileges teleology and analogy over creative negotiation by Africans of the multiple encounters, influences and perspectives evident throughout their continent. It thus impoverishes the complex realities of those it attracts or represses as students. (Nyamnjoh 2012: 129-130)

Nyamnjoh (2012: 137) continues, “Despite some encouraging examples, calls to rethink education in Africa are yet to be translated into action in any significant way," noting among African leaders a "preference for the foreign intellectual and expert over 
homegrown expertise." Nyamnjoh finds that the model of education in Africa has been drawn "from the institutions of the immediate past colonizer, and from the United States of America (USA) and Canada" (137), therefore, the measures of success have not been established in relation to African needs; rather "African universities push lecturers to publish in international journals yet do little to promote journals of the continent" (137). Taking inspiration from Frantz Fanon, Nyamnjoh (137) remarks:

Education in Africa has been and mostly remains a journey fuelled by an exogenously induced and internalized sense of inadequacy in Africans, and one endowed with the mission of devaluation or annihilation of African creativity, agency and value systems. Such 'cultural estrangement' in the place of cultural engagement has served to reinforce in Africans self-devaluation and self-hatred and a profound sense of inferiority that in turn compels them to 'lighten their darkness' both physically and metaphorically for the gratification of their colonial and postcolonial overlords.

While "African universities have significantly Africanized their personnel," the curricula and pedagogy remains anchored in foreign languages and worldviews (138). Drawing on Mamdani, Nyamnjoh argues that under the pressure of "the World Bank and its neoliberal market logic," African higher education has become "too standardized, uniformized, technicized, depoliticized and detached to be in tune with the predicaments of ordinary and marginal Africans thirsty and hungry for recognition, representation and upliftment" (Nyamnjoh 2012: 142-143). Nyamnjoh declares that the protectors of this system

want their programmes to go on without disturbance. They select as trainers and lecturers or accept, engage and sponsor only research and scholarship that confirm their basic assumptions and convictions. But African universities, academics and researchers have the responsibility to challenge such unfounded assumptions based on vested interests, hidden agendas or the habitus of colonial hierarchies of humanity and human agency. (Nyamnjoh 2012: 146)

Yet, some way forward must be constructed, and Nyamnjoh suggests, "Global conversations and cooperation among universities and scholars are a starting point in a long journey of equalization and recognition of marginalized epistemologies and 
dimensions of scientific inquiry" (2012: 147). Nyamnjoh proposes that this journey cannot be about "isolated individuals perceived to be doing 'the right thing', but a critical mass of scholars and non-scholars networking and working together strategically towards achieving the valorization of marginalized humanity and the creative diversity of being African" (2012: 148). The key factor here is not the leadership of the university but rather the critical mass of people within and, more importantly, outside the university defining for themselves how new approaches could revolutionize training and research.

In the case of women's knowledges, what feminist standpoint theorists discovered was that "researchers were to avoid taking their research problems, concepts, hypotheses, and background assumptions from the conceptual frameworks of the disciplines or of the social institutions that they served (the legal, welfare, health, education, economic, military, and other institutions)" (Harding 2004: 6). Rather than relying on a given conceptual framework, "What seems more productive is to dissolve this conceptuality once again back into the concrete situations from which it emerged" (Jameson 2004: 149). Sandra Harding argues that women have long been objects of investigation since "the research disciplines and the public policy institutions that depended upon them permitted no conceptual frameworks in which women as a group [...] became the subjects- the authors—of knowledge" (Harding 2004: 4).

As women have moved into the official workforce, they have inherited new roles for themselves within what remains a patriarchal structure. Judy Rebick (2009: 158) argues that: "Natural leaders exist in both genders, in all classes, and in all cultures, but the dominant culture tends to recognize only leaders that fit the model of the patriarchal 
leader." She even began to notice how this tendency had affected her own idea of leadership: "I covered up who I was" (159). Rebick believes that mothers have a special ability to learn through their relationship with their babies that communication is not simply a rational process, but something that connects mind, body, emotion, and spirit:

Yet as we become leaders in this patriarchal world, we put that knowledge aside. We underestimate and undervalue it. But that kind of understanding is very powerful in a leader, because it gives power in relation to other people-not a power over other people, which is what patriarchal power is, but a power in relation to others that in turn allows others to have more power themselves. If we are talking about redefining leadership, and about diversity in leadership, then we cannot have the kind of leadership that says "To be a leader, you have to be like me. Or him." (Rebick 2009: 165).

Rather than recognize the diversity of types of leadership, institutions tend to shut down that diversity in favour of a more singular version of leadership, the kind that currently justifies who is on top. In this situation, Rebick argues that we all lose out:

With patriarchal leadership, people do not contribute as much as they can. As mentioned, they may either submit, and give the leaders what they want (they could be giving much more, but they give what is demanded, what the leaders know to ask for), or they rebel. A different kind of leadership, more open, more supportive-dare I say, a more nurturing kind of leadership-will get more from people. People give more because they feel more confident in themselves. And that's the kind of leadership we have to develop. (Rebick 2009: 165)

When applied to the problem of how university training and research can better address issues of ecological sustainability, the challenge is to redesign the process of training to support the actual range of leadership capacities that people possess-and not to discipline everyone to fit into a single model.

Nancy Hartsock argues in standpoint theory that "there are some perspectives on society from which, however well-intentioned one may be, the real relations of humans with each other and with the natural world are not visible" (Hartsock 2004: 36-37). This is because different groups experience the world through particular channels of work and life and "each division of labor, whether by gender or class, can be expected to have 
consequences for knowledge" (38). If the understanding of those at the top depends on maintaining the base at the bottom, then only the understanding of those at the bottom has the possibility of fundamentally reorganizing the power structure itself. This reorganization is complicated, however, since "the ruling group's vision may be both perverse and made real by means of that group's power to define the terms for the community as a whole" (39: original italics). In other words, the whole structure is set up to valorize those at the top, thereby making only certain knowledge shape our reality by maintaining specific hierarchies in place. In this way "the ruling group controls the means of mental as well as physical production, the production of ideals as well as goods" (39).

Bringing about a change in the context in which this situation arises is unlikely, therefore, to come from the top (the head institutional administrators or managers). Talking about her experience in a Puerto Rican university, Reyes-Cruz (2012: 152) states:

\footnotetext{
The university, at least the one I was trying to join (not just pass by), does not really want democracy, autonomy or freedom. The governor selects the majority of the trustees, the trustees decide who the president will be, and she in turn decides who the chancellors would be and so on and so forth, in a long line of an authoritative hierarchy that tolerates few spaces for the university community to express their views and desires to then simply ignore them. People complain and keep going. At times, some ask for solidarity with their own cause but rarely for the common good. Meanwhile, the university gets by with its shrinking budget, speeding students through, redefining in the least democratic ways what is worth paying for (gates, private security, redundant and exorbitant legal fees) and what it can't afford (better working, studying, and researching conditions for a vibrant, plural, free, and open university).
}

The problem of starting from the assumption that new solutions will emerge from the work of university-trained experts is the tendency to overlook how this expertise depends on reproducing the same top-down forms of authority that characterize the existing hierarchical institutional structure. Even though this expertise recognizes to some extent that there are problems in its own internal production process (for example, through calls for inter-, multi-, and trans-disciplinarity), the established nature of the production process 
imposes real limits on the extent to which these problems can be addressed (few calls go so far as to question the need to start from a disciplinary base, instead they tend to rely heavily on disciplinary experts in whatever "new" version of inter-, multi-, or transdisciplinarity is suggested).

As a Maori woman and academic researcher, Linda Tuhiwai Smith (1999: 67) points to one of the contradictions of the disciplines when she argues that, on the one hand, they are inextricably bound together and resting on many of the same founding assumptions yet, on the other hand, "they are also insulated from each other through the maintenance of what are known as disciplinary boundaries." Furthermore she states: "Insularity protects a discipline from the 'outside', enabling communities of scholars to distance themselves from others and, in the more extreme forms, to absolve themselves of the responsibility for what occurs in other branches of their discipline, in the academy and in the world" (67). Smith points out that "researchers from different projects and different research teams can be in and out of the same community (much in the way many government social services are in and out of family homes), showing 'as a collective' little responsibility for the overall impact of their activities" (67-68). Smith further states: "The problem is not just that positivist science is well established institutionally and theoretically, but that it has a connectedness at a common sense level with the rest of society who, generally speaking, take for granted the hegemony of its methods and leadership in the search of knowledge" (Smith 1999: 189). 
Thus, universities are deeply implicated in exclusionary and anti-democratic practices, and attempts by marginalized groups to shape the structure of leadership become highly contentious.

\section{Another process of knowledge production is possible}

To better understand the obstacles currently in place, it may be necessary to look at them from the perspective of an entirely different model of community. Jeanette Armstrong, an

Okanagan writer, educator, and activist, describes Enowkinwixw as the process of her community:

The idea isn't to make decisions, the idea is to hear all of the different aspects, all of the different views, but in Enowkinwixw, we actually set up a dynamic in which decisions can happen. It is a dynamic in which we understand that there are always polarities in community, because there is diversity. We try to take the polarities in their larger sense and we give them context in the community. We give the polarities authority in terms of their context within the community, authority which can't be usurped by any other area of the community. (Armstrong 2007: 44)

Armstrong's model of community is based on listening rather than telling others how to be; it is a living model of health and well-being, and according to Armstrong it offers an alternative to the dominant model of community:

I look at how society outside of our traditional community operates with the understanding that some people have more rights than others, that some people have more of a priority to things than others, and that some people not only are born with priority, but are born with the control over who has priority. They live and die within that idea of privilege, control and exclusion of others. (2007: 43)

The form of community that exists in graduate school before graduate students even arrive is a lot like that: based on hierarchies. People are encouraged to play a specific role that supports the structure's existing organization and they are encouraged to relate to each other based on their status within the hierarchy. By contrast, Armstrong says: "I relate to 
people in a really different way because it is how my community relates. I can't recognize hierarchies. I don't recognize hierarchies. People are people in terms of how they relate to $m e^{\prime \prime}(43)$.

It is important to note the relationship between community form and human interactions: Armstrong is saying that she has internalized a way of interacting that feels supportive to who she is as a person, and this way of interacting comes from her own community traditions. Her community has "chiefs," but she explains that:

Our word for chief means to be able to take the many strands that are moving outward and twine them into one strand. One strand meaning one people and unification and a re-balancing with the land. It means that person must have an immense ability to feel what the community is saying, an immense ability to listen to the things that have been said, and to know the things that are happening, and to put it all together and say it back to the people. (2007: 43)

By contrast, authority figures in the context of graduate and professional training tend to be people who enforce how things are supposed to happen, people who tell subordinates what to do-and failing to conform could mean failing to climb the academic ladder. The model of leadership points in the opposite direction from how Armstrong describes the chief's role: "It's not about telling people what to do, or leading people, or forcing people; it's being able to verbalize and communicate what everybody feels and knows and understands and remembers, and being able to put that together to create a movement forward" (2007: 43). Very few disciplinary experts are expected to play this kind of role; rather than listen to the knowledge that those outside their area of expertise bring, the tendency is to impose a fixed, discipline-specific approach to understanding a particular type of problem, and to respect the hierarchical structure of authority that sanctions one's place within the discipline. 
But any steps toward producing new forms of leadership beyond the disciplinary model must include shifting the entire structure to support these new forms, otherwise the current ecologies and their ongoing historical development will tend to funnel attempts at innovation back into the fold. Therefore, even when it is possible to gain a sense that, for example, the history of university-based knowledge production has not supported the range of ways of knowing, the strategy for change will be more effective if it can take into account the ongoing history of struggle and its present-day nuances. Efforts to decolonize the university or rid the institution of patriarchy cannot simply be about creating new departments of Native Studies or Women's Studies (though these can be significant steps); rather, the problem is to engage with the ongoing structural history of discipline and exclusion. Doing so or failing to do so is - either way - part of a political process.

Profound implications follow if the university is going to actually serve as a model of participation and social/gender equity, as many of these institutions remain dominated by white, upper class men (Rose 2004: 67-68). But as a wider diversity of people enter the doors of these institutional structures that remain products of ongoing patriarchal, racist, and sexist processes, there is a need for those moving through these channels to fundamentally question their legitimacy, yet doing so poses an internal conflict, since these channels remain the path toward the dominant version of "success." Certainly, adding a new "environmental" faculty will not change persisting disparities in income between men and women, to take but one type of concrete measurement of inequality (Catalyst 2014). The real work ahead is not about further narrowing people's choices by funneling them into more and more separated fields but, on the contrary, it is about 
putting the production of choice into the hands of the diversity of people coming to the university.

Santos' (2009) "ecology of knowledge" is useful here, as he posits new knowledge as beginning with ignorance of the possible diversity of ways of knowing. Rather than accepting the current dominant incarnation of "Western" knowledge as inevitable, Santos shows how the "West" actually includes a wide range of theories and practices, some of which parallel "non-Western" forms of knowledge, which have been suppressed by the rise to dominance of a particular strand of Western knowledge. By refusing the supposed inevitability of this domination, Santos argues that it becomes possible to work toward opening up the actual ecology of knowledge that exists. Indeed, the actual number and quality of ways of knowing far surpasses the formal (or official) institutionally sanctioned approaches to knowledge production, and rather than ignore the real diversity of knowledges, greater insight and development is more likely to happen by changing the structures that keep certain knowledges off the official list. In Another Knowledge is Possible, Santos et al (2008: xix) argue,

there is no global social justice without global cognitive justice. Probably more than ever, global capitalism appears as a civilizational paradigm encompassing all domains of social life. The exclusion, oppression, and discrimination it produces have not only economic, social, and political dimensions but also cultural and epistemological ones. Accordingly, to confront this paradigm in all its dimensions is the challenge facing a new critical theory and new emancipatory practices. Contrary to their predecessors, this theory and these practices must start from the premise that the epistemological diversity of the world is immense, as immense as its cultural diversity and that the recognition of such diversity must be at the core of the global resistance against capitalism and of the formulation of alternative forms of sociability.

Along with the genocide carried out against Indigenous peoples of the Americas and the African slaves, there was an "epistemicide" suppressing the diversity of ways of knowing that these diverse peoples carried with them. Therefore, any emancipatory struggle against 
capitalism's imposition of the North onto the South will benefit from recognizing the wide range of ways of knowing supported within the world's cultural diversity. Rather than closing down and fragmenting knowledge to fit into a specific disciplinary organization, the goal is to provide the actual "ecology of knowledges" its due place in the world:

Both the proposals for radicalizing democracy — which point towards post-capitalist horizonsand the proposals for decolonizing knowledge and power-which point towards post-colonial horizons-will be feasible only if the dominant epistemology is subject to a critique allowing for the emergence of epistemological options that give credibility to the forms of knowledge that underlie those proposals. (xxi).

If attempts up until now have not changed the overall direction of the development of the ecological crisis, it follows that some type of new initiative is required, but careful attention is needed to determine what would count as a break from the old toward something new. The mere inclusion of a wider ecology of knowledge within the dominant production process may not actually lead to much change; rather what is more likely is that this production process will only continue to disrespect other ways of knowing to fit them within its existing norms.

Moreover, although the ecological crisis continues to worsen this does not necessarily mean that past attempts should be ignored altogether. On the contrary, the gains that have been made need to be acknowledged, carried forward, and multiplied. In other words, efforts must be expanded beyond the scope of current attempts while harnessing the momentum that these attempts have generated. Rather than remain limited to existing forms of expertise, this means working on and off the official list, and drawing on the wider ecology of knowledge available. Any future that includes humanity must include an ecologically sustainable relationship between the natural processes inside and outside the human community. An ecological approach to consciousness consistent with 
the global scale of the crisis, therefore, involves an interaction between the full diversity of human community forms and ways of knowing. If the dominant form of community has contributed to the production of the ecological crisis, then globalizing this community form even further will likely worsen the crisis. The challenge, therefore, is to move toward a global community form of a new kind: one characterized by the diversity of ways of knowing coming together to produce a collective steering capacity—an ecological consciousness on a global scale.

\section{Systems thinking, Indigenous ways of knowing, and historical materialism as foundations for ecological consciousness}

The sustainability of any newly emerging consciousness depends on building new forms of community support, which means intervening in the current ecological conditions at different levels. I look now at three approaches - systems thinking, Indigenous ways of knowing, and historical materialism - that, while harbouring some of the pitfalls I have identified, also push beyond the typical ecological values approach to consciousness. Indeed, these three approaches may be particularly well placed to support the development of a more robust ecological consciousness, as they share a critique of dominant structures and yet dialogue between them remains under-developed and at times antagonistic, which suggests that further dialogue may lead to new discoveries.

From a systems perspective, Fritjof Capra, world-renowned physicist and founder of the Center for Ecoliteracy at the University of California, Berkeley, writes: "The decisive advance of the systems view of life has been to abandon the Cartesian view of mind as a 
thing, and to realize that mind and consciousness are not things but processes" (Capra 2002: 34). In humans, the evolved complexity of the brain and nervous system gives rise to a "reflective consciousness" and a concept of self (Capra 2002: 39). Despite the tendency for new technologies to reinforce the assumption that the individual is the correct unit of analysis, the systemic approach emphasizes that, "interactive processes [with other bodies, brains, and communities of organisms] are crucial to understanding the level of cognitive abstraction that is characteristic of reflective consciousness" (52-3). Capra talks about evolving processes at different scales, from the molecular to the social, and he defines "communities of practice" as "self-generating networks of communications" (108), especially informal networks and friendships that help an organization learn and change. Capra argues that "global capitalism in its present form is unsustainable and needs to be fundamentally redesigned" (157), and he suggests that the first step in "changing the game" means "agreeing on the basic values that are needed to reshape globalization" (214). Capra defines ethics as "a standard of human conduct that flows from a sense of belonging," and he suggests that as "members of humanity" and as people of "the global biosphere" we have a responsibility to "behave as the other members of the household behave- the plants, animals, and microorganisms that form the vast network of relationships that we call the web of life" (214). The ethics of sustainability rest on supporting nature's ability to sustain life but they also include "a respect for human dignity and basic human rights," such as "the basic right of communities to selfdetermination and self-organization" (215). 
From his perspective as an Indigenous scholar and a Tewa Indian from Santa Clara Pueblo, New Mexico, Gregory Cajete makes several points about ecological consciousness. Noticing how under capitalism money has reached the status of a quasideity commanding our lives, Cajete discusses "spiritual ecology" as a constant investigation into the "nature of the spirit that moves us" (1994: 42). Based on a teaching called "for life's sake," Cajete proposes "an epistemology in which the community and its mythically authenticated traditions support a way of life and quality of thinking that embodies an ecologically-informed consciousness," thereby "the community becomes a center for teaching and a context for learning how to live ecologically" (46). This foundational teaching, he suggests, is not restricted to one group of Indigenous people, but rather for all of humanity at all times, "even those of modern education" (187). Cajete recognizes that the form of consciousness that currently dominates in North America is not the only real possibility, however he does not reject all elements of "western knowledge" but rather calls for conditions where a genuine exchange between different ways of knowing might be possible. Cajete argues that the dominant educational system divorces knowledge from its context, producing a particularly alienating effect on Indigenous people (139-140).

Cajete advances a definition of ecological consciousness that rests on the possibility of generalizing some of the traditional knowledge that sits within Indigenous communities to re-appropriate what a "modern ecological consciousness" might mean:

The sense of ecological process and the importance of being in harmony embodied in Indigenous cultural traditions can be replicated in a larger scale within modern societies. Collective experience with the land, integrated by story and ritual, expressed through social structures and arts, and combined with a practical system of environmental ethics and spiritual ecology, can give rise to a true connection with the natural world and a more comprehensive expression of modern ecological 
consciousness. There is an important legacy of traditional environmental knowledge that we must again revitalize for ourselves and for the generations yet to come. Indigenous peoples have been entrusted with an important package of memory, feeling, and relationship to the land that forms a kind of sacred covenant. Modern Western peoples are challenged to strive to educate themselves about this knowledge and associated forms of education. This covenant bids modern Western peoples to reclaim their own heritage of living in a harmonious and sustainable relationship to the land, thereby fulfilling a sacred trust to that land. (Cajete 2000: 265)

Cajete suggests that, "This ancient idea of relationship must be allowed to rise in our collective consciousness once again," adding that "In the perilous world of the twenty-first century, it may well be a matter of our collective survival" (2000: 105). Although he argues that there is value in what modern science has to offer, he insists that "understanding the relationships scientifically is not enough—living and nurturing these relationships is the key" (2000: 95). At their core, Native traditions entail "learning about being fully human while living in a relational universe" (2000: 262) and the key is to figure out how to generalize this knowledge within the context of the modern world. Although there are promising efforts underway, Cajete points out that mainstream education tends to fall back onto a default model that cannot actually measure what matters most:

Most of this work, however, continues to be done within the old paradigms of Western science and policy development, which measure success using mono-dimensional economic references: numbers of people trained or graduated, goods and services delivered, loans or profits made, etc., even though these quantifiable indicators are but one kind of indicator. Deeper-level indicators that reflect the broader dimensions of change or impact are rarely researched, and when they are, they are rarely taken seriously. Instead, the so-called "bottom line" evaluation system continues to be most valued as a measure of success. Meanwhile, community and environmental issues continue and in many cases even worsen, as is the case in many Indigenous communities that attempt to apply Western concepts of development to their unique needs. In general, we know more about the issues than ever before, yet we continue with old-paradigm thinking and actions, seemingly helpless as we continue to speed head-on to disaster. (Cajete 2000: 270-271)

There is a need, therefore, to overcome this tendency and start a process of reorganization. 
One further approach to understanding ecological consciousness comes from the historical materialist perspective through the work of Felix Guattari and his concept of "the three ecologies." Guattari defined the three ecologies as the mental, social, and environmental dimensions of the world, arguing that new forms of work would have to simultaneously address all three levels to really have a chance of steering humanity in a more ecologically sustainable direction. Noting how "the acceleration of the technological and data-processing revolutions" (2000: 133) would interact with "institutional and social class dimensions" (133) to give rise to entirely new processes and forms of subjectivity, Guattari argued against "scientistic" discourse and those who might cling to old authorities, advocating instead for "perpetual reinvention" (133):

Like artists and writers, the cartographers of subjectivity should seek, then, with each concrete performance, to develop and innovate, to create new perspectives, without prior recourse to assured theoretical foundations or the authority of a group, school, conservatory, or academy. (Guattari 2000: 133)

For Guattari, the open-endedness of "eco-logic" was key to confronting the deterioration of the social, mental, and environmental ecologies, which he saw as a consequence of the "fatalistic passivity with which those issues have been confronted by individuals and responsible authorities" (134). Struck by "the general inflexibility of social and psychological praxes" linked to "a widespread incapacity to perceive the erroneousness of partitioning off the real into a number of separate fields" (134), Guattari called upon us to "kick the habit" by learning "to apprehend the world through the interchangeable lenses of the three ecologies" (134).

It should be obvious that Guattari was not calling for a return to a previous more "natural" state, since he recognized that "In the wake of the data-processing and robotics 
revolutions, the rise of genetic engineering, and the globalization of markets, neither human work nor the natural habitat can return, even to their state of being of a few decades ago" (134). Nor was he suggesting that one single group of experts could hold all the answers: "Ecology should abandon its connotative links with images of a small minority of nature lovers or accredited experts; for the ecology I propose here questions the whole of subjectivity and capitalist power formations" (140). Rather, he was trying to articulate what it would mean to confront Integrated World Capitalism (IWC) under the present conditions:

The Marxist postulate which argues that economic semiotics - the semiotics of production of material goods - occupies an infrastructural position in relation to juridical and ideological semiotics has, for example, been increasingly discredited. Today, the object IWC has to be regarded as all of a piece: it is simultaneously productive, economic, and subjective. (Guattari 2000: 138)

The question is how to direct "growth along paths that avoid the absurdity and the impasses of integrated world capitalism" (140), toward fulfilling real human needs.

The main overlapping points in Guattari, Cajete, and Capra are as follows. They share an emphasis on process as a way of knowing and acting in the world: different processes lead to different outcomes, experiences and types of knowledge; new properties emerge through building new relationships, and since particular processes are already in place, genuine change requires intervening at the level of process. Furthermore, all three scholars suggest that current dominant approaches are detrimental. For Capra this means shifting from a mechanistic to a systemic understanding of change; for Cajete this means recognizing the place of Indigenous teachings within the modern world; for Guattari this means developing a collective steering capacity to meet real human needs, rather than simply hiding in authoritative discourse and the absurdities of capitalism. At a general 
level the three scholars seem to agree that humanity carries unique universal capacities for self-directed community formation and an ecologically conscious relationship with the world. Finally, there is a shared concern for the way that capitalism has become a global force destroying ecological sustainability and reorganizing the form of human community, subjectivity, and agency, as the authors call for a coordinated global intervention.

Along with these overlapping concerns, systems thinking, Indigenous ways of knowing, and historical materialism exhibit core differences in how they approach consciousness. For example, in systems thinking human consciousness is often seen as necessarily limited and generally self-interested and, therefore, something of an impediment to wisdom. In Steps to an Ecology of Mind, one of the classic works in systems approaches, Gregory Bateson argues that conscious purpose can never really understand the wisdom of the whole system and, furthermore, with the advent of new technologies, "Conscious purpose is now empowered to upset the balances of the body, of society, and of the biological world around us" (Bateson 2000: 440). Rather than a key ally, conscious purpose becomes what needs to be transcended, for example through art or religion (Bateson 2000: 444-445). By contrast, in historical materialism ${ }^{6}$ the

\footnotetext{
${ }^{6}$ Voloshinov (1973) criticized approaches to consciousness that fell into one of two traps: either they relied on a "superhuman" or "subhuman" description that actually did not explain anything about consciousness" ideological nature. In the superhuman description, consciousness was everything — the one and only generator of reality — as if the objective world were a direct outcome of ideas in the mind such that changing the world were as simple as changing one's mind. In contrast to this extreme idealism, in the subhuman approach consciousness was reduced to an accident of biology. But as Voloshinov argued:

Consciousness takes shape and being in the material of signs created by an organized group in the process of its social intercourse. The individual consciousness is nurtured on signs; it derives its growth from them; it reflects their logic and laws. The logic of consciousness is the logic of ideological communication, of the semiotic interaction of a social group. If we deprive consciousness of its semiotic, ideological content, it would have absolutely nothing left. Consciousness can harbor only in the image, the word, the meaningful gesture, and so forth. Outside such material, there remains the sheer physiological act unilluminated by consciousness, i.e., without having light shed on it, without having meaning given to it, by signs. (Voloshinov 1973: 13).

Since "Signs can arise only on interindividual territory" in which individuals are socially organized, "The individual consciousness not only cannot be used to explain anything, but, on the contrary, is itself in need
} 
development of conscious purpose is central in individual and collective agency, which is not seen as an inherently ecologically destructive force but rather as a collective steering capacity (Foster 2001). In Indigenous ways of knowing, the human role in the cosmos is about actively figuring out how to help keep a sense of balance through participating in the maintenance of all relations. Traditions and ceremonies play a key role in this maintenance, but these are not frozen in time, rather they respond to current needs for caring for future generations. There are strong tensions here with certain versions of historical materialist analysis, especially around the place-based nature of Indigenous ways of knowing (see Grande; Churchill; Bowers), but conscious purpose is by no means seen as the driving force behind ecological destruction, rather it is much more the blindness that comes from failing to consciously direct one's own body that is seen as problematic.

One of the traps that all three approaches try to avoid is that of taking a worldview as a fixed block of knowledge without sufficiently acknowledging the process of community formation that supports this block, naturalizes it, and gives it the appearance of static uniformity. The "problem" of a gulf between different ways of knowing is not, therefore, only a problem of presumed incommensurability of values, for example, but more specifically it is a problem in the process of interaction between different ways of knowing—a process that has a particular history and trajectory that must be acknowledged, confronted and transformed if future collaborations are going to be more meaningful. The challenge, therefore, is not to melt different ways of knowing into a single 
approach, but rather to open a space where they can interact and begin to develop new community forms (other than the dominant form that already organizes interactions, or lack thereof).

In the process, the tensions that emerge from these different approaches may actually challenge dependencies on a single way of knowing, thereby opening up greater possibilities for the development of ecological consciousness. For example, there are many efforts underway to realize some of this potential leading to some intriguing collaborative work (see Dei 2000; Denzin, Lincoln, \& L.T. Smith 2008; Davis 2010). Recognizing the partiality of any one understanding challenges and supports existing efforts to discover new practices and forms of awareness, while developing a praxis that embraces diversity. If, as I am suggesting, ecological consciousness is not the property of any single discipline or theoretical approach, but rather a capacity to bring together different knowledges into a community development process, then it is only through exploring tensions that a suitable community form can be developed.

My proposed framework for ecological consciousness thus builds upon - and pushes back against - certain academic and popularized understandings of what it means to think ecologically. Rather than imparting a specific environmental ethic (Leopold 1949), scientifically grounded ecological worldview (Uhl 2003; McHarg 1969) or biocentric paradigm (Suzuki 2012; Uhl 2013), I am suggesting that the first step toward greater ecological consciousness is much more about replacing disciplinary approaches with

\footnotetext{
${ }^{7}$ There are many relevant examples of collaborations centered on developing greater collective steering capacity with a view to an ecologically sustainable future, but to name some that explicitly deal with different ways of knowing see Jackson (2000), Berkes and Folke (1998), Berkes et al (2000), Kovel (2007), Peet and Watts (2004), Vaughan (2007), and Gibson-Graham, Cameron, and Healy (2013).
} 
spaces where a wider ecology of knowledge can develop and express itself (Santos 2009; Santos 2008). Although a paradigm shift (Kuhn 1962) may be what is needed, it is also necessary to understand what this shift entails beyond training individual minds to accept a new way of looking. Since consciousness does not develop in a vacuum (Vygotsky 1962; Volishonov 1973), but rather exists in relation to a particular set of circumstances including the physical environment, the form of community and type of social relations (Guattari 2000) - changes in consciousness require special attention to the relationship between consciousness and context. Indigenous methodologies and pedagogies are an important part of this change. A paradigm shift requires, however, more than a commitment to one's own personal values or ethics—it requires a change in the ecology of the surrounding structure through which minds are produced.

Defined in this way, an ecological consciousness framework requires looking beyond the ideas themselves to see the democratization of various contextual levels that give rise to them. Ecological consciousness is thus better understood as an ongoing relationship - not an endpoint - within the struggle to develop forms of community that support the diversity of knowledge that people have to offer each other-and this definition has pedagogical and methodological implications, to which I now turn briefly.

\section{Pedagogical implications within an institutional and global development frame}

Ecological consciousness cannot limit itself to a fixed understanding guarded by, say, those credentialed in ecology (or any other field for that matter), even if that understanding contributes key ecological insights. Rather, ecological consciousness is made up of the 
widest diversity of ways of knowing which must find a way of reshaping established processes and contexts so as to produce new outcomes. The expression "learning by doing" has become a cliché, especially in educational circles, but the idea is critical in that the means of learning (the process through which learning happens) communicates a much stronger message than the contents of learning (what is stated by those in charge of teaching). Since it is the learners who must do the learning, this poses a challenge to traditional teaching roles where the teachers impart the answers to the students. Dedicated educators must, therefore, develop congruence between the context and contents of learning, so that the message in the contents is reinforced through the medium itself.

Renowned $20^{\text {th }}$ century American philosopher and educator John Dewey advanced a theory of education that strikes a balance between received ways of teaching science and the development of new innovative approaches. In considering what kind of learning experiences tended to give rise to better learning experiences in the future, Dewey argued that the educator had a specific role to play in intentionally setting up experiences that would invite students to push beyond their existing knowledge, but he found that certain experiences were actually "mis-educative," in the sense that students emerged from them with a diminished capacity to learn. ${ }^{8}$ The value of the learning experience was not in the subject matter itself, he argued, but rather in how it related to the "stage of growth attained by the learner" (Dewey 1938: 46). Genuine preparation gave learners a taste of the actual conditions they were likely to encounter in the future, so that they might begin learning from those conditions now. For example, Dewey believed that being tested on facts was

\footnotetext{
${ }^{8}$ Recent studies by Nobel laureate Dr. Carl Wieman reached a similar conclusion in relation to first-year university science courses—see Adams et al 2006.
} 
good preparation for being tested on facts, but it was very poor preparation for being able to use those facts in some other context. Thus the key was to make the classroom experience into a kind laboratory for encountering parts of real-life contexts, while offering space for reflection as this would allow new useful knowledge to emerge within the learner's experience itself.

Two implications follow from Dewey's analysis. First, to be effective, training should bring people into contact with some of the actual conditions they will face; there is little point in telling participants the "right" answers when the real challenge is for them to develop their own answers within the conditions that they face. Secondly, training must cultivate the learner's capacity to handle those conditions based on having developed his or her own new knowledge about them. According to Dewey, the goal of scientific research, teaching, and learning should not be restricted to demonstrating the truthfulness of established facts-facts which serve to reinforce the existing form of scientific knowledge and further solidify who is in the know and who is not. On the contrary, Dewey argues that the goal of science includes an educational function that supports the human capacity for collective re-organization and on-going learning.

In Pedagogy of the Oppressed, Paulo Freire - the Brazilian educator engaged in literacy training with agricultural peasants from the 1940s until being exiled in the 1960s begins with the notion that education can be either humanization or dehumanization and indeed history has been made up of moments that push in both directions. Within a social order built upon oppressor-oppressed relations Freire argues, "Only power that springs from the weakness of the oppressed will be sufficiently strong to free both" (1972: 26). 
Handouts from rich to poor do not address the root causes of social inequality and, in fact, this "generosity" is only made possible by the underlying oppressor-oppressed relations. Having the oppressed become more like the oppressors does not provide any further solution. The goal, therefore, is to be rid of the "reality of oppression" altogether, and education is part of a struggle to produce a social order in which greater humanization is fostered. Against what he called the "banking" model where knowledge is deposited from the minds of the experts into the minds of students (as if students were empty vessels waiting to be filled), Freire argued that people have the capacity to develop their own knowledge and that the educator's role was to help the development of this capacity.

Freire's and Dewey's praxis can help understand what a participatory approach might entail within the context of international development research. Participation in the Freirean sense is not strictly about the percentage of people who take part in a project, nor is it about the correct application of a pre-made "participatory" framework; rather it is about the quality of participation in terms of people's capacity to practice their own autonomy throughout and beyond the confines of the project. In this sense, genuine participation lives in the ability of people to push up against and transform the existing constraints that restrict and shape their activity.

But the notion of participation has "moved virtually unchecked from the margins to the mainstream of development since the mid-1980s" (Hickey and Mohan 2004: 3), prompting a backlash questioning not only the results to date but also the possibility that participation could ever live up to its promises for empowerment and emancipation (see Cooke and Kothari 2001). Anthony Bebbington (2004: 279) argues that although it is 
possible that all the talk about participation could amount to so much "hot air," or worse, it could amount to "a discursive strategy to facilitate the management of a global transition to deep-seated neo-liberalism," he nonetheless insists that such effects were not likely part of "the intent of those who committed their lives, careers and often families to fostering such changes" (279). Therefore, rather than race to criticize participation, a more interesting approach is to uncover the following:

How did such apparently progressive agendas emerge within these bureaucracies in the first place; how was it possible to promote such new languages and arguments within these institutions; and then, how were these languages and initiatives reworked and captured, both within these institutions and within the countries in which they operate? (279-280)

The word "captured" suggests perhaps that participation has become imprisoned in bureaucracy, but the point as Bebbington sees it is not to simply leave participation there, but rather to investigate the "internal processes" (280) of agencies fostering participation, as a way of arriving at more fulfilling future successes. Bebbington's point about the underlying structure of participation is also worth repeating:

The point of framing not just participation, but also the sites from which it is advocated and promoted, in relationship to structural context is to be realistic about what is more and less possible, and also - and this is more important still - to be clearer about the obstacles to social transformation and increased levels of meaningful social inclusion. It means that participation events - projects, research cycles, planning processes etc. - should never again be considered without considering the 'immanent' conditions under which they occur. (Bebbington 2004: 280-281)

To work more effectively on international development projects it is necessary, therefore, that graduate students and young professionals have the opportunity to develop their own capacity to theorize what participation means in relation to the material context in which this work takes place. These types of big picture questions are exactly what came up during my interviews with ecohealth experts-in-the-making, as they navigated the search 
for a genuinely participatory approach and the need to complete their projects on time and "successfully."

But taking responsibility for addressing such big picture questions cannot happen through a pedagogy that aims to change individual minds through individual projects. While this individual scale can be seen optimistically as an attempt on the part of individuals to consciously take responsibility for their actions, as a global strategy it always comes up short, since the realities encountered in the world are not simple products of individual actions but rather the outcomes of ongoing processes from which individuals cannot be magically exorcized. Of course, the notion of taking individual responsibility comes, for the most part, from a genuine place—it indicates a real desire to do something about the problem. However, individuals cannot take responsibility for collective processes—only collectives of individuals can do that. Furthermore, individual attempts to assume the right attitude and beliefs can often lead to disdain towards those who do not abide by the same moral code, thereby making others into the scapegoats for why problems in the world exist (see Cronon 1995). This creates further divisions and antagonisms, when in fact the only way to take responsibility for reality is to do so collectively, not as a single individual trying to live an ethical life alone.

A more realistic pedagogy of ecological consciousness would seek to accommodate the different values and interests that individuals hold, while using the tensions to develop a collective strategy for global change. The ideas in individual minds are not automatically wrong; rather they can be put to good use: since those ideas are produced in relation to the world, when put together they reveal a great deal about how the world currently 
works. When the ideas remain isolated in different individual minds, however, they are more easily manipulated to fit within existing structures and ideologies (Eagleton 2000). The deck may be stacked in favour of the existing designs of the world, but there are steps that can quickly be taken to begin the groundwork for building new designs that better meet collective human needs - not just individual concerns or anxieties - starting by bringing groups together to confront their own experiences and construct alliances across existing institutional hierarchies. Antonio Gramsci, the Italian communist thinker asked:

is it better to take part in a conception of the world mechanically imposed by the external environment, i.e. by one of the many social groups in which everyone is automatically involved [...] Or, on the other hand, is it better to work out consciously and critically one's own conception of the world [...]? (Gramsci 1971: 323)

Gramsci argued that, in some cases, people's conception of the world was "strangely composite" (1971: 324), exhibiting "disjointed and episodic" tendencies toward "a multiplicity of mass human groups" (324). The goal, he argued, was to overcome this state of affairs by criticizing one's own conception of the world, separating it from the mechanically received conception imposed by one's group. If in so doing there suddenly appeared a sharp contrast between the group's words and actions, this could indicate that the larger "social historical order" was imposing itself on the group and distorting its mental production:

[The co-existence of two conceptions of the world, one affirmed in words and the other displayed in effective action...] signifies that the social group in question may indeed have its own conception of the world, even if only embryonic; a conception which manifests itself in action, but occasionally and in flashes-when, that is, the group is acting as an organic totality. But this same group has, for reasons of submission and intellectual subordination, adopted a conception which is not its own but is borrowed from another group; and it affirms this conception verbally and believes itself to be following it, because this is the conception which it follows in "normal times" - that is when its conduct is not independent and autonomous, but submissive and subordinate. (326-7) 
In these cases, the only way of achieving greater coherence was to confront and reconfigure the production process of the social historical order itself.

By examining the current conditions and how they would have to change to better support different ways of knowing, the ecological consciousness framework puts the emphasis on understanding the conditions - and not simply on adopting a given paradigm - thus opening the possibility of changing those conditions, and this is the basis of any paradigmatic shift. Learning from difference is an important part of developing greater solidarity, since the more difference is taken into account the more the underlying patterns and structures that produce difference can be uncovered and confronted. 


\section{Chapter 2. Pathways to the Encounter with Ecohealth}

In this chapter, I map encounters with ecohealth training, which give rise to two fundamental tensions. The first is about the extent to which the ecohealth training course breaks from a more traditional graduate training model. I argue that interviewee comments need to be understood not simply in terms of individual preferences but as a whole diversity of experiences pointing to certain incongruences between the medium and message of the training course structure. Secondly, there is a tension around what this training is for, which splits interviewee responses between trying to change the existing norms of research and trying to fit into them better. By listening to the range of interviewee responses, it becomes possible to see the effects of the ecology of graduate training on the production of consciousness, which in turn helps prepare the ground for understanding what a different ecology - and a different consciousness - might entail.

\section{Contrasting Responses to Ecohealth Training}

In Caroline's view, not only were the course concepts "eye-opening," but the approach to learning about them fostered strong bonds with the other participants. In particular, she referred to the "watershed" and the idea of "upstream and downstream" as literal and figurative metaphors "for the greater scheme of things," which she felt could apply as much to projects involving actual physical ecosystems as to projects focused on the "social side" of issues. She said, "I definitely liked the people I met: from the students that were there, to the instructors, to the alumni from previous years," and she came to the 
understanding that "multidisciplinary means not just different types of researchers but people in general from all over-it transcends disciplines." To her, ecohealth was "an overall approach, not just to research but to life," and she hoped that "maybe one day there will be a research model of like-minded people."

For his part, while Marlo also developed bonds with other students, these seemed to occur largely outside the intended course design and were not linked to learning new course concepts. According to Marlo, students felt "like our input may have some value here instead of just being lectured at":

What happened with our group was, again we didn't have much time to interact and then once we did start, one night everyone just kind of ended up at the pub, it kind of came out that everyone was having the same issue with the course, which was too much lecturing at, not enough discussion.

Marlo said: "it wasn't as much the ecohealth concepts that brought me into it, it was the people." But while he said the course included "a great group of students" and the professors were "very approachable," he was left wondering "what the practical outcomes were beyond that kind of network-forming group"? Marlo came to the course to be trained in how to use the ecohealth approach, but he found that there were not "any concrete methods or anything like that applied to it." Instead of a straight answer, he was often told that he would have to define ecohealth for himself. To him, ecohealth became a "nebulous" concept, less of an actual doable approach and more of "a unifying theme," especially for "people who have historically come from a more narrow focus and really latch onto this idea in medicine of looking at aspects beyond the clinical approach." At times, he noted that "there was almost a spiritual side, which is totally fine," but he said "academically, in terms of my thesis it hasn't turned out to be a huge source of useful information." For a particular group ecohealth might be an "interesting academic exercise," but to him it still was not clear "what it brings concretely," since as he put it, "it's not a social movement, that's not the right term at all, but it seems to me that the value of it is the community and the support that it lends, but not necessarily the health outcomes." 
Moreover, their descriptions of the course seemed to point toward totally opposite forms of group process, with Caroline emphasizing human interactions and Marlo emphasizing redundant lectures. In Caroline's words:

What was really good about the course was how it was small enough that people actually worked together on solving problems and there was so much engagement so you had the chance to develop bonds, right, and literally were forced into situations where you had to work together, you had to plan together and it drew everyone closer, it put that intimacy back into things, which is awesome. So I think they definitely need to keep that focus and maybe offer opportunities for alumni to come together and all different types of alumni and workshop situations like that, and just keep these settings where people can meet, collaborate on these forced projects.

Compared to certain academic conferences where she felt as though people interacted primarily on the basis of shared professional titles, Caroline said that the ecohealth training course was "special" because "it br[ought] back these human interactions" where people had the opportunity to "genuinely know each other."

By contrast, Marlo said:

I felt that sometimes the group, it sometimes felt like it was a bunch of people who all had different experiences but when they came together they kind of dumbed down some of what they actually felt to kind of fit it into this box. The first week was essentially lectures on the importance of the pillars, which again I thought was a bit redundant because we'd done all the readings on these sorts of things, I don't remember a ton of details about the individual lectures, I remember there was quite a few of them, they were long days.

Marlo was quite specific: he was not criticizing any of the people involved with the course; in fact, he "found it very interesting to talk to some of those profs outside of that setting." The problem, however, was the setting itself. In his conversations it became obvious that the professors "had more complex views about ecohealth and the approach than they probably let on during the course," and to him, "those complex views were more relevant and interesting than reiterating the same topics over and over and over":

It seemed like they were just trying to convince us of the value of doing interdisciplinary research and considering some of these other factors, which felt like there was a bit of a generational gap in the sense that it seemed like to some of the older generation who had come from more silo-based academic disciplines, this idea was new to them and they latched onto it. I felt like a lot of the younger people who signed up for the course had already been exposed to that sort of stuff. 
Marlo said he appreciated the course instructors" hard work, acknowledging that "this was a two-week course so I totally understand they only had time to cover certain things but..." He felt that the details, tensions, and challenges of actually doing ecohealth research were missing from the course and "those are the sorts of things that I think would have been more valuable to the student or young researcher."

Caroline and Marlo seemed to be describing two entirely different teaching philosophies, one pointing toward the merits of a bottom-up approach whereas the other suggesting that the course was taught too much in a top-down fashion. Arguably, any group process—and a training course is a group process by design—contains a tension between received structure and open-ended development. Bottom-up approaches tend to emphasize the latter, whereas top-down approaches tend to reproduce the former. The effect of each is quite distinct: working as a group on a problem is an inherently different experience from sitting through a lecture together, even if both experiences focus on the same general topic (e.g. ecohealth). For one, while group work tends to necessitate that people interact with each other, a lecture tends to prevent people from interacting because of the expectation to pay attention to the speaker at the front of the room. More fundamentally, while bottom-up approaches tend to encourage active participation in the production of the group's learning, top-down models tend to push toward individualized conformity to the already formed answers of the instructor.

Based on the experiences of interviewees, it appears that the ecohealth training course contains both bottom-up and top-down approaches, with some variation in the exact blend depending on the year in which the course was offered. A perusal of the 
course syllabi as well as my own experience of the course confirm this: there are a number of presentations given by experts on the different pillars of the approach, along with a number of group work opportunities focused on a key theme or specific case study. Special guests may be invited from the local setting or students might take a day-long field-trip to visit a site related to ecohealth issues. One challenge with this kind of blended model is that it can become unclear what is the intention behind its design. While it might be possible to argue that this kind of blend offers something to suit everyone's learning preference, sharp contradictions are bound to arise between the stated aims and the actual methods used during the course. Logistical factors (such as the availability of faculty and funding opportunities that shape faculty priorities) as well as the disciplinary expertise of the faculty available shape the course content and impose scheduling constraints.

Interviewee reactions to this blended model were, predictably, mixed. In Nancy's case, she enjoyed the ecohealth training but she said, "sometimes it felt like it was pressing ecohealth onto projects or trying to fit them into this thing." She noted some activities were geared toward doing fieldwork in another country, which presumed an international development scope, and she remembered having to identify the pillars of ecohealth in her project: "it was challenging to try to place the same label on all our projects, especially when for a lot of people, and for myself definitely, I wouldn't say I was doing an ecohealth project." Yet, Nancy liked how the course was about "hearing all these different people doing things that could seem very different" and she came to the following understanding: "I don't think that every single project can cover all aspects of ecohealth and its pillars, I thought the collectivity of our projects could definitely do that." 
Nancy's experience shows a double layer with one tendency toward understanding ecohealth as a pre-defined context to which students must make themselves relevant, and another tendency toward generating a new understanding of ecohealth in relation to the collectivity of participants' projects.

In general, interviewee responses depended on their experience with the wider context of graduate and professional training to which they had become accustomed. In Daryl's experience of graduate education in Canada, for example, the norm is based on a top-down lecture model compared to which he said that the ecohealth training showed "an effort to teach a course in a very different [way] than top-down, like non-lecture style." When I asked Daryl about the most rewarding part of his involvement with ecohealth, his first reaction was to say: "definitely not the material or musical productions that are produced during the course!" In some course activities students have produced photographs, songs and poetry, but Daryl said that the most rewarding part for him was "disseminating knowledge that I have accumulated in my experience." Later in the interview, however, he described an artistic production as one of the course highlights: "it was a moving experience because it was pleasant to be exposed to that production of convergent effort," adding "that was kind of in contradiction to my earlier statement about what was rewarding." Daryl's admission of his own contradictory response is revealing. When students become accustomed to the top-down approach of most graduate training, they may experience discomfort when confronted with a more bottom-up approach, regardless of the advantages it offers in hindsight or upon further reflection. 
In the normal mode of graduate training, students expect to learn from the teachers: the teachers are the experts with the knowledge and experience, and students are there to pay attention and absorb what is being said; thus the teachers are in charge and the students follow their lead. But ecohealth training runs into a bit of a cross-roads. On the one hand, there is an intentional attempt at valuing bottom-up research approaches; on the other hand, much of the course models a top-down lecture format covering the principles and pillars that students are supposed to adopt.

Julian's reaction to the course exemplifies this tension. Initially, Julian said:

Before [the course] I was on this argument of right or wrong, of anthro versus eco, of left and right, and this is how we should do things, and I was so busy delineating myself and marking down the position of who I am that all of these walls that I was building up to position myself essentially cut me off from interacting with other people.

When a course instructor suggested that "thinking ecologically" meant making ecology the process rather than the object of health, Julian said: "that just hit me, I felt like that was the untying of the knot and then everything was just loose and I was able to absorb whatever was coming." By the end of the course Julian felt like he had reached a new understanding:

We have all these differences, we have all these positions but the important thing is how can we all relate and work together in spite of these circumstances. And so it's not like I don't know who I am anymore or I don't hold a position anymore, I do, but that these positions are... they're more flexible.

But Julian also found himself doubting whether the group process followed during the course would actually work in a "real" community setting:

Because I don't think it would work if let's say I, if I just gathered up a troop in this community and we have people of all different backgrounds and then for all of us to sit in a circle and realize that we all come from different places and for me to then say "okay, it's great that we all feel this way, but let's find the common ground." Like, in my mind that works really well within an assimilative, not assimilative, but within the context of ecohealth training. But if I were a community member coming to a place like that I would feel like no, we can't just move on, this is really important to me, my sense is really important to me, I can't just move on from it. 
Julian noted that during the course some participants seemed able to express themselves much more forcefully than others, whereas in his own case he remarked: "I really diluted myself a lot so that I could accommodate this collaborative learning." Julian's case exemplifies a contradiction between what the course in theory is telling students (to emphasize process, to recognize multiple perspectives, etc.) and what in practice is dictated by the course design itself (that the teachers have the authority to say what is right and wrong, and when to move on).

Given this incongruence between the medium and the message, Caroline's and Marlo's contrasting experiences may have less to do with their own differing opinions and more to do with the different layers of group processes pushing in opposite directions. The wider group process of graduate education tends toward the top-down model of experts disseminating their knowledge to the experts-in-training and, by comparison, the ecohealth course could appear to some as following a much more bottom-up approach where knowledge is generated by the participants themselves. Yet, significant parts of the course ultimately remain anchored in the instructors' authority and the general norms of graduate training, which dictate how topics are covered (emphasis on expert presentations and teaching a set content) and the logic of the schedule (designed around delivery of set content). While there are significant elements within the course that push students to reflect on what it means to practice ecohealth themselves, on the whole ecohealth is something done to the students rather than something that students are given room to do themselves. 


\section{Aspirations and realities}

What is realistic depends in part on which context frames the goals and aspirations in question. Along with all of their differences, it is worth noting that in relation to the most general context Caroline and Marlo shared an appreciation for what they believed ecohealth was trying to achieve. For example, Caroline remarked:

I liked how ecohealth was more about a taking a systems level approach to stuff, you know, and I feel like the last so many years I've been in this biomedical model that I don't really believe in that much - I believe in people and interactions and environment-and it just seemed that with ecohealth it was just seeing that we all live within an ecosystem and if you want to make change, you want to actually solve problems you can't just narrow in, you have to look at the whole system.

For his part, Marlo acknowledged that upon "understanding how complex the systems are you realize that the silo-based approach, the findings that come from groups that look at one aspect, if they don't consider some of the broader context, may not be applicable to other areas or locations." In essence, Caroline and Marlo would agree that new approaches to research beyond the biomedical model are necessary for confronting the complexity of sustainability issues as they actually arise in the world.

Apart from this, however, their encounter with ecohealth would seem to have led them to nearly opposite conclusions about what is realistic: whereas Marlo raised concerns about the impracticality of ecohealth, Caroline pointed to the need for a cultural shift away from the status quo. Marlo felt that students were left with practical questions:

Well how? Where do I get the money for this? How can I possibly do this in a graduate degree? How do you create a team involving community members? It makes sense to me that you should involve community members but how do you, realistically, get a community you're working with to get involved with data interpretation?

Furthermore he noted, "in my department, this approach, if I try to get an ecohealth project approved, I would be told it's impossible, I'd be told to cut it down and focus on 
one or two of the issues." At best, he felt "you could tackle certain parts of it, or you can incorporate its thinking into your project," but he argued that on the whole graduate training was not designed to have much of a practical application beyond meeting the interest of certain authorities:

I was fairly realistic and I didn't feel like my project was going to have a huge impact on humanity. It's been valuable to the [government agencies] that I've worked with, but that's the extent of it, and realistically I think that's the most that you could ever get out of this stuff. You try and get some sort of practical application out of it, very few will have huge impacts, but I think the vast majority train people to think in a certain way, train people to think about the complexities involved but you're not going to solve the world's problems in your PhD, I tend to think you're not.

Marlo felt that the funding structure behind the ecohealth approach did not itself mirror a participatory approach:
Now that I understand how the funding structure and that stuff works, I realize in some ways it really was a funding driven approach. I'm not saying that there is no value to it, but there was a funding approach by the IDRC and that's what triggered all this stuff, and I'm quite curious to see how long this group and this approach lasts without funding, because it did seem so funding driven, it seemed like IDRC decided this was an important concept and a bunch of people who I'm sure felt it was important, but it didn't feel like a bottom-up thing as much as a top-down support.

In sum, Marlo said: "I certainly appreciate what ecohealth is trying to do, it just seems like the methods haven't caught up to the theory or the dreams."

By contrast, Caroline felt that ecohealth offered the possibility of making some of her own dreams come true. She argued that, compared to the standard scientific approaches, ecohealth offered a more realistic way of addressing issues in the world:

It's not just putting it into a lab taking part of it, dissecting A, B, and C. It means actually taking a problem and looking at all the determinants around it. Like I think research, like the clinical stuff, it compartmentalizes, but here it's not, it is just broadness. I literally think of an Earth.

For Caroline, ecohealth seemed like the start of something genuinely different, though she acknowledged certain contextual barriers and limitations. For one, she said, "Well for me, my parents always said that you're going to go to med school," and compared to medical school, wanting to study the environment "didn't seem very pragmatic." From the point of 
view of her parents, studying the environment may seem more abstract than becoming a

medical doctor. Also, the prevailing norms of the surrounding institutional context were a

huge factor shaping the development of any new ideas:

So I guess what I'm trying to say, if you get into an environment where it's biomedical or purely scientific, you're going to have a hard time bringing in these different ideas because people a) don't get it, b) might be open minded to it but they're kind of set in what it is, you know, c) it's not just, like even if your supervisor gets it, usually you're working with a broader group, so it's kind of also made me realize that, it's back to life, you have to be careful of who you surround yourself with and always kind of trust in your heart that if you believe in something there is a niche, there are people, like there, so don't just grab at the first thing that looks really cool, but just kind of hold out because when it comes down to it the institution will give you boundaries that you have to stay between.

Even within the context of her current project, she noted:

If I say right now "let's study the trees" or "let's take it a different way" well, the project's been funded, it is what it is, it's kind of too late to study trees. So it's a choice, everything's a choice. It just depends whether you made it downstream or upstream or you keep floating down the stream because it is what it is. And even in the grander scheme of life I'm starting to apply it, you know. We all get impatient and it's our ego, but you're not alone, and that's a big thing that ecohealth also made me... I'm mean I've always known it, but there are people out there interested in similar things. So just stay true to your vision because even if it's a small niche, there's niches there, people work together and band together and make it happen.

Indeed, Caroline yearned for "a cultural shift where we're not so disassociated from everyone and everything," and she saw ecohealth as a possible step in this direction. She wanted to follow her ideals and "actually apply them to actual research and campaigns for change," and she hoped that ecohealth would become a support network for what might have initially "just seemed like a crazy idea, not something that seemed feasible to pursue if I actually wanted to have some form of career."

Despite their apparently polarized views, both Caroline and Marlo expressed concerns raised by many interviewees, which suggests that rather than standing in complete opposition to one another, Caroline and Marlo may actually be expressing something that springs from the same phenomenon in relation to which all interviewee experiences occurred. This is the tension built into the position that graduate students and 
young professionals occupy: on the one hand, seeking to define new leadership for tomorrow, while on the other hand being subjected to the full weight of today's institutional norms and measures of success. Without an understanding of how this phenomenon operates it becomes impossible to make sense of the totality of interviewee insights and experiences.

Looking in more detail at the key points of tension between Caroline and Marlo, first, there is the problem of defining ecohealth and its key concepts: what is the substance of the approach and who is in charge of defining it? Any response to this question must take into account how meanings of ecohealth are tied to interviewees' own aspirations and movement through the channels of graduate and professional training. Secondly, there is the issue of whether ecohealth is helping to move science in new directions or is itself at risk of being made to fit within the current norms and expectations of graduate training and research. The key question here is this: how effectively does ecohealth challenge or conform to the established research norms and institutionalized measures of success? I argue that ecohealth is caught in the tension between simply extending the reach of "normal" science into new territories versus developing support for entirely new approaches to science. Third - and very much related to the previous points - there is a tension around interviewee aspirations to do the type of research (and to become the type of researchers) they want while having to fit themselves into the demands of existing channels of employment. All of these tensions spring from a split within interviewee aspirations themselves: on the one hand seeking to develop new innovative approaches, on the other hand seeking a place within established centres of research expertise. 
In what follows I begin to make sense of the tensions running throughout different interviewee accounts - beyond Caroline and Marlo and the CoPEH-Canada ecohealth training course - by examining the question of which reality will impose itself more: the established norms of biomedicine (for example) or the need to confront the complexity of how issues of health and sustainability actually arise in the world? The answer, however, is not as simple as making a choice between the two realities, as each will affect the development of the other.

\section{Hopes for ecohealth}

Initial responses to the question - what does ecohealth mean to you? - tended to fall back on references to the three pillars: transdisciplinarity, participation, and social/gender equity. This is not surprising, given that at the time of my interviews these were still the official terms through which ecohealth was presented in the literature ${ }^{9}$ and in the training course, and it is likely that interviewees interpreted my question in part as a test of their understanding of this terminology.

In their own words, however, interviewees elaborated on the significance of these terms. For example, Abriana linked transdisciplinarity to the sustainability of natural resources, arguing that by looking into the cultural, environmental, economic, biological, technical, psychological, health-related, and anthropological aspects of a given situation, ecohealth could ensure that "humans can live in balance with an environment where resources are protected." Djibril echoed the significance of the links between human

\footnotetext{
${ }^{9}$ Since then, new terminology based on six principles - systems thinking, transdisciplinarity, participation, sustainability, gender and social equity, and knowledge-to-action - has now begun to replace the threepillars, approach, see Charron 2012.
} 
health and the environment as made visible through a systems approach: "So they say that there is a direct link between the environment and the quality of health, so I think we need to integrate in all dimensions, specifically a systems approach—we should not view the disciplines in an isolated fashion, we should take the disciplines as a whole." In Lucia's words, ecohealth was "an approach that attempts to address environmental problems that affect the health of human populations by using different perspectives to arrive at feasible and sustainable solutions that take into account the complexity of the problem." Carla explained that ecohealth was about conserving "a healthy environment" where "there is no contamination" since "if we're not well with our surroundings, we're not well with ourselves, so it's a direct relationship."

But the significance of ecohealth took on even greater proportions as interviewees began elaborating further on the meaning of ecohealth in relation to their own wider aspirations. Take Felipe, for example. He took the stance that "ecohealth cannot think of itself in small terms, like a quaint environment for human health," since:

Ecosystems are not isolated things. Ecosystems are basically obliged to respond to how man transforms them. My personal aspirations have much to do with this precisely because there are many points in common with those that I see that there is a world that is possible in another way. And so, basically, it is this that obliges me to work with ecohealth.

The point was not to section off ecohealth into its own field since "ecohealth intersects with various of these things, such as social justice and environmental conservation," and having worked on a major ecohealth project in Central America and having participated in various training workshops and discussions, Felipe said:

Ecohealth is very close to my personal aspirations that I've always had to work with people. I've always been interested to work in communities for communities, because that's basically where my growth and formation took off, not just academic but also personal, from life stories about childhood and youth, I've always had some kind of consciousness specifically about the work and expectations that should be realized with people from there. So when I had the opportunity to study 
at university, I always looked for a way to be with communities, I don't like the clinical context or being in the hospital. I've always liked being outside trying to have a more direct contact with people. I'm very interested in another type of health or medicine that is not properly positivist, but rather involves many aspects of life.

Felipe's comments resonate closely with some of the ideas that Caroline presented, such as the desire to go beyond the clinical context toward actually making a difference, but they also confirm Marlo's observation that those attracted to ecohealth are often trying to find their way out of the more clinical approaches to medicine.

Initially Felipe described his aspirations very much in line with ecohealth, but when I asked if there were any points of divergence, he replied "Yes there are, very important ones, but not with the approach itself so much as the way it is promoted." He pointed out that ecohealth was not born in the university, yet the current way of promoting the approach could make it seem that way:

But there are two things: there is a theme that has grown up in the world, a theme of consciousness, and there is a group of people interested in financing it, and what worries us now is to what point is it viable to continue working according to this logic in which we are dependent upon a single funding source: when will we have arrived at the point that we can continue working on ecohealth without financial assistance? Because we will reach this point at some time.

There is an interesting ambiguity in the last sentence. While there is no doubt in Felipe's mind that the funding for the approach will end at some point (he effectively anticipated the drying up of IDRC support for ecohealth), it remains to be seen what this will mean for ecohealth. In one sense, Felipe warns that the current approach depends too much on a single funding source without actually building the capacity of communities to carry ecohealth forward themselves ("the university arrives and does a project, but this does not empower the people and so whenever the project ends that's where everything ends"). In another sense, Felipe sees the essence of ecohealth differently, not as something brought to life by funding, but rather as "the opportunity [for people] to construct their own idea of 
ecohealth, their own hopes and visions of what ecohealth means." Thus, when Felipe states above, "Because we will reach this point at some time," he simultaneously evokes two different outcomes: one in which ecohealth as a university-based approach comes to an end, the other where the capacity of non-academic communities to carry ecohealth forward begins.

Denise's hopes for ecohealth point to a gap between how most academic research currently happens and the actual needs and interests of communities:

I came from a very [traditional scientific] background and I found that it was far away from people, far away from people's concerns. Also, it didn't actually amount to anything very useful. So there's a need to get closer to people's needs, a need to open myself up to something other than my discipline, and a need that it leads to something in terms of actions in communities. So it was interdisciplinarity that was the first thing that came to find me. And then after that I learned more about everything related to participatory approaches.

The contrast in Denise's comments about the general irrelevance of disciplinary science versus the sense of possibility for doing research in a different way is echoed Gabriel's comments below:

Well, what attracted me a lot was the integration of many aspects, from many people, and not just professionals but also community actors in search of not only a research project but also a way of actualizing in the communities. For example, you have to find political strategies and ways of using university studies not just to create data, but to make that data available to the community, so that communities can use the information, in this case, for the benefit of their health conditions.

Interviewee interest in the possibility of bringing together stakeholders and experts in some form of collaborative group process suggests a desire to get beyond research-for-research's sake, toward a more direct confrontation with - and resolution of - real community issues, as further exemplified here by Azim:

What impressed me from the beginning, before even having taken the course, was the multidisciplinary aspect, since I hadn't conceived of how technicians with diverse competencies and from different horizons might sit down around the same table to confront a topic, each bringing his or her own capacities, and together proposing a solution to a given problem. So this was what initially really impressed me. And also, the ecohealth approach allows gender to be taken into account. This is very important in our society, which is a society where women have for a long time 
been considered marginalized, excluded, when in fact women have their own voice and all activities turn around them. So this aspect also really impressed me, and it is truly necessary to see how to counteract this vice or blockage in our African society such that women's voices can be heard. In effect women must be implicated in order to arrive at a true depiction of reality with respect to a particular situation. The ecohealth approach offers an effective means of finding one another's voices and opinions, not just women's, but those of the minority. This is very important because the goal is to solve the given problem. So already, those two aspects motivated me to jump into the [ecohealth training] course and find out how all of this manifests itself in a concrete way.

Unlike disciplines that restrict their researchers to work with a given approach to a particular type of problem, interviewees talked about how ecohealth allowed them to draw on a wide range of expertise - whatever seemed necessary for addressing the problem at hand - and this integration of knowledge toward a practical end is what Alicia found most exciting:

the thing that interested me most was that I could combine a lot of the different interests that I had, things like history, learning about human health, learning about community development, about environmental sciences and ecology, that there was a way for me to combine these different interests into this big thing.

The collection of comments above show how, in theory, ecohealth aligns with interviewee aspirations to address real health and environmental problems, by pushing back against the disciplinary tendencies of the biomedical model, where knowledge becomes artificially separated from community issues and fragmented into seemingly distinct fields.

In practice, however, it is worth looking at some of the concerns generated through interviewee encounters with ecohealth. For example, Mitch's initial reaction when he first read about ecohealth was full of promise:

I was genuinely attracted to it, not because I'd met people but because the ideas resonated with me enormously, basically because I was fairly unsatisfied with the limitations of my research, being that I knew that coming from a natural science background that all I would do is some article that would just disappear into nothing. 
Upon further exposure to the approach, however, he found that ecohealth amounted to "a lot fluff about the wonders of social science work and the wonders of natural science work, and 'tada' there's going to be this miracle when both of them are combined and the world will be saved." At the training course it seemed to him that some of the instructors already thought they had the answers and that all that was left to do was to convince others to go along with them, but this contradicted ecohealth's own pillar of participation, since what was the point of setting up a participatory process if the outcome was decided in advance by those in charge?

To explain this contradiction Mitch said, "I would attribute it not to a personality flaw but to a structural problem with academia," which he said was making ecohealth into "nothing more than a couple of nice words and a few citations in a journal, that's pretty much it." To him, what had initially seemed like a possible answer to his malaise about academic work revealed itself as just another part of a competition for funding and authority. But then Mitch came to the following realization:

It isn't ecohealth itself that is necessarily bad. You know it's kind of like communism, it's a great idea, cool, fantastic, you know, philanthropy, oh that's a great idea, no hierarchy fantastic! Ecohealth: let's integrate people and research and decision-making, that's great! So it has nothing to do with ecohealth. What has happened, what has changed is that previously I thought that ecohealth was the only thing that did that, ecohealth was the only way that could happen. But the realization came that it was another punt or academic BS funding research group just like anything else. If you want to do proper research then you just have to have proper research questions and the integrity — and the ethical integrity — to do it. That's it. That should lead into any ecohealth style research one way or the other.

Ecohealth initially presented itself to him in a deceptive aura, as if ecohealth was itself the magical solution, which obscured the actual work that people have to do to arrive at answers. The distinction between Mitch's original understanding and his later realization 
is critical: in the first conception, only authorized experts can be within the aura of answers, whereas in the second anyone can become an expert through their own work.

While ecohealth and the CoPEHs are sometimes framed as an emerging field of research full of promise, Alicia had difficulty at first to find her way in: "I was really interested in it, I was starting my Masters and I didn't know how to become a part of ecohealth, I was seeking out opportunities to be a part of it, and at first I would try to talk to the people who were involved." Interviewees interested in ecohealth found their roles limited to either applying to - or helping with - the training, grants, jobs, conferences, call-for-papers, and other recognizable steps in an academic career. When I asked Denise about her involvement in the future of ecohealth communities of practice, she said:

Such things always inscribe themselves in the context of financing and in a socio-political context. So with our current Prime Minister, we don't know what the communities of practice will become, but as a young researcher I think that it's very interesting and stimulating, and a source of comfort to be implicated in CoPEH-Canada because it's a comfort zone, next to the medical paradigm that I encounter regularly. How do I see the future? I have to continue implicating myself in CoPEHCanada in another way, for example by teaching courses, that's what I see. But at the same time, I have to be honest, we're running out of time! I would like to get more involved but I also have to build my C.V. and publish publish publish, so sometimes I feel like I don't have enough time and I would like to be more involved but I will not be able to play the role that I've played in the past. So I think that at this moment you realize to what extent the communities of practice rest on the shoulders of researchers that are already overloaded with work.

The competing pressures expressed in this passage say a lot about the current situation. Looming in the background are questions about how much longer the IDRC will be able to fund a program like ecohealth, especially given the priorities of the Harper government; friendships among CoPEH members offer some comfort that comes with sharing a space together but as an academic career progresses, emerging scholars will find themselves pulled in different directions; teaching courses in ecohealth may become an option for some, but the time required to find a job and be successful in it makes it difficult to make 
time for what then becomes the side-project of keeping up with the CoPEH. The continuity of the communities of practice may be left in the hands of the few who are paid to keep them alive, so long as the funding lasts—unless another means can be developed for carrying something forward.

On the one hand, interviewees regard the CoPEHs as a desirable space that offers a larger frame (compared to their disciplinary affiliations) in which to contextualize their work, a support group of thoughtful people, and a potential opportunity to get involved in projects that have an impact beyond the publication of journal articles. On the other hand, interviewees are cautious about what the CoPEHs can really offer them, since these communities still remain organized around a series of conferences and publication initiatives, which may not turn out to be that different from other fields except for the fact that the field of ecohealth is not as well established and therefore has fewer employment opportunities. Take Daryl for example. When I asked how he saw his role in the development of the communities of practice, he said:

Perhaps someday I'Il do an ecohealth project as a natural scientist wanting to develop competencies in areas that I haven't explored previously. So as a learner, definitely, in that process, provided that it doesn't cut into professional affiliations, like I see ecohealth as being complementary to my academic and professional pursuits and I can see that by reaching out, by getting people at the formative stage of their career, by attracting people and by encouraging people to remain connected in whatever way, I see that that network approach can be fostered and a student might come back to talk ten years down the road once they've established themselves in their career. So just having different definitions of alumni I suppose and providing some kind of opportunity for people to just retain that connection down that road.

That Daryl sees ecohealth as a complement to his own career development exemplifies the challenge of sustaining an approach that draws its practitioners from other more established academic and professional careers. Furthermore, rather than something that Daryl feels in charge of developing himself, ecohealth is presented as something that 
already exists (for example as a training course). Given these parameters, Daryl's only options are to jump in and make ecohealth his main career path (an option not under consideration here) or to keep ecohealth as a kind of side-project to his real career, something that he can keep thinking about whenever he has the time.

Daryl began to describe what he called a "tension" in the way that there was a core group of people invested in organizing ecohealth activities, while everyone else's participation was limited to taking part (or not) in those activities: "there are maybe some people who are very invested in this brand, invested in this term, invested in this idea that's being called ecohealth, I can see that there is a tension and it would be interesting to see, okay what did it achieve?" One of the most obvious reasons for this tension is that the structure of the CoPEHs flows outward from the funding that principal investigators can secure. As such, the principal investigators overseeing a given grant become invested in promoting ecohealth, whereas the students in the training course are, in one sense, only there because the grant money created a place for them to fill. Of course, that is only one way of looking at the situation, which does not take into account the fact that students also have agency in the production of ecohealth: it is their interests, projects, and willingness to explore what ecohealth means that brings meaning to the whole initiative. Still, learning what it means to capitalize on this potential agency remains a critical avenue to explore in sustaining ecohealth beyond the next funding grant.

Noting that in Africa the state had so far not made any real financial commitment to supporting the ecohealth approach, Gilles' remarks below speak to this sustainability challenge: 
My biggest concern is really in terms of the means for partnerships, because I'm convinced that if there were more partnerships the CoPEH would necessarily have a lot more opportunities and visibility. There are a lot of programs now that, in order to attract students, must support their research, to co-opt a certain number of students. We were co-opted by the CoPEH because we had the chance to be paid by an IDRC grant. If we did not receive that I'm not sure that we would be affiliated with the COPEH. So that means that if the COPEH had a few more resources I'm sure that it would necessarily have a lot more members because it would probably have enough resources to eventually employ people and give out more research grants. This is, I think, the scale at which a maximum level of effort is needed to grow the portfolio of partners of the CoPEH.

Gilles felt that, "the IDRC alone cannot sufficiently finance the network along with the regional coordination of the different nodes," and since "at the level of the state, there is no real involvement yet," he said, "within this context, ecohealth is not particularly viable for many people," with the exception of a small group of academics "who, by perseverance and concern, have invested themselves in this approach." Once a grant is obtained, then more people - such as graduate students - can be hired to help with a project that has largely already been defined. As a result, there tends to be a select number of paid temporary staffing positions to help support official ecohealth initiatives, such as conference coordinators, course facilitators, node coordinators, etc., with the occasional opportunity for additional volunteer labour to help with a specific project. This funding structure implicit within the project of field-building ensures a core number of key decision makers at the centre of the communities, a layer of key resource people to draw on from time to time, and an outer layer of potential volunteer labour.

With this structure, the possibilities open to interviewees for a relationship to ecohealth become limited to a few short-term contracts and volunteer work to help administer larger projects that require wider participation. Despite the satisfaction of working with an extraordinary group of people, this funding structure could never be expansive enough to sustain a broad-based movement. Thus, when all of the activities 
depend upon a single funding source, the future of the communities of practice is always a bit precarious: who will be responsible for carrying the approach forward when the funding dries up? Although, in one sense, the form of the communities of practice pushes back against the normal isolation that occurs within academic work (for example, by creating communities that occasionally come together to work on funded projects), in another sense, by virtue of having the principal investigators at the centre with a group of "extras" floating in the surrounding virtual spaces, ecohealth is set up much like any other type of academic specialization: as a form of expertise that can only be accessed through terms defined by a core group on the inside of academic and professional channels.

With this nodal structure in place and with the "official" goals of the CoPEHs already established by certain contractual agreements, it is understandable why the most common response among interviewees was to suggest continuing in the direction of the current path, which, as David saw it, was the institutionalization of the approach within university curriculum and, eventually, in government policy. David noted:

In Mexico they already have great advances because they've carried the concept in what they say over there, and maybe who knows where we could embed the ecohealth project in the university [here] perhaps in this ultimate part of the project, to give the approach a better institutionalization. In Mexico I understand that they already have ecohealth better coordinated in various universities.

As a result, aside from helping with the development of the official channels, interviewees did not see very many opportunities to develop the future of ecohealth themselves. For example, Gabriel said:

I think that the way the community of practice is planned in Latin America is a good form, a good way, which is the institutionalization, the part with the universities and institutes, I think this is a good trajectory to maintain for the future, and by incorporating these plans into undergraduate and graduate studies, we can have new researchers using the ecohealth approach from the beginning. [Matt: what role do you see yourself playing in this?] Ha, ha, I don't see myself, ha, ha, in truth I don't see myself... Maybe it would be possible, I don't know how, like to share experiences of how it has been applied, like talk about research experiences and what I do. 
Yet, while this approach to further institutionalization seemed promising to many

interviewees, they also raised numerous problems that would have to be overcome. For

example, although Lucia was committed to curriculum development, her comments also

show a concern for the sustainability of the communities of practice:

If we can make accomplishments in terms of certain products, those are the key or a bridge for the continuation of the work of the community of practice. If we could, for example, continue with curriculum development-including for professors - this would provide a more concrete path forward. I think that maybe as a community the levels of participation vary for different members. For example, at the coordinating level and the working committees in the different nodes that have a more active participation, these are people that are already definitively identified with the community, and so I think that with these same forces at this level and the relations that exist, it is possible to maintain ourselves as a community of practice as such, I think this is what will permit us to continue.

By drawing on people already implicated in a particular discipline or profession, the communities of practice remain dependent upon the amount of labour-time that members can donate on top of their own career paths and other commitments, and since the field of ecohealth has not yet gained its own material base, those interested in ecohealth find themselves working largely in a virtual sphere, as François explained:

But the difficulty for the communities of practice in ecohealth is that most of time we're working online without a fixed base, you see, each one in his or her sector or profession, and we try to exchange online, to share some ideas, to propose a project that we want to get up and running, but you can see that evolving in this way at a certain point isn't optimal, it's not optimal because we don't have a base, we don't have a reference point. Suppose you suggest an ecohealth project, where will we meet? We don't have a physical locality where we can find each other. I don't know if you've heard the talk about institutionalization, but an organization with a fixed location would help. If not, for the moment, sure we can work as a network on the web [...] but this can be an obstacle for getting projects off the ground when we don't have any permanent staff, each one having his or her own employment that does not forcibly have to be related to ecohealth.

In times of increasing austerity, it is understandable that young professionals are concerned about their own job security. As a network of academics and professionals tied to their own disciplinary affiliations and departments, interviewees' relationship to 
ecohealth cannot help but be dependent on the search for security within dominant institutional channels.

In response to the situation, however, interviewees went beyond simply supporting the current design toward creating new spaces for themselves and attempting to re-design the form of community of the CoPEHs. For example, when I asked Gilles about the possibilities he saw for the development of ecohealth communities of practice, he said:

\begin{abstract}
So that it can go on, we must continue to train young people, but also, after a certain time, we must try to see how we can capitalize on our goals. This would allow us to develop new orientations, even to try to refine this approach so that it can adapt to the difficulties of our realities, because it will not be the same application of the approach in Canada as it will be with us in Africa because we have different realities. The notions remain practically the same, but at the level of practice there can be some changes from one environment to another. So it is important that we should be able to initiate from time to time some workshops, some forums so that those trained in this approach can discuss together their knowledge and try to see what can come of it, how to capitalize on what we can do. So it's in this sense that I see us continuing to develop this community in ecohealth.
\end{abstract}

Although he acknowledges the need to continue with the approach as it has already been defined, Gilles also emphasizes the importance of taking ownership over the approach and redefining it to meet the specific practical circumstances in which trainees find themselves working. In other words, rather than simply accepting what institutionalizing ecohealth means as given from the outset, Gilles is suggesting that the next generation has a role to play in redefining the approach through a set of workshops where peers can compare their experiences working with the approach in different settings.

Other interviewees also questioned the current purpose and organization of the communities of practice, suggesting that other possible ways of working might be preferable. For example, noticing the fleeting nature of course-based relationships, Nancy remarked:

I guess for a community of practice, one thing that could maybe generate a bit more motivation or momentum for it is if there's a project or a goal that everyone's working towards at the same time, 
because while you're in the course and you're doing this work together, but then you kind of leave and go back to school and working on your own project, and I think that at that point for me I didn't have as much motivation to read an ecohealth journal club or you know do those kinds of things, but I don't know I guess if there was, I think maybe if the ecohealth community had a bit more social action in some way, saying, okay, we want to put out an article or an editorial or we want to work on this topic, can we look at it from these different perspectives and bringing in all those aspects so that everyone's different abilities and knowledge, but towards a bit more of an active purpose and towards maybe some sort of an ecological cause, that would be interesting.

In fact, many interviewees had at some point attempted to initiate something new-an ecohealth discussion group, speaker-series, social gatherings, writing projects, club, etc., online or in person. These initiatives would need to be studied in greater depth to understand their successes and challenges; but at the very least, they point to a need to open up more opportunities to for young researchers to pursue interests in ecohealth. Vincella had this to say about the logic driving the development of the CoPEHs: "In most cases, all these things are driven by more senior people, which of course they have more experience and they have also the tools, the contacts and everything to do it, which is fine, but I think young researchers should drive that process much more than they do."

She further commented:

I guess what always comes up in my mind thinking about this ecohealth thing, how much I would like to put it into my daily professional activity and these things, yeah is that, yeah I don't know... I think these communities of practice can be really useful, I think that is what will make us feel less isolated, and actually give us much more strength to make things happen, but I still don't know what is the good way in which these communities of practices can work. And it's not anything that you can just create and hope that it's going to work, it has to, I mean people involved in communities of practice, they really need to feel they are part of it, and they want to and they have to be willing, that this network works for something. So the communities of practice have to have a name and objectives and actually have people that are convinced that that can work and that that should work, rather than just putting people together because we have to create a community of practice. I guess I struggle with the concept all the time, yeah we have communities of practice but actually are they helpful at all?

This question of how to evaluate the CoPEHs-and perhaps more importantly, the implicit question of who should be in charge of this evaluation-suggests that there may be more options than the ones currently on the table. 
There is a pattern that can now be identified based on the interviewee experiences presented so far. The interviewee is initially drawn to the concepts championed by ecohealth, as they align closely with personal aspirations to conduct meaningful research. Very soon, however, the interviewee develops mixed feelings: part of the encounter might confirm a sense of hope and possibility while the other part reveals a number of obstacles. Despite the diversity of interviewee aspirations and experiences, this basic pattern seems to emerge each time, suggesting that there is something driving it, something that makes it arise as a defining characteristic of graduate student and professional encounters with ecohealth. The experiences and comments collected here point to a terrain in which interviewees may be interested in appropriating ecohealth for themselves, yet the opportunities to do so are not obvious: it is not yet clear what base could support both the application of the approach and the career development of those interested in it. As a result, there may be an opportunistic tendency to exploit whatever ecohealth seems to offer at given time, while being careful not to burn any connections to disciplinary channels that might provide more secure forms of employment, even if they limit the extent to which the principles of ecohealth can be embodied.

Having now mapped the experiences of encountering ecohealth training, I turn in the next chapter to interviewee experiences navigating the institutional frame of the university, where many interviewees are searching to find their niche. 


\section{Chapter 3. Navigating the Institutional Frame of the University}

This chapter looks in detail at the split within interviewee aspirations, on the one hand, pushing the envelope of what scientific research can mean, on the other hand, pulling back to fit within a fixed number of choices offered on the terms of existing institutional norms. This tension sits at the centre of interviewees' goals while at the same time defining the central problem of what it means to institutionalize ecohealth itself. After presenting contrasting perspectives on the meaning of institutionalization, I suggest that interviewee experiences speak to the challenge of standing up for one's own values within a context that has power and authority over your future. For all of the theoretical possibilities that make ecohealth attractive, existing research norms systematically impose barriers, and the extent to which those barriers can be challenged through individual efforts remains highly limited.

Take Gilles' situation for example. Gilles was interested in "questions of community health, the well-being of populations," especially at "the level of small communities," but his own discipline was "not necessarily about going to study health questions at the level of communities." Coming to ecohealth from the social sciences, Gilles explained that, "at the theoretical level, what was most enriching was that I found myself in a domain for which I was not already destined from the beginning" and Gilles hoped, "that finally the ecohealth approach would allow me to effectively analyze these questions, without requiring that I be a health professional as such." But he explained: "When you are in a university, there you are, and there comes a time when you are asked to make some choices based on the inventory of interest centers that are proposed for you throughout 
your educational career," and having chosen projects and courses focused on "this

relationship between environment and health," he said, "I finally had all of the necessary

elements to be able to adopt—perhaps not permanently—but to adopt the ecohealth

approach within the context of my work."

But the following two quotes from Gilles demonstrate how the appearance of

ecohealth can shift quite significantly depending on how the context of graduate training

frames your position. At the beginning, Gilles was excited:

I would say that the way of working, the logic of the work, that is very impressive, it shapes you a lot, the way you work within the ecohealth approach, because it calls for a lot of patience and openness toward other domains, scientific specializations, it gives at once a much broader vision, forcibly a different vision, that is, in our environment or in any environment we won't have the same outlook as the other people, so we will necessarily have an analysis or a heightened sensitivity to this relation of environment to health, which is not always very established, but that is very pertinent in understanding the life-conditions of people. So for me, turning on this theoretical possibility, the discovery of a way of thinking, a way of analyzing social problems, it's effectively the possibility of working with disciplines, different horizons, of working in a way that is not always straight forward, and the possibility to have another perspective and, very importantly, the solutions that we arrive at or put in practice within ecohealth work is very rewarding, it's very pertinent.

However, Gilles also offers insight into nearly the opposite reality, where ecohealth

becomes very difficult to adopt:

Fieldwork, involving the communities, this demands mobilizing quite a few resources. I'm convinced that one of the fundamental elements is the grant program and the ecohealth training, it's very interesting and very difficult. Suppose that at the level of the universities, ecohealth courses already exist, but the catch is that once the student enters the year of research, he must adopt a methodology. The ecohealth approach becomes difficult when he begins to realize 'I must contact a doctor, I must contact an environmentalist, I must contact an economist, I must contact a sociologist...' and who will work for free? What is the honoraria? What is our remuneration? So, on top of the basic costs of conducting research, which cannot be ignored, and then you have to go into the field to really work with the community, and being in the community requires resources, so if the student doesn't have adequate support, he will not be able to engage with this work, or he will engage with it anyway and probably do a poor job.

In effect, Gilles's position suggests a combination of the views of Caroline and Marlo from the previous chapter: ecohealth offers some conceptual support for the idea of doing research differently, but then you are still faced with the inertia of the existing structure of 
graduate training, which tends to shut down the theoretical possibilities proposed by ecohealth. One of the challenges that all of the interviewees faced was navigating the different layers of possibility and evaluating what was realistic in terms of their own relationship to ecohealth at a given time. Within this constant evaluation process there are times when new conceptual insights seem to dissolve all of the barriers, and other times when those barriers suddenly reappear more real than ever, destroying any glimpse of theoretical openings.

This tension between certain aspirations and existing realities may help explain why interviewees said their perceptions of ecohealth shifted over time. In referring to her own experience, Janet said:

You're constantly in your research in a pretty biomedical science background, so everything was always needing to be rigid and completely objective and you don't want to practice any of that fluffy stuff, but I felt this conflict between what I was interested in personally and feeling split between my interests and what I should be working on.

When she took the ecohealth training course she was about to start her fieldwork and she really wanted to know, "what exactly do I have to do to call this 'ecohealth' research?" Many other students echoed this anxiety about what doing ecohealth research specifically entailed — what was the methodology, how much time to spend in the field, how to analyze data, what did community participation really look like, how to fit this into their particular graduate degree, etc.? Since moving from fieldwork into the writing phase of her dissertation, Janet had begun asking different questions: "it's not a methodology, it's not a paradigm, and so how do you mix that with scientific validity, if you need to?"

Now she liked to think about ecohealth as part of "a bigger social change," as going "beyond what you could measure in a quantitative way in science disciplines," adding, 
"and so I guess I see it as a bit of a group that allows you—it's not just a group, it's broader themes, broader ideas, it is about seeing these bigger connections and being interested in something that is equally applied as it is just about truth so to speak." Hearing herself out loud, she laughed: "It's so funny how I feel like I'm saying exactly what they say to us in the course but at the same time it's become a little more internalized, which changes it somewhat... So maybe a mode inquiry?" Janet found that ecohealth helped her recognize the legitimacy of approaches outside the standards of biomedicine, offering her "a way to be working on what I'm interested in but also introducing a rigor that's beyond just passing interest." She did not, however, abandon her own disciplinary expertise; rather she said, "I'm looking at very detailed stuff related to [my discipline] but I'm setting it into a broader framework and it allows me to pull all of that together around something and see the themes we're all working towards rather than getting lost in each of them-it's synthetic." Still, despite having reached a new understanding of what ecohealth meant, in looking at the future of her academic career she felt it would be challenging "trying to figure out how to manage [her interests in ecohealth] and being okay with... it's not like you have to be $100 \%$ into it at all times."

What is interesting about interviewee responses is how they are not limited to only one tendency; rather, different ideas are appealing at different times. What makes ecohealth more or less appealing to one interviewee at a given time depends on that interviewee's relationship to the broader context of graduate and professional training, which suggests that so long as those working on defining ecohealth are primarily academics and professionals, then part of the meaning of ecohealth will be tied to the 
institutional norms that define academic and professional work—even if ecohealth is presented as pushing back against these very same norms. This poses a genuine problem: how might it be possible for interviewees to fulfill one set of aspirations (for example, those associated with breaking away from the dominant research norms) while still fulfilling another set of aspirations to integrate themselves (for example, by finding employment) within the existing institutions of research?

From Lucia's point of view, the problem can be posed by contrasting ecohealth as an abstract concept versus ecohealth as an institutionally recognized approach. Lucia said how much she enjoyed the "processes" and "spaces" that allowed professionals with different experiences to come together and work on a common theme, emphasizing how these opportunities were important because without them "the jobs of different people, I think it is a limitation." But Lucia noted:
At times it seems very complex, especially the practice. Because, I recognize that it has to be a group, but it is very complex and at times I feel an inability - I don't know if it's methods, methodology or tools, probably tools like gender or community participation-how to get to the practice? At times I feel that we collect a lot of information and that is still very... it seems to me that the approach as such, with this name "ecohealth" is still a little abstract. As a term, I can look for information on gender, but as gender, information on community participation as community participation, but as such, as an integrated approach that links all these aspects and experiences, it's with this that I feel there's still a long way to go, at least in my experience so far.

Lucia's uneasiness about "how to get to the practice" suggests a desire for ecohealth to be more "real" in two different ways. First, as she talked about her wider aspirations, she made a distinction between producing research papers and producing an actual change in the world: "I would like to produce a project that has a real impact, not just a thesis." While there was a sense in which ecohealth should align with this desire to have "a real impact," in Lucia's experience ecohealth had not actually gotten there yet. Second, she 
expressed a desire for ecohealth to gain institutional approval on par with other approaches to research: "I would like to see more concrete products, such as a real institutionalization of the approach within a part of a program, a course, within university studies, to help sustain the community." Here, there is a sense in which ecohealth remains under-recognized within universities, which therefore made ecohealth itself seem less "real" compared to other academic fields. These combined desires for "a real impact" and "a real institutionalization" help flesh out the contradiction that interviewees face: on the one hand pushing away from institutional norms, on the other hand pulling back in search of greater status therein.

As a field of study ecohealth risks embodying this contradiction too, as some proponents of the field want its relevance acknowledged as a distinct area of academic expertise, but then where does this leave claims that ecohealth is a genuinely transdisciplinary approach? Naturally, there is some resulting confusion about just what ecohealth is striving to become. Daryl started out by saying: "it's two buzz words: eco and health." He then said it's "a scientific discipline that is in a state of flux, as should be all healthy academic disciplines." He then added: "if we use the word health, it means that some kind of measurement is happening, some kind of judgment." In the same breath he continued, "I think it means looking at big picture stuff, like global scale happenings." Finally, he settled on the idea of ecohealth as "a platform where we can exchange ideas about what we think is, could be and should be." This mix of ideas characterizes the inherent challenge that ecohealth presents, at least within the context of graduate and professional training, namely, the challenge of defining a different approach in a context 
that has largely already been defined by disciplinarity. Later, at the end of the interview Daryl reflected:

Is it actually a discipline in state of flux, is there a desire to have new perspectives brought in? Because biology is biology is biology, math is math, chemistry is chemistry, all those worlds are pretty well defined and all those disciplines are pretty well established and turned into faculties and departments and I don't know if there's a department of ecohealth anywhere...

That interviewees tended to discuss ecohealth in relation to the established norms of academic research and professional work should not, of course, come as any surprise given the fact that ecohealth training has been directed primarily at those pursuing graduate degrees and/or already working in certain professional fields. But this focus has consequences for defining the meaning (real and imagined) of ecohealth, which becomes subjected more and more to the constraints of the context in which its practitioners are working.

As experts-in-the-making, interviewees must prove themselves according to established measures of success, yet it can be difficult to do this while holding onto many of the wider aspirations that attracted them to ecohealth in the first place. If ecohealth deviates too far from the limitations of normal scientific research, then it may become harder for interviewees to adopt the approach and find employment within established academic and professional career paths; but if ecohealth conforms too much to existing standards, then it fails to provide a genuine alternative to the status quo. From the point of view of graduate students and young professionals, therefore, a fundamental tension lives within the definition of ecohealth itself. Of course, there may be ways of moving that allow a balanced integration of professional success and the realization of wider aspirations for change. The dilemma here relates closely to my discussion of Gramsci in 
Chapter 1 . There are times when groups achieve insights into a genuinely new conception of the world, even if that conception remains subordinate in "normal times" to another conception of the world that still contradicts the new one. On the whole, ecohealth would appear to be in what Gramsci would call an "embryonic" phase, since its meaning has not become fully distinguished from the dominant order of normal conceptions. Thus, there is critical work involved in unpacking the meanings of ecohealth, seeing which ones help push toward a transformation of present norms and which ones support their reproduction.

Given the wider context of graduate student training, there is a tendency on both a conceptual and material plain for turning ecohealth into a thing in and of itself. Conceptually, while drawing on a wide range of literature and previously used concepts, ecohealth is presented as a new arrangement of a certain number of key insights—a new conceptual solution. Materially, the goal is to anchor this new arrangement within the ranks of some existing institutional base, such as government policy and university curriculum. However, this tendency may wind up contradicting the stated aims of the approach, pushing it, as Mitch argued, to become "nothing more than a couple of nice words and a few citations in a journal." And the situation becomes more problematic the more successful it is: the more this thing called ecohealth actually does begin to take on a material reality (for example, in the form of actual conferences, budgets, post-docs, journals, courses, etc.) the more it gives the illusion that its conceptual solutions are in fact working, when in reality ecohealth may be only starting to fit itself more and more into acceptable (status quo) forms of academic work and state policy. Or, at least this is one 
possibility that needs to be considered. Another possibility is that the institutionalization process actually does allow a new type of research to emerge.

Daniel and Felipe expressed different views that help explore these possibilities. For Daniel, institutionalization meant solidifying the place of ecohealth within universities and governments, so that ecohealth would become officially recognized within the dominant curriculum and government policy, all the while expanding and sustaining the network of expertise associated with the CoPEHs. Felipe criticized this process of institutionalization on a number of fronts and argued instead that the future of ecohealth lay in its appropriation by primarily non-academic communities: not just experts, government officials, or those in positions of power. Let us look at these two approaches in a bit more detail.

To begin with, Daniel focused on ecohealth as a practice made possible by the network of academic and professional expertise of the CoPEHs. "For example," he said, "often when we're looking for information on a specific topic, the first thing that we do is look for someone in the CoPEH who is an expert that could support us." In his view, "what the approach is trying to do is systematize, consolidate what ecological understandings we have," but the "huge challenge" was to get beyond the disciplinary allegiances that some experts seemed to hold onto:

There are people who don't believe in the approach as such because they say that the pillars of the approach were taken from biology, I've heard this from biologists. And the biologists are a bit reactionary, they don't want to engage with this topic because they feel that Health Sciences is taking over the parts that used to belong to biology, so it's as if health belonged to them. So they feel that what's happened is that people have started stepping into their field, into the field of biology, and they say no, all of this was already here since 1950, you're not bringing anything new. And we agree, nothing new. What the approach is trying to do is systematize, consolidate what ecological understandings we have, and put it all together. And now, if I wish to put humans in the centre, well the biologists are primarily interested in maintaining an ecosystem, an aquatic or terrestrial ecosystem. Great, but relations with human beings are left aside. So another challenge is this one, to 
be able to enter into disciplines that feel invalidated by the approach, they feel like it's their turfwhy are these people coming, why anthropologists, sociologists, why doctors? - that is another challenge. But there's no problem, it's nothing, everyone is welcome.

Daniel's comments make an appeal to disciplinary experts: why not put differences aside and work together? From his point of view, the field of ecohealth is certainly open to including different disciplinary experts but the problem is that not all specialists are open to ecohealth. And as Daniel explains further, there are specific reasons for this:

Well there are anthropologists that say "you can't do community work because you're not anthropologists." And why not? They feel like you're invading terrain that is specifically for anthropologists, for biologists, for medical doctors... And so a huge challenge is to take care and be well together, but what happens is that the anthropologists say "what would happen if we wanted to evaluate human health in certain communities?" Well, they can't do it because they don't have... For example, ethically, they cannot take a blood sample from someone, they don't have the scientific base in health as such. I'm sorry, but can't we work together to strengthen our capacity, so that we can see the issue differently? But some people don't think so.

The challenge is thus framed in terms of how disciplinary experts can work together, since they each have legitimate claims to their own expertise and authority. Daniel pointed out that the people in the community of practice in Latin America were "open minded" and "very humble" —"we're not going to get our ideas caught up with our egos," he said—and while "depending on the country, there can be more or less hierarchy, and changing this is difficult," this type of change was exactly what the CoPEH was designed to do: "From a very disciplinary world, we have to transform it into a multi- and then transdisciplinary world," which entails "convinc[ing] people that it is a different approach, more accessible, a more encompassing approach." In describing the work ahead, Daniel said "we have to fight—not fight—but we have to work hard together, to make [specialists] a little bit more sensitive, but that's not easy."

By contrast, Felipe made it clear from the outset that in his view ecohealth should never be defined strictly by the expertise of the CoPEHs. Rather than seeing the CoPEHs as 
the lifeblood of ecohealth, he explained that, "consolidating ecohealth means precisely its appropriation within the [non-academic] communities." He suggested: "What I would try to do is to direct the communities of practice [CoPEHs] into the communities, to the people." In essence, Felipe advanced a different vision for institutional change: "This idea of changing institutions so that institutions can be closer to the people, I don't share it entirely. I think that it is the people that will change the institutions, as in a change from within the communities all the way to the top, and not the reverse." Felipe cautioned specifically against framing ecohealth as a practice contained within the CoPEH because suddenly this makes ecohealth dependent on the funding of the CoPEH when instead he proposed that ecohealth needed to begin by "involving itself more with the communities, but in a real way, like I said before, in a participatory way." The point was not to publish another article, since "the communities do not read scientific revues-the scientific journals it's you and I and the academics that read them, no one else!" And since he did not believe that IDRC support would last forever, Felipe explained that it seemed much more logical to him to develop communities' (not just CoPEHs') capacity to carry ecohealth forward.

Indeed, Daniel's and Felipe's visions of ecohealth relied on different ideas about where capacity building should take place. For example, Daniel explained that the CoPEHs did not have funding to support work directly with communities. Instead, the CoPEHs' function was to build capacity in their members by sending them to meet each other in workshops. He said, "I, as member of the community [of practice], therefore, 
what I do is build my own capacity and then after try to replicate what I'm doing with other people." To this end, ecohealth had a key role to play within the university:

We want to institutionalize the approach through its incorporation into different complementary educational careers, such as biology, medicine, environmental health, to give courses in programmes. If we could accomplish this at least in Central American universities, I think that we could have success. It would already be in the curriculum so people would already have it.

Daniel justified the current rationale of CoPEH-LAC based on the need for stability: "So far we have concentrated mostly in the universities, institutions of the government or the state, I feel this is where people are more stable." He argued that "keeping a certain amount of job security" would eventually allow ecohealth to flourish in a way that would not be possible otherwise. For example, he explained that it would not be ideal to work on ecohealth as "a consultant" because "today you're interested in the approach, but tomorrow? Tomorrow you have other things, you already have other calls, other obligations." Likewise, approaching ecohealth through "volunteer work" was not any better "because you have your family, your life, you can do it in your spare time if that's okay, but how much time can you dedicate, an hour, two hours, the weekend?" Thus Daniel stated, "This is why we stay with the universities, with the institutions that are a bit more stable, when people have a job and a salary, where people have an interest in seeing change, that's where it can stay." Daniel felt that the CoPEH was already headed in the right direction and with more funding and further institutionalization CoPEH members could continue "the innovative research projects" while making time "to see each other face to face at least once a year." But there was a catch:

But I don't know, financing is a problem. There is no more money for this type of activity. There's one more year for the IDRC in this type of project, and then we'll have to look for other options, but if we don't find anything we'll try to maintain ourselves, but it's very difficult without physical contact. Furthermore, these are social processes, we cannot change a hundred years of history in only five years' time. 
By contrast, Felipe said that if it were up to him,

I would elect to do more work in the community halls, in the schools, in the churches, where the people are. Because, sadly, our people are not in the universities. The social base is not in the universities, a certain group of people go to the universities. So one of the challenges is to insert ourselves so that the ecohealth approach inserts itself from the base, with the women in their houses, with the men in the square on Sundays. Because much like any other thing that requires social support, it has to begin here.

In Felipe's view, while the universities may offer some institutional stability, the people

working for them tend to move around a lot:

It's not that universities and academics are not important, that is all good. But if activities happen only in the universities, there will be a tendency for ecohealth to disappear, and that is worrisome, because more than anything we the academics are people who move around a lot. If you manage to convince a dean, well tomorrow the dean leaves. But if the issue is internalized in the students, if there is a social demand for the theme of ecohealth, if the communities demand that we think about ecohealth, if high school students arrive at university asking for courses in ecohealth, well the university will offer it. But if you only convince the dean and the dean leaves, or if the priority of the dean is to go to a conference in Barcelona or to pay for a course in London... This is very ironic: there was a meeting in London not long ago and these types of meetings are not very convenient for me. It's not that I have any bad feelings for them, it's just that I don't believe this is the priority -if I could decide where to spend ecohealth money it would not be on an event in London!

Along with being positioned to go where the jobs are, Felipe suggested that "in the moment when people go to university, their consciousness is already leaning in a particular direction and it is already full of information, lots of firm beliefs." For instance, he did not believe that the future of ecohealth lay in the hands of this elite group of people poised to climb the ranks of institutional expertise—rather it depended on the state of ecohealth within the consciousness of the general population. As he put it, "the point is to mobilize more elements, not just those that are already in power":

That's why let's say that ecohealth needs more political or social contacts, not just with the institutions, the university or the ministry or the mayor, but also with the opposition, the socialist party for instance or any other party for that matter, the Christian party or the friends of Jesus, what do I know.

In Felipe's assessment, too much of the work done under the banner of ecohealth was limited to the activities of the CoPEH—essentially university-based projects that supported 
capacity building for academics, without actually supporting communities' capacity to transform themselves. In fact, the problem that Felipe criticized was that the people do not have enough say in the setup of the structure to which they are expected to conform, such that even within the ecohealth communities of practice (the CoPEHs) the approach taken thus far generally seemed to mimic the lack of participation in people's current relationship with the state:

\begin{abstract}
We live in countries with very dysfunctional democracies, where 'democracy' is a misnomer I would say: you vote for someone and it's over. In four years you go back. In participatory democracies you would have the power to transform, to discuss, to think, to bring something useful to society. To me it seems that the way the [ecohealth] approach is being carried forward currently, there is very little of this. We're here, the academics, we're going to show the communities something. It seems to me that what has been tried in terms of involving others has been very weak, very weak because if you look at colleagues' projects they're largely university based, based on what academics will bring to the community, and if there's some community participation it's very instrumental, we continue to bring the instruments of participation to them, and in reality we don't give them tools that they believe are their own to use.
\end{abstract}

As a result, he considered "the work that has been done thus far to be of little consequence, or let's say that it does not correspond to the principles that we've taken as guides."

Daniel and Felipe are both looking to transform the world as it currently exists, but their strategies carry different assumptions about how change happens. Perhaps the key question is how might these two approaches work together, one based on expanding the network of expertise within universities and governments, the other based primarily on capacity building within non-academic and non-professional communities? Currently, the dominant approach is toward institutionalizing ecohealth within universities and government ministries. 


\section{Finding a place within the university's disciplinary frame}

Interviewee experiences negotiating the institutional frame of universities reveal a fundamental tension between fitting into and pushing back against the established norms of research, which can be understood as playing a double-disciplinary function. The first part of this function is to fragment the process of knowledge production into different disciplines, each championing its own claim to fame, its own authority. The second part entails a much wider meaning of discipline, one that transcends disciplinary boundaries to penetrate all aspects of work. The function of this second part is to pressure anyone hoping to share a piece of the disciplinary pie to constantly demonstrate subordination to it. Taken together, these two aspects of disciplinarity make up the antithesis of a democratic learning community: rather than developing a form of expertise based on maximizing the collective capacity of all, disciplinary expertise advances knowledge in exclusionary ways that reinforce existing social hierarchies. When it comes to ecohealth, while there may be conceptual support for a more democratic approach, the material ground upon which that approach is anchored remains chained to a disciplinary structure.

Take Julian's situation for example. In describing his project, on the one hand, he said:

So there are three very distinct disciplines and three very distinct lines of thought that brought in very different professors for the committee, but ecohealth fits in that it puts the equal signs between all these disciplines and gives me the tools to actually make things connect and interact.

On the other hand, he noted certain challenges:

The first one that stood out was working with the three different disciplines of thoughts or professors. Like, individually I can address the relevant piece clearly with them, and that was fine. [...] But the challenge has been that I need support from the committee as a whole, but the professors themselves don't talk to one another. 
Despite a good relationship with his committee members on a one-on-one basis, Julian found it "awkward" that they did not "have that intention to work with one another." Instead, he said, "they came to the meeting, they all said 'yes' to their individual piece and then they all said 'no we don't understand what the other two are talking about, but if they're okay with it, we're okay with it'." This made it difficult to put into practice the "holistic perspective" Julian was striving for:

\begin{abstract}
Well by these three committee members I really mean them and the discipline or the department that they stand for. So the challenging part has been that I have to find the people and the resources that were very much in the in between space, in between spaces of all these... and that means that sometimes I would end up reading things or participating in things that my department would deem as too spread out or spread too thin, and they would tell me to focus it all. [...] Yeah, and then each one of my committee members said something to me, but then they all each had a different focus. Yeah, like even until today, I don't think my, individually, my committee members know what I'm talking about!
\end{abstract}

Thus, the committee members that were supposed to support Julian's work became one of the main impediments to pursuing a more holistic approach—or more specifically, even though Julian could see how his project would fit well conceptually with ecohealth, materially the disciplinary structure behind his committee was blind by design to the type of integration that Julian was looking for.

In some cases, the pressure to fit into an established disciplinary approach was applied quite directly through the authority of professors. For example, after presenting to the class a research proposal based in qualitative methods, Nancy was told that she would "need to get some hard evidence," as the professor proceeded to tell her "all these things that I was not thinking of doing but basically were the only methods that he thought were okay or valid in terms of a study." While she said, "I didn't take too much to heart what he 
said," she sensed that in her department there were "more typical paths to follow," adding:

I think the biggest challenge for me was that the more I got into my project, the more I was reading, I was looking at a lot of stuff that was not in [the official department heading], even though that's my department, so I think the biggest challenge was trying to bring it back to that all the time.

Being made aware that she was taking a different approach from the norms of her department and knowing that some professors might look skeptically at her work, Nancy found herself "caught in this very isolated thing," feeling pressure around "making it really good." Having now managed to push through and defend her degree, Nancy noted in looking back "the separation between this intense solitary work" and "the connections" that actually do exist as she began once again talking to others. Fitting in may be linked to pressure to work within recognized standards of quality and success, yet following standardized patterns is not the only way of producing high quality original research. Furthermore, although graduate work can become incredibly isolating, it remains connected to the rest of the world—but these connections only become fully visible once you begin interacting with the world again.

The pressure within the institutional context of graduate training, however, pushes away from making these connections, toward containing student work within established disciplinary lines. Consider, for example, Jonathan's experience presenting at a conference some of his ideas about what it means to take science in new directions. During his presentation, Jonathan was confronted by a professor who essentially discouraged him from pursuing the project. The incident made Jonathan think that "our most difficult challenge" will be to transform the "narrow" thinking that happens within academia and he said, "the only way to do it is to take our place, because, that guy, if I had of listened to 
him I would have said 'okay, I resign, I'm going to do something else' $[. .$.$] he really hit me$ pretty bad." Although it may seem possible and perhaps necessary to convince existing authorities of the validity of another approach (or the limitations of current approaches), Jonathan's comments seem to suggest that, in fact, a different strategy is required "to take our place." Indeed, although authority might seem to reside in the personality of professors sanctioned to enforce the norms of the existing structure, this authority does not actually originate in the personality itself, rather it flows through the position that the professor occupies within a wider disciplinary structure, in this case, the university's graduate school. As a result, efforts to change someone's mind may only go so far (as Caroline suggested already in Chapter 2, when working within a broader group within predefined institutional norms).

However, Jonathan did manage to locate some support for developing new ideasnot through formal institutional channels but rather in developing his own informal peer networks. Jonathan described interactions with a core group of graduate students from different institutions in the same city. From having taken a course together, they continued to reconnect on an ongoing basis and Jonathan attributed much of what he learned as a graduate student to these relations, even though they had nothing formally to do with his program. Many of the core readings and theoretical concepts he was using came from his interactions with this group. Similarly, Mitch described his support network as, "a group of friends where I'd done my research where I don't know how unique it was but I was very pleased to have been in that social group to speak in and to explore and to basically refine my ideas," and he said: 
The important thing is to recognize that supervisors, their goal is not actually the enlightenment of their students, their goal is to get their students to be publishing, so that they can put it in their CV. Your peers have the same goals as you. You've got to look for people who have the same goals, not people who want to manipulate you.

In essence, peers and supervisors interact within the wider disciplinary structure of graduate training, but their relations hold very distinct potentialities in relation to that structure. What makes the structure disciplinary is not just its departmental organization, where each department represents a different academic discipline (although this aspect certainly plays a key role in disciplining students), but rather it is the way that students are taught to discipline themselves to fit into the logic of the established structure and the wider production process. One of the roles that professors play is to stand in for received ways of doing research that fit with the institution's existing form of organization. As a result, rather than attempt any innovation, the incentives built into formal institutional supports can attack the capacity for self-directed, autonomous research, as young researchers find themselves encouraged to compete with each other to gain acceptance within the status quo, which helps explain why in some instances (not all) professors act to conserve the traditions of the institution. Peer relations, however, seem to point to other potentialities that I will discuss in detail in Chapter 5.

One initial response by some interviewees in negotiating the university's disciplinary frame was to stand up for certain values and reject the institution's status quo approach. But steering science in fundamentally new directions may require more than individual commitments to concepts. For example, in relation to the concept of interdisciplinarity, Beatrice said:

I think there's still pressure in the science world that we need to be expert at something, um, to be valuable, to be... and that I think sometimes it's still the case in interdisciplinary research, and to me 
that's the kind of research that brings together different groups but they don't necessarily cross their disciplinary lines, they're just speaking to each other, working together maybe, but it's almost like sometimes in interdisciplinary research experts are actually valued more, because then you have your role and you can contribute to the team. Just the history of, like where we've been, we do a lot of what we do now because of what's been done before and a lot of what's been done before, you know, is the biomedical approach to health, and reductionist linear science and so you know that's how the science machine works, you build on research and knowledge that's been created. And so because that's been the kind of, the past, it's easiest to keep going along that path rather than trying to do science in a different way.

Even if some of the headings advertised along the way promote the concepts of inter-, trans-, and multi-disciplinarity, Beatrice found that on the whole graduate school was - by design - an isolating experience.

When shifting from the Master's to the PhD, she said: "I was lacking a support network at my institution" and "I was feeling somewhat isolated in this new kind of education":

Nothing was happening to bring us together. I had actually tried several times, you know, I emailed people several times - I need the list of PhD students so I can email everybody and we can start trying to go out and do stuff together-and it just never happened, it never kind of came together, but it was something that-and I've spoken to some of the other PhD students and this wasn't just me feeling this way-we were all feeling the need to kind of lean on each other a little bit.

Although it might seem logical from an administrative point of view to create spaces that facilitate new students working together and getting to know each other (why else spend so much time and resources on creating a program and attracting new cohorts every year?), this was not what the administration was trying to do in Beatrice's experience. On the contrary, it seemed that even when she was interested in helping to bring the cohort together, the administration offered little support. In essence, the dominant administrative view would seem to confine itself to ensuring that students show up to the program and individually move through its requirements; little support is given to the collective potential of the student experience, despite labels that promise otherwise. 
Beatrice's response to this sink-or-swim style of education is quite complex:

I'm thinking specifically here in terms of throughout my graduate school work. I guess, like finding my place has been really challenging. And then dealing with the reality that I don't actually have a place-and that's actually what I want! So I don't actually want to be situated in a certain way of thinking or a certain way of doing things that's static, but then there's this constant sense of a little bit of uneasiness existing outside of a place, do you know what I mean? And most often it is not a problem, it is kind of what fuels me, that kind of uncertainty, you know, being one who kind of thinks a little bit differently, being a bit of an outsider, sometimes that's what I like and what fuels me.

Beatrice's initial reaction is to rise to the challenge of being an outsider that does not conform to existing practices. Yet, being an outsider within an institution shaped by traditional approaches to science may not be the best way to find support. Beatrice continues:

But at the same time it can be really challenging, so if there are other things in your life or in your work that are becoming a challenge, then that feeling can start to feel almost too much and you get this sense of wanting to go back, you know, kind of looking for a place, moving towards the discipline, moving towards kind of traditional science or thinking because it is sometimes easier. And this was actually happening to me during right before the ecohealth course, and I was starting to think okay, I'm going to simplify things, I'm going to make this more linear, I'm going to you know [laughter] cause it was feeling quite daunting, I was having a sense okay, let's strip away some of these... let's zoom in actually is what I was thinking, let's zoom in and get rid of some of these, some of these other complicated issues and let's think about this problem at a much smaller scale and in a much simpler way and answer it, you know, kind of easily with traditional [scientific] tools and I'Il just be done in a couple years you know, [more laughter]. And so I think the reason that I was moving in that direction was because I was feeling really isolated and, you know, just didn't really have people... and I was coming up to some really challenging conceptual ideas, some challenges in my research and not necessarily having people to bounce these ideas off of, that support, [and] because that wasn't there I was close to moving away from some of the stuff that really makes me the researcher and the person that I am, which I would say is not wanting to conform to traditional disciplinary knowledge creation and not wanting to do things the way they have been traditionally done.

While Beatrice tries to make the best of a difficult situation, eventually that situation starts to shape in fundamental ways how she sees herself and how she rationalizes the type of work that she can do. In short, context matters a great deal, and what might at first appear as small details may cumulatively affect what the production of expertise actually means in fundamental ways. 
Beatrice continued to explain how it was difficult obtaining "funding to answer the types of questions that address ecohealth type research," and without money, "you start to have to take on some other contract jobs and things like that, [...] maybe TAing one extra semester." The lack of adequate support can ultimately force a reevaluation of the entire frame of the research project:

It's easier sometimes to just become an expert and focus: you know exactly what funding bodies to apply to, you know exactly what journals to read, you know exactly who you are supposed to be working with, who you should be, you know, those things that the boundaries of your work are pretty clear. So in a lot of ways I think it's easier to navigate that type of work. When you're doing work that might cross different types of disciplinary knowledge, different ways of creating knowledge, then it can be much more difficult, it's a little more of a bumpier ride.

At some point Beatrice realized that: "we're just spending a lot of time and resources convincing people that aren't going to be convinced anyway." To her, it was clear that the standard approach to scientific research in her field "isn't going to adequately inform the type of action that I think is required," therefore she felt that it was time "to move ahead with what we're going to do about it." She even felt that her own research "doesn't really get there" and while she might be able to address part of the question with traditional scientific tools, there is another part of the whole relationship between health and environment that demands "moving the science forward and coming up with new ways of doing things and identifying new data that we're going to need." Beatrice's experience of the tension between fitting in and being herself shows the links between disciplinarity and the perpetuation of the status quo. Standard departmental practices-in conjunction with other factors such as funding, isolation, and disciplinary inertia — weigh down to shape the self into an image that fits with the departmental norms, which can make it difficult to find support for taking science in new directions, even if those directions correspond more 
closely with the type of research and researcher many aspire toward. Recognizing these constraints does not mean there is no wiggle room for making spaces where alternative practices can be developed. But there is a double challenge of proving you can fit into existing terms of success while at the same time pushing the envelope in new directions. In response to the weight of the academic world, Denise was learning to disguise herself, or at least to present herself on terms that were recognizable to the institutional authorities. For example, in applying to certain funding agencies she learned that, "I can have notions of interdisciplinarity but if I come with the words 'ecosystem approaches' they will say 'hey what's this?'" In order to get the money, she has found that:

You will have to do 'science science' and show them that you're really capable. I think it's always a challenge with ecosystem approaches, as people from outside this approach perceive it to be a little like anything goes, so you have to be rigorous, you have to try not to fall in the hole, yes that's it, you have to persevere with a high quality science but with an approach that is more open. So I think that's the huge challenge, to develop a whole strategy for the young researchers, since there are no jobs.

Denise had reached the point where there were few institutional supports open for her to

pursue a career in ecohealth, and if she wished to move forward she would have to show

her relevance on the established disciplinary terms:

What I hope to be able to do is to integrate myself as a researcher and professor, and ecosystem approaches offers a doorway, but it's a knife that cuts in two directions, in the sense that we have an innovative training that fits with a new paradigm but the jobs to which we can apply are still inscribed into a disciplinary paradigm. So, particularly in the health model, in the medical paradigm, where, more and more there's a certain opening up, but it depends on the university, it depends on the department, it depends to what extent the department is run by medical doctors. Because doctors are often quite suspicious of working with people, not suspicious, but for example even someone who arrives with a doctorate in epidemiology, medical doctors will not always see this person as relevant. But someone who arrives with a doctorate in [my discipline], it's like "oh my God who are you?"

It is a difficult situation: being caught between having a job that may compromise one's core beliefs and not having a job. Everyone must sustain himself or herself somehow. But while Denise was learning how to "play the game," her sense of self suffered: 
Once you arrive [at this stage of your academic career] you realize the extent to which the war is ferocious, that's it, the war is ferocious, that's really the right word. There is a lot of pressure. People have excellent CVs. So you learn to play the game but I'm not sure to what point I want to be... You know, you start off as a puppet in the game of productivity, of competition, to try to have a career, to then find a job, and then obtain some grants. It's as if there are times that I don't feel... I find that it's not who I am.

Unless there is a way of changing the game, the challenge of living up to two different sets of standards - those used by the institution to measure your success and those you use to determine your own success - in the long run plays into the reproduction of the status quo.

One of the key measures of success through which young researchers were encouraged to define themselves was the acquisition of publications in recognized journals. In trying to publish his research, Mitch said: "if you want to use ecohealth as your theoretical framework, basically, you will be bagged." He acknowledged the existence of some "interdisciplinary journals" but still felt that, "The system is not designed for interdisciplinary science." This reality poses a real problem for the kinds of aspirations that interviewees associate with ecohealth. On the one hand, ecohealth means lifting the disciplinary blinders, promoting the integration of different kinds of knowledge, and encouraging experts from different fields to work together on addressing real-world issues. Yet, on the other hand, obtaining a career as an expert in ecohealth remains for the time being chained to disciplinary norms and standards of success, as Beatrice remarked:

I recently was working on a paper, you know, we were starting to think about where it would potentially go and Ecohealth was pretty much the only journal that we came up with, you know, that seemed suitable? And that's crazy that this kind of, so something that I was working on could only go there!

She acknowledged that perhaps her search was not exhaustive and that there might have been journals that she overlooked, "but Ecohealth definitely seemed like the most 
appropriate." In other words, the tendency to funnel "ecohealth" work into a very narrow label is already strong. Some interviewees even found that the EcoHealth journal was itself only supportive of very particular versions of the ecohealth approach, and all of these versions are in the process of becoming streamlined with the normalized production of a field, as those funded to work on ecohealth seek to promote its legitimacy on the terms of the existing terrain, for example, by organizing a journal, conference, and special community of recognized experts.

But the extent to which those interested in ecohealth mimic or push back against normalized practices remains an open question. There are those like Beatrice who found in ecohealth a reason to believe that push back is possible so long as there is a network of support: "I didn't have a network, and that's why I think I feel quite excited about ecohealth, because I see it as becoming a network for me." For others, ecohealth might remain, at most, a side project to their own disciplinary career advancement. Finally, for some the challenge of adopting ecohealth was not the core of the problem, which instead resided in changing the academic structure itself; it was not so much ecohealth that was needed, but any approach that helped confront the limitations of the status quo. On the whole, the experiences collected here reveal tremendous pressure on graduate students to fit themselves into the spaces provided for them: rather than the university supporting the development of new leadership, the new-leaders-in-the-making are being asked in so many ways to conform to the demands of existing structures. In the next chapter, I follow interviewees from the university to the field to understand the implications of disciplinarity for framing relations between researchers and non-academic communities. 


\section{Chapter 4. From the University to the Field: Framing Relations with Communities}

In this chapter, I present interviewee comments and experiences related to attempts to apply some of the principles of ecohealth research in non-academic community settings. Graduate students and young professionals working on ecohealth projects find themselves caught between steering their work toward the ideals of participation and transdisciplinarity, while having to complete the project on time to meet the demands of funders and/or supervisors. From these efforts, a tension emerges in the meaning of specialization: pulled between responding to new understandings of the communities' own priorities versus maintaining the prior disciplinary framing of the research problem. This tension manifests itself in questions about who is an ecohealth expert, who has authority over a given project, and how can research actually make a difference in the lives of communities. In exploring the tension in these questions, I present interviewee experiences in relation to three basic frames: the university, the nation-state, and the context of international development projects. Each of these frames reveals a flow of topdown authority inscribed within employer-employee relations, in response to which interviewees propose a number of different researcher-community relationships. I argue that the channels that make ecohealth research possible in the first place also systematically impose limitations on what the application of the approach can look like.

First, I present interviewee reflections about the meaning of participation and transdisciplinarity within a discussion about the tension between specialization and 
discipline. Next, I look at how flows of authority factor in through the nation-state frame.

Finally, I present three mini-case studies of interviewee experiences conducting ecohealth

projects in the field, analyzing their cross-cutting themes in relation to a wider selection of interviewee comments.

As a paid research assistant, Beatrice's terms of engagement with a research project espousing participatory methods happened through a set of employer-employee relations, and while she liked the title of the project she was being paid under, she found the title and the actual work did not really align:

Well, I'm still working out my relationship with this idea of participatory research. I guess for me, one of the things I struggle with as a researcher is this feeling of extraction, and I know that participatory research is attempting to address this issue, what do they call, you know, parachute researchers, when they go in, take stuff, take knowledge and then leave and publish. But sometimes it still seems to me that participation is still extractive, and again it's just so context dependent, but I think that one of the experiences for me that has brought up this uneasy relationship is, ahh... [she cites an example of a so-called participatory research project in which she worked as a research assistant] but the problem was that [the populations supposed to participate in the study] were so overburdened [with their own daily work activities], but the problem was that on top of this, there was so many NGOs and so many research groups in this small geographic area, which is known for being one of the poorest of all of South America in poor health outcomes and that sort of thing, there was so many wanting to be participatory work that it was actually this humongous additional burden. And so it started to feel like participation wasn't doing what it was supposed to be doing and had become very extractive.

While such projects may depend in part on the energy, motivation, and hard work of research assistants, the research assistant's role is not usually about redesigning the project, which at this point has already been framed and funded. Rather, the assistant's role is to help carry out the project as it has already been designed.

Still, in Abriana's view, part of the strength of the ecohealth approach was that it "begins with concrete observations regarding everyday realities." But there are challenges:

The first challenge is to bring the people to tell me about their situation, to express their concerns, but when you are sick, what do you do? There is a tendency to hide your problems, especially when they're related to health. So bringing people to a point where they could express in their own everyday language... And then there's the encounter with the authorities, whether administrative or 
traditional authorities, it's not always easy, and very often the communities are tired since you might be the third person who has come to the site saying 'you should not do this, you should not do that, you should do this instead' and then there is no follow up with those recommendations. So the fatigue of the peasants in their voices, in their knowledge, so this is an initial challenge each time, a challenge that must be confronted each time.

Interviewees valuing the ecohealth approach do their best to listen to the realities that communities face, but their status within the hierarchy of the university frame poses certain limitations on what graduate students and young professionals can do to fulfill the meaning of the labels under which they are trying to work. These hierarchical divisions built into employer-employee relations can shut down the possibilities for working out better what it might mean to practice a genuinely participatory approach to research, since the space for this discussion is taken over by the need to complete the project. There is a tension emerging here between specialization and discipline, that is, between developing knowledge relevant to addressing a specific context versus getting the job done as it has already been defined for you by someone with authority over you.

Like participation, transdisciplinarity is another aspect that ecohealth research projects strive to bring to life. François noted, "the ecohealth approach is a transdisciplinary approach, yet today transdisciplinarity, at a certain moment, is not, if I may say it like this, something easily shared." He explained:

One of the main challenges is when you choose people, for example from a particular discipline, and when I was working on my ecohealth project, you have to in effect prepare them. It's bit like a training to explain to them where we're going so that they can appreciate and understand exactly what you want to do. Without this, at a certain point it becomes difficult for them to follow you. There was a point in the project where each person had to contribute a piece. We needed a sociologist, then a technician, etc. And once again, each one stays within his or her own personal specialization, so the major difficulty is that we don't actually succeed in really defining this transdisciplinary language where everyone has the same grasp and can work together on the project. 
If experts need to be retrained to be able to see past their own area of expertise, this might say something about the insularity of their previous training. On the one hand, ecohealth is looking to support the development of a specialization that is capable of making itself relevant to the problem at hand, a problem that may not be well defined in advance. On the other hand, ecohealth may become its own form of disciplinary expertise, where only those trained in the approach are able to genuinely participate. What may be confusing for disciplinary experts unfamiliar with approaches like ecohealth is this: why ask them (specifically, as opposed to another kind of expert) to work on a project if it is not specifically to contribute their disciplinary expertise-what could they possibly offer besides this? François understood that applying the ecohealth approach was not simply a matter of attaching the ecohealth label to the project:

I see development through a general lens, not necessarily health-based. So on this level, personally, there comes a time when the ecohealth approach does not line up perfectly with my priorities, with my projects, because there is a development dimension but health is not at the centre of my concerns. Yet the ecohealth approach, the small reservation that I see presently is that, it is an approach that would like there to be a direct link with health, and if at some point you're not working directly with health, well, you're obliged to adapt certain criteria, [...] and this is where a falsity enters, in my opinion, into an approach that would like for us to act upon the environment to intervene in health.

In development projects where health was not part of the frame, François faced a dilemma: either he must drop ecohealth or he must stretch the criteria, potentially widening the gap between the meaning of ecohealth in principle and in practice. How, then, might it be possible to use the ecohealth approach within contexts framed by predefined norms? 
Although it could be argued that each field of research already plays a specific function, which is justified and relevant, Alain had reached the conclusion that the typical mode of academic knowledge production was itself inadequate:

There are many specialists like this working in environmental fields with problems related to ecohealth. So they themselves do not know how to present their research, or how to take into account and raise public awareness: though they have research results, they do not communicate them in a way that ever leaves the laboratory or the study. The studies are done, but there is no way to use them.

In Alain's view, this failure to actually use the results of the studies was largely due to the "modesty of researchers who are not ready to open up and share their work," and since most academic degrees did not help researchers overcome this, he saw an opportunity to train academics to "appropriate the means of communication," for example, by learning new skills and capacities for effective engagement with the media: producing documentary films, radio shows, and other ways of conveying results to engage a broader audience beyond the readership of academic journals. In effect, Alain's proposal takes the concern about making results relevant to another level by suggesting that it is the understanding of the public at large - and not only the understanding of the specialists that must be addressed if change is to come about.

When I asked Olaitan about the challenges of implementing ecohealth he said that there was no problem so long as the group members were familiar with the approach:

But when you have to speak about the ecohealth approach to people that do not know this approach, sometimes this is a little difficult, because you need collaborators, and for each activity where I decide to use the ecohealth approach I need the collaborators to involve themselves in the actions with me and they must understand and see things in the same way, so in instances like that it is difficult.

Furthermore, Olaitan noted that those unfamiliar with the approach may not realize how demanding it can be: "you see it's an approach that demands a lot of personal investment, 
that requires a willingness and determination on the part of those who must adopt it, so it's not easy to bring other people to see things in the same way." In his experience, he found himself having to bring everyone "back into a straight line." Others also described ecohealth in this way, as a group of people defined by the specialized training that they had received, which is why working with non-academic communities or other people trained in a different academic discipline proved so difficult.

In one sense, this response is entirely consistent with how the approach is presented to interviewees: as a type of training offered only to a select group of graduate students and professionals taught by university-based experts. In another sense, however, this response would seem to clash with parts of the meaning of ecohealth by limiting who can work on the approach to specific disciplinary experts (even when seeking to transcend their discipline). In other words, starting with ecohealth as an already formed centre of expertise with its own recognized specialists does not really explain how this group of people came to be or by what authority they claim expertise in ecohealth, other than the fact they have access to university credentials and are interested in issues of health and environment- -these are not necessarily the wrong criteria, but it is still not clear why they are currently the main criteria defining the actors of the approach.

Vincella's remarks help illustrate the tension around this dilemma about who really can be an ecohealth expert. On the one hand, she felt a strong affinity for the ecohealth approach:

I felt ecohealth was trying to explore problems in a broader way and I just felt that made so much sense. I guess in research I've been always quite frustrated that we tend to focus into very specific aspects of problems, and yeah yeah you might find a solution for something but it doesn't really look at the whole problem. 
On the other hand, even though she said ecohealth "fit so much with my own way of thinking," she also sensed a tension with her disciplinary training: "my mental approach is too natural scientist driven, and that doesn't match very well with what ecohealth needs really." So while she explained that she was "very open minded" and she tried "to look at problems from a very broad perspective," she also said that she always tried

to rationalize things and understand things very deeply, and probably when you really try to do ecohealth and put it into practice that's something that sometimes you have to put aside a bit and try to be a bit more capable of improvisation and capable of understanding, because some things really escape rationality. Yeah, like, for example, social behaviour and culture, these kinds of things, it's very hard for me to incorporate that into my actions or my look into reality or into the problem.

In essence, while the approach made sense to her, Vincella sensed that her own disciplinary training did not really match with what an ecohealth researcher ought to be able to do.

By contrast, rather than seeing ecohealth as made up of a group of people all sharing the same outlook and skills, Gilles described the approach as fundamentally open-ended: "The ecohealth approach will necessarily be dynamic — why? — because it draws on different approaches, which means that when I work in ecohealth, I feel like saying it's practically an effort to bring together a certain number of ways of thinking, it's really about sharing those different ways." Still, Gilles was the first to admit that sharing those different ways was not easy: "the big difficulty often encountered in group work, in bringing people together, is their availability." When he received the IDRC grant he immediately had to drop other work responsibilities in order to complete the project on time, but the rest of the research team remained pulled between different jobs, long hours and commute times, which made it hard to meet as a team. Although he tried to explain that the ecohealth 
approach required working on all parts of the project together, he found that some

specialists could not see a role for themselves outside of their own area of specialization.

Felipe pushed the idea of who could claim expertise in ecohealth further by making

the following distinction when I first asked about his experiences with ecohealth:

Okay, here I would think to distinguish between... if you're referring to ecohealth in terms of COPEH or if you're referring to ecohealth as a practice that many people have developed independently. Like, I don't recognize the term 'CoPEH' but there have always been many questions relating to ecohealth that have been developed let's say instinctively or primordially.

Felipe went on to challenge the notion that ecohealth was born in the university:

Well, let's say that ecohealth arrives to regroup a number of things that have been worked on historically, because this is not something completely new, maybe there is confusion, I don't know if it has been badly interpreted or misinformed, but what ecohealth has done up until now is to consolidate elements that have always existed.

At the same time, however, Felipe's understanding of ecohealth did not by any means rule out the insights gained through academic pursuits; rather the key seemed to turn on how different kinds of knowledges could be integrated into new understandings as they developed through new experiences. For example, when I asked whether his understanding of ecohealth had changed over time, he replied:

\begin{abstract}
Yes, yes it has changed because let's say that as one goes forward one always begins to see things from different perspectives. It's not the same if you look at a theme or ecohealth and you don't know anything about epidemiology, whereas if you take a couple epidemiology courses you will see things differently afterwards, and it's the same if you study health and society, or if you begin to recognize structural problems in the society in which you live, this too will lead you to different ideas. So for instance when I involved myself academically with ecohealth, well it was very theoretical. But when I went to the country to get to know the workers, their living conditions, their aspirations, well I also saw things in a different way. For example, if you look at the conditions in which large-scale plantation labourers must work, and you realize that in reality nothing in history has changed, that today we simply say that there's no slavery but the exploitation of man by man is continuing anyway, and that besides this, that which fifty years ago was a forest is today a plantation, well you realize that the relations have changed such that you have the ecosystem and you have the workers, but in reality the principle that it is relations between social actors has not changed at all. So my concept of ecohealth has changed from the merely biological and ecological, let's say studying the ecosystem and human health, to a vision that involves the social conditions and structures, that which is in the middle of the ecosystem. And so I think that yes, surely my understanding continues to develop, since to conform oneself to a single idea is to never obtain more knowledge, to stop studying altogether.
\end{abstract}


In this view, no one is ever entirely in charge of ecohealth, though certain groups of people may have pushed their own understanding further than others. In any case, ecohealth is never a fixed body of knowledge frozen in time, but rather an ongoing development based on the contributions from various groups.

Antonio Gramsci's comments on the role of intellectuals may be relevant here, though the problem is posed in slightly different terms:

is a philosophical movement properly so called when it is devoted to creating a specialised culture among restricted intellectual groups, or rather when, and only when, in the process of elaborating a form of thought superior to "common sense" and coherent on a scientific plane, it never forgets to remain in contact with the "simple" and indeed finds in this contact the source of the problems it sets out to study and to resolve? (Gramsci 1971: 330).

Gramsci was concerned with what a "philosophy of praxis" might look like. He noted: "One of the greatest weaknesses of immanentist philosophies in general consists precisely in the fact that they have not been able to create an ideological unity between the bottom and the top, between the 'simple' and the intellectuals" (1971: 329). His own take was that a genuine philosophy of praxis does not limit itself to certain intellectual groups but rather includes mass social movements. Still, he argued that there was a role for specialized intellectuals to play:

A human mass does not "distinguish" itself, does not become independent in its own right without, in the widest sense, organising itself; and there is no organisation without intellectuals, that is without organisers and leaders, in other words, without the theoretical aspect of the theory-practice nexus being distinguished concretely by the existence of a group of people "specialised" in conceptual and philosophical elaboration of ideas. (Gramsci 1971: 334)

Gramsci's insights go part of the way in reconciling the different views expressed by interviewees since, on the one hand, he understood that a specialized group of intellectuals would be necessary to help organize the masses, and there would be an ongoing tension between them since, "there continually recur moments in which a gap 
develops between the mass and the intellectuals (at any rate between some of them, or a group of them)" (335). On the other hand, Gramsci recognized that the goal of a philosophy of praxis must never be limited to forming an elite group: "For a mass of people to be led to think coherently and in the same coherent fashion about the real present world, is a "philosophical" event far more important and "original" than the discovery by some philosophical "genius" of a truth which remains the property of small groups of intellectuals" (325).

On the whole, while interviewees expressed concern over the challenges that arise, working on ecohealth projects was part of their own career development. Thus, the relation between these projects and interviewees depended upon relations of employment, ultimately controlled by the university frame, which poses the tension between discipline and specialization.

\section{The impact of the nation-state frame}

There are strong links between the disciplinary structure of the university and the structure of the state. Both are divided into fields and those who work in those fields are encouraged to define themselves and their work within strict parameters. Gilles explained:

\footnotetext{
Environmental questions evolve in their own sphere, health questions also evolve in their own sphere, and between the two spheres remains a huge gap, a giant hole. And sometimes you have to force reflection a bit further but we don't always respect each other. People working on questions of health only work on questions of health, and for those in the environmental sphere, it's primarily biodiversity and environmental assessments, health is but an aspect, it's not marginal, but it is not one of the primary centers of interest.
}

It is worth pondering what Gilles means by "force reflection a bit further." He points out that the current divisions within state infrastructure are not designed to handle how issues 
of environment and health actually occur in the world: while the issues are

interconnected, the specialists have mandates specifically designed to not see the whole

picture:

I remember an inquiry that was done to see how the public could intervene in questions of environment and health, and they interrogated people from the Ministry of Health and people from the Ministry of the Environment and in the end they realized that questions linking environment and health were not being addressed: you had environment on one side, and health on the other.

But is greater "respect" between employees of different spheres what is really missing to work together on addressing issues?

Even within a single ministry - let alone across different ministerial spheres - efforts

to cultivate respectful relations were systematically trumped by the top-down flow of authority. For example, Lucia found that:

Well, here in Costa Rica, a challenge-it's the same system! Let's say if we're talking at an institutional level, whether it's the university or the ministry. If we take the Ministry of Health, for instance, it is divided by areas and it is a hierarchy: it has a regional level, a sub-regional level, and it has a central level. The politics of how things happen go from the central to the local level. So I believe that both directions are important, but at times it is very difficult working at the local level when they have to do, like the form of actions comes from the central level. It is the same in the university and I don't think it's very different in other institutions either.

While the will to work across hierarchical structures is certainly necessary for going beyond a narrowly defined job description, this will can quickly disappear when all of the structural incentives are pushing against it:

the Ministry wanted to collaborate on this project but when it came time for actions, the topic of pesticides was not a priority at the central level compared to, say, dengue. So despite the interests of local actors, they said, 'well we can only go this far, because the central level is imposing limits on our actions'.

Another tiresome factor that Lucia encountered was that "the people working for the Ministry change," meaning that it was hard to keep up relations when there was high employee turnover.

Similarly, Daniel's experience led him to the following conclusion: 
All of the decisions are taken in the capital and these become the directives that everyone else must follow. The Minister of Health or the Minister of the Environment, they follow what has been said in the capital. But at the very local level there are organizations that want to get a hold and work with the type of information produced through our studies, but often the Ministers at the central level of the government don't want to move forward with any of this, they want to stay right where they are.

Two observations can be made here. First, the challenge and opportunity proposed by the ecohealth approach entails coordination between different levels—-from the local communities all the way up to the top state authorities-yet the flow of authority runs from the top down. Second, following the ecohealth approach, interviewees try to build bridges between local conditions and central authorities, yet they find that the gaps separating these different contexts are not accidental, rather they are part of the design of the infrastructure itself.

\section{The international development frame}

Interviewee responses have already begun to reveal how the same channels that currently make ecohealth possible also systematically give rise to a number of obstacles that get in the way of what might otherwise be a better application of the approach. To look at this in more detail, I will focus on the experiences of three interviewees - Cecelia, Alicia, and Azim - who provide fairly detailed accounts of their work on ecohealth projects in different parts of the world. ${ }^{10}$ I examine the cases one-by-one, identifying key issues and discussing them in relation to other interviewee comments and relevant literature. But the goal in delving into these mini-case studies is not to evaluate them individually, rather it is

\footnotetext{
${ }^{10}$ Indeed, not everyone I spoke to had conducted fieldwork, nor did my interview questions focus specifically on fieldwork experiences (rather, they were about the interviewee's encounter and experience of ecohealth however they defined this), therefore there were only three or four examples that provided sufficient details about the challenges and opportunities of realizing ecohealth through fieldwork activities. Elsewhere I have discussed two of the same cases along with another, see: Feagan et al 2014.
} 
to identify some of the crosscutting themes. Indeed, although each case represents a separate experience, the emerging tensions around community participation, the role of the researcher, and the integration of knowledge for bringing about meaningful change, suggest certain systemic properties that cannot be adequately understood except as connected to the patterns and contexts that frame from the outset how international development fieldwork happens.

\section{Cecelia's case}

Cecelia's project focused on the health effects experienced by a community dominated by agricultural production for exportation. To Cecelia, applying the ecohealth approach meant going in a different direction from traditional scientific research, especially in terms of community participation. Rather than simply showing up, collecting data and leaving, Cecelia made it a priority to spend time getting to know the remote Central American community where she conducted her study. This entailed participating in community events, talking to community leaders, and developing relationships of trust over an extended period of time prior to starting her data collection.

Compared to previous studies she had conducted elsewhere using a more traditional scientific approach, she found that the time she invested in getting to know the community led to a more satisfying experience and higher quality data. For example, having established good relations with the community's "natural leaders," she found that people were very receptive to her study: no one refused to participate. Furthermore, community members helped identify the best timing for collecting samples, which not 
only led to a more complete data set, but also helped contextualize the data within some of the social relations that were contributing to the problem in the first place. Overall, she was pleased with the results: "for me, this type of work is the ideal for addressing health problems," adding that, "compared to more clinical studies, ecohealth offers a holistic approach that integrates not only the biological and the social aspects but also the approach of the participants themselves within the health problem, so that they can contribute to a better solution."

Cecelia's struggle to take a more participatory approach entailed first of all confronting the norms of biomedicine within her department. To strike a balance between her interests and the kind of scientific study that would satisfy her degree requirements, she secured external funding to give her the means of spending sufficient time in the community. She noted, however, that her supervisory committee questioned the amount of time spent in the field as well as the validity and generalizability of the qualitative data that she was trying to integrate into her analysis. Having observed the limitations imposed on some of her peers, Cecelia speculated that if it were not for her external funding, she probably would not have been able to conduct the study in the way that she thought would best meet her expectations or the criteria of ecohealth. She hoped that the results of her study would become a tool for community members to use in confronting their own situation.

Cecelia's experience trying to implement the ecohealth approach revealed other challenges too. Referring to ecohealth's other pillars—-that of transdisciplinarity and gender-Cecelia explained that she had consulted with certain government and university 
experts who helped shed additional light on the situation, but she emphasized that in spite

of having reached certain accomplishments, there were shortcomings:

The part that we didn't accomplish completely was the analysis of the problem on the level of power, because we achieved collaboration at the level of the community, but for the authorities at the local, regional or national levels, a problem in an agricultural community is but one in a thousand problems, so for example, we never worked with the mayor in that area.

Furthermore, despite making repeated requests to the central state authorities, Cecelia

never was able to obtain information about the regulations and policies that had been in

effect previously in that zone. Although impressed overall with the ecohealth approach,

she said:

The only aspect that I see that you could say is perhaps unrealistic, or where the ecohealth approach could be seen as very ambitious, is in addressing problems that stretch beyond the regional environment. Because including the approach of the country, for example, it's impossible to gain the attention of the different institutions involved, I think it's too complex to achieve this. For example, in my opinion [the health problem in this part of Central America] is in large part due to the role that this country plays in the production of agricultural produce for exportation, but using the ecohealth approach how am I supposed to actually raise awareness and change the position of the country from within the local context? So I think this is too far away. But I do believe that the construction of this understanding at the local level is useful. But thinking more about what lies beyond, at the regional level, what do I know, in Central American countries with similar problems, I think that the change is too big of a step to be realistic.

\section{When I asked Cecelia about her next steps, she said:}

In theory, I will have finished [my degree requirements] in the coming months, but I will not have finished analyzing all of the information that I have collected from the project. Furthermore, there is the important point about posterior work with the community. With this approach it's not just about completing an investigation and it's finished. Now I must return something to the community, changes have to be implemented. So in this step, once I've met the requirements of my degree, my commitment would be to mobilize funds to be able to return to the community to implement changes, in the implementation stage. [Matt: you want to initiate another project?] It would be the same project but up until now we have arrived at the stage of understanding the problem, so it would be the same project with the same community but now we have to look for solutions to the problem.

In sum, Cecelia was able to conduct her study in a way that allowed her to reach new depths of insight and satisfaction—in breaking from the biomedical model, in taking a more participatory approach, in developing meaningful relations with the community, and 
in producing quality results that could help inform a process of implementing solutions-

yet she felt that her analysis at the level of power was still insufficient, due in part to a lack

of engagement on behalf of the authorities and in part to the role that agricultural

production imposes on the region as a whole. With this tension lingering in her mind,

Cecelia felt that she would have to adjust her original assumption about implementing all

aspects of the ecohealth approach in one shot, toward a longer-term view involving different phases of work with the community.

Perhaps, then, the central challenge that Cecelia faced was the integration of the ideal of participation within the framework of a more traditional scientific study, as in the way that Lucia described the ecohealth approach here:

Without the [ecohealth] approach we're really just talking about a more epidemiological study about measuring exposure to certain substances; with the [ecohealth] approach, however, the whole perception and involvement of the actors to find solutions, the understanding that community participation - and not just the results - is necessary to find a solution to the problem, that is how I see the difference with and without the approach.

When conducting fieldwork against the backdrop of the biomedical model, the meaning of participation must be made to fit within a containable, doable project that meets the standards of a given graduate program. A distinction, therefore, emerges between the range of meanings of participation in theory and the actual range of meanings available in practice - a distinction that other interviewees also experienced, as François' description below suggests:

You see, when the ecohealth approach was presented during the course it seemed rather cumbersome, in the sense that they presented to us a system where you had to take into account and involve all the stakeholders. So you had to involve the administrative decision makers, the public, the populations, those responsible for this or that, everyone had to be involved if the approach was going to be participatory, and this seemed sufficiently daunting. So when I began my first ecohealth project, it required enormous amounts of time and money, because if you have to ask the local authorities to move around they will ask you for payment, and it is not easy to budget for this. In effect, each person brought into the process will require some form of payment, and it seems 
excessively cumbersome to budget for so much money in terms of meetings and coordination. [...] So you come to realize that you have to work at a somewhat more superficial level, you have to simplify matters and adapt them to the local context. So at some point you're obliged to limit what participation means in order to obtain results. So the grandiose dimension presented during the course, when you arrive in the field you realize that the ecohealth approach is certainly interesting but putting it into practice seems awfully difficult because you need an on site preparation so that the local populations can understand the process and are able to follow.

François points to the limitations imposed by the "local context," including the lack of familiarity that local populations may have with the ecohealth approach, but implicitly he is also talking about the limitations of the whole context of research, which includes the conditions faced by young researchers in relation to their own departmental norms, assumptions about university-based research, funding associations, degree requirements etc.

Other interviewees questioned in different ways the reliance on external funding, especially when the money and expertise flows from north to south. For example, initially Daryl was not sure why Canadian research money should be spent in other countries, suggesting instead that perhaps "the Canadian money is better spent in Canada." Then he noted that this may be part of the point of ecohealth: "but I can appreciate it and I can see how the events, the economic happenings in South America are connected to what's happening up here, so I can see that it's maybe a bigger scale than what I'm used to working with." In Felipe's view, however, people in Latin America have witnessed countless projects where money and expertise arrive from afar:

But what is felt here is that we historically have been unable to develop ourselves, and so we don't take up this expertise. For example in this project, we put a lot of energy into data collection. We have data on environmental exposure, hair samples, blood samples, urine samples, we do many interviews, we follow through with a basically positivist science. But our work with communities in terms of expectations and emancipation, it is secondary to the data, which we need for publishing one article more. [...] We basically show up, collect, and leave. 
This tendency to reproduce a positivist approach to research was not due to researchers' bad intentions but rather to the fact that the channels that allow researchers from the North to bring their expertise South are in essence the same channels designed to extract wealth from the South to the North—this has been the history of colonial relations and capitalist expansion, which continues into the present, as Felipe points out:

The economic model that exists today, the capitalist model that up until now has been providing the money for this... For example, the Canadians, I don't know where the money that arrives at the IDRC is generated, but perhaps some of it ultimately comes from mines in Latin America, these are Canadian companies doing the destruction!

Researchers valuing the ecohealth approach thus find themselves in a position where Canadian money funds ecohealth research and at the same time Canadian capital is used by corporations and governments to gain greater access to resources: while the corporations extract the minerals in the ground, northern researchers "mine" southern communities for research results to publish articles that serve their own career advancement.

These longstanding historical patterns of unequal North-South relations ${ }^{11}$ may help explain why interviewees felt certain reservations about the extent to which they had actually been able to bring about change, despite a great deal of enthusiasm and dedication to ecohealth. Indeed, there is a mismatch between the ongoing history of exploitative North-South relations and international development research projects as the unit by which meaningful change is measured, as Fred Carden states:

As we are pushed increasingly to demonstrate results, there is an emerging realization that the results are not evident solely in the projects, but also in the environments where the projects are implemented. Because results are generally translated into short-term measurable impacts of

\footnotetext{
${ }^{11}$ The history of structural adjustment policies imposed by the World Bank and International Monetary Fund continue to shape the role of entire regions. See for example Davis (2006: 156-157), Biesanz, Biesanz, and Biesanz (1999: 49), Gordon (2010), and Wallerstein (2004).
} 
projects, the very nature of research for development to build capacity for the future is at risk. (Carden 2000: 176).

Carden argues that "the project may be the wrong unit of analysis" (2000: 177) since individual projects may not be a good indicator of long-term objectives related to institutional capacity building, and he proposes "giving evaluation away," that is, moving control over evaluation out from the hands of the donors into the hands of the communities. Certainly, this is an important step in building institutional capacity at the local level. But any serious international development work must also challenge the wider settings through which such work has been produced, including the on-going history of extraction of wealth from the South to the North, which makes any attempt at "catching up" (see Fanon 1968) impossible since it takes for granted the basic inequality built into the gap between North-South institutional capacities in the first place.

This ongoing history forces the prospect of an ecohealth "solution" to acknowledge a much longer-term time frame and scale of work, as Cecelia concluded:

Well at first I thought that for a project to be considered as part of the approach it had to have all of the elements, you had to accomplish everything in one shot otherwise you couldn't say it was... But with time I realized that it's very difficult for a project to have accomplished all the elements in one single initiative, and that the most important thing was to go bit by bit introducing the required changes. Yes, and through applying this approach I have gained a more integral vision, which may not be entirely complete, but it certainly gives me more information than a traditional approach.

\section{Alicia's case}

In Alicia's case, although "the most rewarding part" of her involvement with ecohealth was "to actually go and do fieldwork and work within a community," she pointed out that "you don't have to be in ecohealth to do fieldwork and work with communities." She went on to draw the following contrast: "it's a lot different to talk about working with 
different stakeholders and across disciplines and making your research sustainable and participatory-that's easy to write on paper but that's really difficult to do." Indeed, she found that journal articles and project proposals might give the impression that "the project's conceptual framework [...] is going to be participatory," and the researchers may even state that "they're intending to work across disciplines," but it remains important to ascertain "what does that even look like?"

In her experience working on an ecohealth project in a developing country she said, "it was challenging first to understand the project that I was looking at because it wasn't my project, it was someone else's project." Like a number of other interviewees, she found herself working on a project that in part had already been defined in the context of a certain disciplinary literature and funding provided by more senior researchers. It was "hard" she said, not only "entering the community" and "building relationships," but also doing the type of research that seemed most meaningful. For instance, she remarked that "within [her discipline], we try to say, okay, let's look at upstream—what's causing the problem? — well I think it's even beyond that: not just what's causing the problem but what are the conditions that make these causes a problem in the first place?" While spending time in the field she felt that, "well I'm not actually doing anything to help these communities," and she came to realize that "traditional research" did not allow sufficient room "to address the broader issues." However, in raising these types of concerns with the project supervisor, she said:

I was told, 'okay you have to focus on your research question, where is your data, because you have to publish this,' and I was told 'well, what you're talking about is a social goal, it's not a research goal, you have to do good quality credible research and publish this,' cause that's what researchers are expected to do. 
She came to the conclusion that "you have to go beyond what a researcher does," suggesting that there was "an extra ethical responsibility for the researcher to actually do something about the problem." She added: "I'm not saying that within ecohealth you don't need good quality credible research—that's important too [...] but the other part, the social change aspect, because doing good quality, or publishing your research is not enough!"

Furthermore, she noted that even within so-called participatory projects there was a tendency "to parachute in as a researcher," collect your data, do your analysis and then present findings back to the community at the end of the study: "here's our evidence based on objective scientific methods, now here's our recommendations: you need to change your behaviours!" However, in her view, whether in developed or developing countries, "that's not going to work anywhere," since research results meant little outside "the social and cultural context" faced by community members themselves: "Because you don't know, when you start out saying you want to do a participatory project, do you know what the issues are? And issues according to whom? Maybe the community doesn't find that to be a priority, but you view it as a problem." She further noted: "development in the community takes a long time" and community members "don't work on your schedule!" So she explained that the real challenge behind the ecohealth approach was "to do it within the constraints [of] our current organizations." Indeed, as a researcher she was "still expected to produce a product," and since the methods, funding and time-frame for the work were largely set by the academic institutions and funding agencies, it became difficult to organize a project around the community's own situation and needs—even if 
that was the intention. In the future she hoped to mobilize more funding so that she could return to the community where she conducted her research and organize a new project that would better address people's actual priorities.

Alicia's experiences intersect with Cecelia's on a number of levels. First, they both discovered that bringing about fundamental change in the situation faced by a community usually cannot happen within the time-frame of a single research project. Secondly, they both encountered pressure from their direct supervisors to stay within a particular research frame, even if it did not correspond to the goal of a genuinely participatory approach. Finally, they both in their own way attempted to push back against the limiting factors imposed upon them with varying degrees of success, even if the basic contexts and patterns framing their work remained intact.

One of the issues expressed sharply in Alicia's case might be posed as a general question: how can research make a difference in terms of social change? From spending time in communities, many interviewees gained a sense of possibility for research to play an emancipatory role, yet by virtue of their own position within disciplinary power relations, their job was already defined for them and thus whatever sense of possibility they may have found was cancelled (or at least challenged) by the need to complete the research project on time and "successfully" (as defined within the constraints of current organizations).

Interviewee comments point to a number of different types of responses, one of which was to argue that the role of the researcher was to provide communities with 
accurate data without dictating what the communities ought to do with it. For example,

David said:

Well from what I've understood of the project, it's not like we're going to show up and tell them how to improve their conditions, but the possibilities for development lie primarily in developing knowledge. Telling people here is the actual situation, for example with agricultural producers, telling them if they produce organically these can be the benefits, and here are the benefits of agrochemical production. It's like giving a vision to the people so that they can have an idea about how to proceed, [but] the decision is theirs.

Some ecohealth projects have led to the production of pamphlets distributed in the communities as a way of raising awareness and promoting best practices, and David explained that by providing communities with "informative materials [...] we're trying to contribute to the development of better health conditions for the people, giving them consciousness of what they're doing wrong and how it could be done in another form." In one way, David's position could represent exactly what Alicia was criticizing: an approach to research that leaves communities with recommendations about how to change their behaviours without looking at what gives rise to the conditions in which communities live. In another way, however, David's position could be seen to be much closer to Alicia's ideal approach to research, in that he seems to be proposing a role for research that provides objective analysis of the conditions that agricultural producers face without imposing a solution from the outside regarding, for example, whether to go organic or use agro-chemical production. Certainly, David saw his work as contributing to social change through providing communities with accurate scientific data: "the part I like the most is working with people - not a private company - so that the benefits belong to the community." 
Like David, Gabriel wanted to make research relevant to the needs and interests of communities in such a way that the results might be appropriated and used to address real problems:

\begin{abstract}
Data is a part of an investigation but it serves nothing if it doesn't apply to the community, improving human health means nothing if those whom we intend to help are not involved, because you can have a population and take biological samples from them to see if they are at risk of being exposed to things, but if they don't want to use the data or it's not of interest to them, nothing will come of it.
\end{abstract}

But in referring to his experience as an employee working on an ecohealth project, Gabriel noted: "this is a very big project and we're advancing with one part, but there are many parts, some that we have not initiated—for example, the part of working more with the communities, more with the decision makers, for me we haven't started this yet." If by design the production and dissemination of academic knowledge is destined to follow certain channels far removed from the lives of non-academic communities, then any approach that aims to actually intervene in real-world issues must take seriously the need for re-designing the channels through which knowledge is produced and circulated. Based on the experiences collected so far, there seems to be a general agreement that normal academic research remains far away from the needs of non-academic communities, and while some experiences may suggest that it is possible for research to play a meaningful role, others suggest that there is little point in trying to use research to fulfill a different function from the one it already serves: to stay within the constraints of existing organizations.

To explore this tension further, consider Denise's experience trying to overcome the usual separation between academic work and the lives of community members: 
I think we try to work—-there are always challenges—but we try to work directly with the people, even if we risk not always taking into account all of the preoccupations of communities in these projects, we try very hard, we work hard and we do it with good intentions, and you know there are all the steps before beginning: we present, we discuss, we go back [to the community], we present, we discuss... I think the most important thing for me is to be capable of talking with the people, the recipients of the research, but also to show them that there is no simple solution. You have to make choices. I think we can bring, or rather what I want to bring to the communities is information, and to tell them now it's up to you to make a decision, we can even make decisions together if you need me.

Denise described a conversation with a community member who told her that, initially, he did not really understand the proposed research project, but over time he had come to realize that some of his behaviours had probably contributed to the health problem in that area, and in the future he said he would take better care of the environment for the sake of his children. Denise said:

That really touched me, you know, you say well, we were able to successfully establish a dialogue, (1), to establish a sense of confidence but also to allow the people to... to... You know people are extremely, they are very unconscious of the complexity of what they're living, they live in the everyday, they always do things... but that he told me like that [his new understanding of the importance of the research project], I think that environmental consciousness is changing a lot in that area, we're not the only ones to help people open their... I think for me, the ecohealth approach, there is a lot of that, being close to people, it allows a dialogue between one equal and another, for me it's really that.

Such positive interactions say a lot about Denise's desire for research to play a useful role in the lives of community members, however, questions remain about how such interactions - whether positive or negative - actually affect the wider context of relations in which researchers and communities encounter each other. Is it possible to establish a dialogue between equals when there are power differences between outside researchers and communities? Are such dialogues the basis for change in the life-conditions of communities? There may not be a single right or wrong answer to these questions, and yet some response is needed to determine if real change is actually taking place. 
Marlo's experience contrasts sharply with Denise's regarding the potential of researchers and community members to relate as equals working toward the same goals:

They [community members] have their own vested interests. I can only speak from having worked with the one community that I had, and I had a great experience with it, I enjoyed the people I was working with and they were not naïve in any way. [...] They knew exactly what the academic game was, they knew how to play, they were getting something out of it that they wanted that was completely different from what I was getting out of it.

At first, Marlo may have been inspired by the ideals guiding the ecohealth approach, but over time it became hard to fit those ideals into his thesis:

There were so many challenges involved in using community members to help collect data or to design projects and it just got to at the end of the day the investment involved wasn't going to feed into my entire thesis, it was one portion, and the amount of time that I invested into building those relationships, dealing with the issues around that, for what I was going to get out of it, for what they were going to get out of it, I don't think it was worth it. I think it certainly was valuable in the sense that it built relationships [...], but at an individual level you spend so much time dealing with issues involved in incorporating community members and trying to manage from a distance, I mean it was, again, it wasn't the central theme of my thesis and eventually it became so time consuming that it wasn't worth continuing, to be honest.

Marlo noted that in his discipline researchers tended to work with government authorities in a particular function, which typically involved large amounts of quantitative data, so trying to take into account issues of social justice and gender equity simply was outside the scope of his graduate degree: "the idea of incorporating communities, interdisciplinary groups, multiple determinants, I honestly think doing that in a four to five year $\mathrm{PhD}$, if you're a student who hasn't worked in that specific area or location before, is basically impossible." Given the specific function of his academic discipline, applying the ecohealth approach would have meant going so far beyond the expected role of the researcher that it became unpractical. Marlo said: "I totally understand the value of having [community members] incorporated at every stage but there is something to be said about being trained for five years in something that's going to give you insight into an issue that 
someone who isn't trained won't have." Thus, Marlo found himself working more and more within official forms of expertise recognized by his department.

\section{Azim's case}

As a young professional engaged in development work in West and Central Africa, Azim was immediately drawn to the ideals behind the ecohealth approach, pointing out that for him the approach was not only relevant in a research context, but also in the context of his work on other development projects: "So without necessarily pronouncing it, 'here is the ecosystem approach', I still know that I must integrate such and such aspects and I know that they come from the ecosystem approach, so this truly helps me on a daily basis in my own work with the approach." Part of his job includes evaluating "whether the population is capable of managing a given system":

Thus, it is important to consult the beneficiaries, and not just the household heads but the youth, the elderly, the women and others, to have their opinions and then to organize them in relation to the problem. And you have to find the means of gathering these opinions, since in our African society, generally the man, the man as head of the household, he generally responds for the whole family. Yet, what he says does not reflect the whole truth, so we are obliged to go above and beyond to gather information in more depth.

Although inspired by the ideals of ecohealth, Azim also described some of the challenges

he faced in a specific project:

So it was important that I was able to meet the population so that I could speak to them about my project. So during the activities, I encountered... there were some hesitations. You see there have been so many projects taking place in this same zone, such that the community here believes that people are carrying out projects that hardly benefit them at all. So the people are hesitant and they reject all of a sudden my project. Therefore, I had to find a way so that they might accept the project, I had to find a way to explain the project and show how it could be useful. [...] Because it's as I said before, the population has seen a lot of projects here but there hasn't really been an outcome, there haven't really been any repercussions [...] it's projects that bring more projects, but the projects disappear from one day to the next. So what am I supposed to do now to captivate the population, what can I do so that the people might accept the project? 
The strategy that he found most effective rested on emphasizing the health side of the equation, "because above the environmental aspects, what really interested them was the

focus on their health." However, this raised other challenges, since "the subjects we were

discussing were sensitive," and gaining people's trust was imperative to obtaining the

required information for the study:

So it was important that they [the community leaders] were well informed about the project, and that we showed them the immediate interest that the populations could bring to it here. We also had to show them the ecosystem approach that we were applying. So once we convinced them, they became the spokespersons or at least people who could transmit with fidelity and passion the objectives of the project to the populations. Now, since they knew the populations better than we did, we were the project coordinators but they understood the populations better than us, so from time to time they also would tell us with respect to this issue or situation, they could indicate to us to approach it in this way instead of in that way. So they too contributed a good deal to the application of the ecosystems approach. They would say, 'instead of going about it that way, instead of saying it this way, we would advise you to do it like this'. But we, for reasons related to aspects of the approach, each time we tried not to deviate too much. In sum, they too, even the populations, contributed to what we were able to put into practice in terms of the approach, even without them being aware of it.

But the biggest challenge Azim faced was finding a direction that made sense to the whole research team:

Especially as coordinator, it is up to you to know how to find the common ground, the consensus, that is the difficulty. Each one will try to bring a solution that seems like the best one. Now, it's up to you to find the happy medium, a solution that can satisfy all of the members of your team. At a certain point, we no longer understand each other because we are speaking several languages. The sociologists and the engineers, for example, it's true that we can talk but the approaches are different, the language is different. So already there is this difficulty at the level of language that we have to surmount. And now at the level of the approaches, we have to try to consider, to discuss in a tolerant way. So this is where the difficulty lies. Another difficulty is the gender approach, which means that if the ecohealth approach wants to valorize the gender aspect, it is precisely because there are a certain number of groups that are quite marginalized, that are quite excluded. How then do we go about collecting their views? This is very important. So, with you in charge, you are the one responsible for the project, the head of the team, to define the means-because the ecohealth approach does not give you this. The ecohealth approach says that you must integrate the gender aspect but it doesn't tell you how to integrate it. It's up to you to define the ways and means to integrate it into your project, to be able to collect the views of those without a voice. There you have it, those are the difficulties, but with time, with experience with different situations and activities, you do finish by putting something in place, a strategy to be able to have the views of others, to be able to integrate the gender component. So it's a bit like that, the difficulty is that they give you the concepts, they give you an approach, but it's up to you to apply it-the teachers are no longer there to tell you this is how it should be done, it's up to you to define the methods, to define the ways that you can put it into practice in the field, and that is the real difficulty in all of this. But 
with hope and with time, you finish by putting something together, and you apply it, and there you go.

When I asked Azim where he turned for support when faced with such challenges, he

said:

Well, I must say that whether in the project I was telling you about or in my professional activities, I am never embarking completely alone, because with each activity there is always someone ahead of you, someone who frames the project or perhaps a mentor. In my project I worked with one of the course facilitators, who provided advice and guidance. In professional activities, you have ahead of you someone who is responsible within your company, someone with a certain amount of experience to whom you can refer to help figure out how to proceed in a given situation.

He also acknowledged the support of his peers, which consisted of an exchange of emails among those who came through the same training course and were also working on field projects.

When I asked Azim whether his understanding of the ecohealth approach had changed as a result of this project, he said:

Of course. When you receive new knowledge sometimes it is fairly evasive because you're still in the theoretical domain. But once you successfully apply it in the field, you develop mechanisms, you develop aptitudes that allow you to effectively appropriate the method. This means that you try to develop aptitudes that will facilitate people's acceptance and understanding-because you have aims to reach, and for you to reach them it's up to you to define the path that you must take. So when I applied the approach it allowed me to effectively see in what measure, how I could get it up and running in a practical sense in the field. And this experience was very enriching, such that even above and beyond this research, this purely scientific research, I now try to integrate the approach in more practical terms.

As for next steps, Azim was interested in pursuing graduate research, but for now he would continue working as a professional on the development projects available to him.

As Azim's case illustrates, graduate students and young professionals find themselves put in charge of projects in areas of high research traffic, where community members may have grown skeptical about the benefits of past research projects, and while belief in the ideal of community participation remains strong, the job in fact is to get the community to accept the project and to complete it on time. This entails negotiation between different 
levels of authority: community leaders, other community members, members of the research team and other authorities, such as the funder and the project supervisor. Certainly, the experts from the university (including the graduate students and young professionals trained in ecohealth) are playing a leadership role, yet there are bigger contexts and patterns that frame their actions in ways that make certain meanings of ecohealth possible while imposing certain constraints as well. As for the non-academic communities who, in theory, are supposed to be full participants in the process, the quality of their participation seems highly questionable, especially if participation entails some sense of ownership over the work. But if neither the experts nor the communities are completely in charge, who is?

There are subtle and profound tensions around the role of the researcher, between facilitating an exchange among stakeholders and maintaining authority over the research process. Gilles said:

The ecohealth approach gives me the possibility to put in place sustainable solutions, and sustainable solutions are those that can be put in place by the populations themselves, even if the study that I conducted is completed, the solutions that I have been able to identify, they have to be capable of staying there and being valorized by the communities, and more precisely through their participation. So for me this is a fundamental element that motivates me in my day-to-day when I try to actualize work or to conduct investigations all the while valorizing the ecohealth approach.

It is worth paying attention to the subtleties of this response. Initially, Gilles credits the ecohealth approach itself as providing the possibility of sustainable solutions, but he defines sustainable solutions as "those that can be put in place by the populations themselves." The value-added by the ecohealth approach is thus the identification of useful next steps in addressing a given problem, steps that communities in turn must take responsibility for implementing after the funding for the official ecohealth project is 
finished. Community participation thus holds a somewhat ambiguous place since efforts toward sustainable solutions remain framed as something made possible by the experts' approach, even though these efforts require that communities come on-board. While there certainly seems to be the potential for expertise to play a role in helping communities organize themselves, the current reality of projects seems far away from this ideal.

In balancing the immediate constraints of their situations with the broader goals of ecohealth, interviewees found themselves immersed in a set of pre-existing employeremployee relations, whereby their own roles were in part defined and evaluated by those with power over them. As Alicia was plainly told, despite her commitment to the aims of participatory research, it was not her job to help community members identify their own issues and begin their own inquiry process; instead her job was to publish another research article. Similarly, Azim's official job was to carry out the project as it had been conceived, even if the community was hesitant and even if the project was supposed to valorize the elements of the ecohealth approach—-to do otherwise could presumably have meant failure in his own eyes and in the eyes of those funding the project. As for Cecelia, having her own external funding may have allowed some additional wiggle-room to conduct the study as she saw fit. Yet, she too found herself having to adjust her own expectations about what she could realistically accomplish, so as to meet her degree requirements and supervisory committee's expectations. Cecelia, Alicia, and Azim have each attempted to apply the ecohealth approach in an actual community setting, but it is now possible to see that there are common themes cutting across their experiences, such that the issues they have encountered cannot be understood on a strictly case-by-case 
basis_-indeed, these issues are not isolated incidents or pure coincidences; rather they are systematically connected through an underlying context. In effect, it seems that in a particular case the "problem" may only show part of its total aspect, but when looking at interviewee experiences as a whole, it no longer makes sense to see the problem as a simple issue arising in the field; rather, issues encountered in fieldwork are intimately tied to the disciplinary frames of the university and, ultimately, the state.

For example, the "hesitations" that Azim encountered, the effect of regional trade agreements on agricultural communities that Cecelia noted, or the gap that Alicia sensed between addressing community priorities and answering disciplinary research questionsthese issues are connected through contexts and patterns that any meaningful international development research project must necessarily confront. Such issues are not contained within the projects but rather the projects ignite or make visible certain ongoing historical challenges. Focusing on the messiness of the context in which research happens may not be what supervisors want from graduate students or research assistants, who are generally contracted to carry out the grunt work needed to advance a specific part of disciplinary knowledge, yet ignoring the messy context can only lead to research results that are largely divorced from the places where social change actually happens. The issues that cut across all of the cases examined here were present before any of the specific projects were even conceived, but the projects become the way through which interviewees experiences those issues. As such, addressing these issues requires a two-pronged approach. One approach happens in the field in response to the issues as they are encountered, and this is the most common type of response. But while this approach is 
necessary, it has serious limitations since it is always reactive and usually means finding a way to carry out the project regardless of any other considerations. The other approach would entail a confrontation with the conditions that give rise to the issues before they are encountered in the field. Rather than taking the projects themselves as the basic terrain where social change can occur, now it is the institutional arrangements that frame the projects that must be acted upon.

This chapter concludes the presentation of the ethnographic data collected for this dissertation. I have shown how interviewee experiences raise critical questions about the extent to which participatory, transdisciplinary, and equitable approaches to research are able to live up to their names when organized through the current hierarchy of institutional frames, including those of the university, the state, and international development projects. In the process of moving from the university to the field, these frames do not vanish, but rather continue to shape the types of relations that researchers can develop with communities, raising questions about the role of expertise in international development. The next chapter offers a reflective synthesis of the lessons that can be gleaned from Chapters 2, 3, and 4. By looking at the ethnographic data as a whole, I begin to flesh out the role that graduate students and young professionals can play in collectively confronting the contexts in which they are working. 


\section{Chapter 5. Toward a Conclusion: Working Inside and Outside the Limits of Academic Development}

Having now finished presenting the experiences of graduate students and professionals trained in ecohealth and/or working on ecohealth research projects, this final chapter offers a combination of reflection and analysis to help bring out key lessons, opportunities, and ongoing challenges, as they relate to the production of ecological consciousness. The claims I make here are based on my interpretation of the data already presented; they remain tentative conclusions, since the story continues to emerge and change. Although I argue that the data fundamentally questions the general assumption that academic research and training serve the purposes of social change, I also offer some theoretical possibilities for how the pieces of experiences collected in this dissertation can contribute to a different future, one that corresponds more closely with the stated intentions of those working on ecohealth. Furthermore, I argue that the point of view of those in the middle not the principal investigators, donors, or community "recipients" of research, but the experts-in-the-making - offers a critical vantage point from which to understand both the context in which these efforts play out and the potential for transforming that context. It is the degree to which this potential is acted upon that determines the extent to which a more ecological consciousness can be produced. First I offer a synthesis of the insights from the previous chapters, emphasizing the need for a collective confrontation with the conditions of graduate training and research. Then, I explore the potentiality of peer relations as a means for graduate students and young professionals to engage each other in a collective transformation process. I finish with a summary of the implications for 
ecological consciousness and the relationship between training, research and social change.

On the whole, graduate student and young professional experiences reveal some of the institutional pressures that shape the type of researcher and the type of research produced through the university frame, creating a tension between self-directed production and the production of the self within established norms. This can be seen rather strikingly in Denise's case, following her calling to move out of traditional biomedicine into interdisciplinary and participatory approaches, but then finding she has to disguise herself more and more to compete in the "ferocious" world of academic grants and jobs. Some interviewees come into the process of graduate training and research to pursue certain aspirations that fit with the stated aims of ecohealth, but they soon encounter the disciplining character of the academic terrain. This certainly was Beatrice's experience, pulled toward conforming to the established disciplinary pathways, while wrestling with what it would mean to take science in new and innovative directions. Gilles, too, describes his relationship to ecohealth as allowing him to fulfill certain aspirations to work at the level of community health, yet he senses that he must ultimately find his place in more established centres of academic expertise.

While some of the lessons of ecohealth training may sound promising, attempts in applying them reveal obstacles that may not have been initially understood as having a structural dimension. Whether in Mitch's case, where initial excitement for ecohealth turned into a discovery about the general character of top-down authority built into the structure of academia, or in Lucia's pronouncement that in her experience this same top- 
down authority existed in both universities and ministries, those seeking paradigmatic change quickly discover that the main obstacle is not merely what sits in other people's minds, but also the structures in which those minds sit. In other words, there is a fundamental relationship between Olaitan's observation - that it is difficult to expect those unfamiliar with ecohealth to fall in-line with the demands of the approach - and Julian's interaction with the disciplinary personalities of his thesis committee: it is not so much that the principles of ecohealth are missing in other people's minds but rather that the dominant incentive structure prevents such principles from being systematically acted upon.

Caroline's and Marlo's experiences of ecohealth training suggest that students would benefit from more time and space within the course to work out what the principles of the approach mean in practice. As suggested by François' comment about the "grandiose" version of participation presented in the course versus the much more limited version implemented in the field, it is not so much that trainees need to be trained to value participation, but rather that they face practical constraints in implementing it within the given conditions of academic research and the local community context. Rather than being supported in a process of learning how to confront these conditions within the training process itself (learning-by-doing), there has been a tendency to uphold the image of participation without ever having sufficient room to experiment with its possibilities and limitations.

In seeking a place within the university's disciplinary frame, upholding certain values may not be sufficient for developing innovative approaches to research. A number of 
interviewees - Nancy, Jonathan, Denise, and Julian - described direct encounters with the authority of professors who seemed more invested in making young researchers fit within prescriptive channels rather than supporting innovations in mixed method approaches. While seeking to take research in new and meaningful directions, interviewees found themselves poised to climb the ranks of institutions that imposed increasingly strict (yet normalized/naturalized) limitations on the type of research and, therefore the type of researcher, produced. Confronted with two worlds - the ideal and the real - interviewees had to learn how to navigate the distance between them. On an individual level, strategies depended on interviewees' own position within the channels of graduate training and research: for example, at times, ecohealth could offer Janet a real network of people to bounce ideas off of in helpful ways, whereas at other times, the ideals of ecohealth might get squeezed out by disciplinary priorities and time demands that impose themselves. On an institutional level, results are also mixed: on the one hand, institutionalizing ecohealth might seem like a pathway to making it more real, as Lucia, Daniel, Gabriel, David, and François mentioned; on the other hand, if in the process of institutionalization the ideals become more in line with the existing norms of the university's disciplinary frame, then little has been gained, as comments by Felipe, Vincella, Daryl, and Nancy suggest. Thus, the relationship between the worlds of the ideal and the real can take on a number of different forms at different times. However, so long as those attempting to define ecohealth find themselves working on the established academic terrain, the meaning of ecohealth will remain chained to the norms and terms of success of that terrain. 
In moving from the university to projects in the field, a tension between specialization and discipline manifests itself on parallel levels. First, interviewees find themselves working within employer-employee relations that serve to keep the project in line with the framing imposed by a given discipline through the authority of the supervisor. Alicia's experience, for example, shows that rather than support the development of her own specialized knowledge in relation to the issues encountered in non-academic communities, the discipline (enforced through her supervisor) required her to make her work relevant to a pre-established theoretical framework and the context of her own career advancement as a researcher. In parallel to this, interviewees in charge of a given project sometimes found themselves having to discipline the research participants (including other specialists as well as community members) to fall in line in the research process operationalized under the given constraints and chain of command, as Azim's case illustrates. Here, interviewees find themselves playing a role perpetuating much of what they experienced in ecohealth training, where notions of participation and transdisciplinarity are promoted without sufficient room to develop their meaning in practice. This does not mean that attempts at transdisciplinary or participatory approaches do not carry significant successes. Abriana's commitment to starting from the realities of the people encountered in the field, Djibril's views on the need to transcend a singledisciplinary frame to see the whole system, and Cecelia's success in using ecohealth to push her own approach to scientific research in a more participatory direction, all show that despite the obstacles, interviewees are capable of victories that point to a bigger potential than what the current disciplinary authorities care to recognize or support. 
But this type of success also shows how the current design of knowledge production within the context of graduate training and research is already set up to work against the production of certain meaningful results. As Alain suggested, "the studies are done, but there is no way to use them." In his view, this was largely due to the modesty of researchers and their inadequate training in media relations. While this may be partially true, once again the challenge here is to understand the relationship between this problem in the minds of researchers and the incentive structures that prevent another type of work from being practiced. Although the problem on the surface may appear as simply a need to further promote the links between a healthy environment and a healthy population - as Carla pointed out - it is also necessary to take into account what Gilles said about how environmental questions and health questions evolve in separate spheres, with few obvious options for the public to force ministries of environment and health to talk to one another. Or, as I argued in Daniel's case, the problem presents itself initially as a question of tolerance, respect, and open-mindedness, when in fact these personal attributes depend a great deal on the disciplinary context fragmenting the process of knowledge production from the outset into different fields of prescribed turf.

Under the effect of this discipline, the meaning of specialization shifts from the development of expertise in relation to a particular issue, toward the re-enactment of a particular set of power relations within an established hierarchical structure. Whereas specialization emerges in relation to genuine problems faced by society that a particular group of people aims to understand and help tackle, discipline uses specialization as an extension of ongoing historical patterns of domination and subordination. While 
specialization naturally evolves with changes in the issues themselves (and the technological/scientific capacities to deal with them), discipline imposes its frame onto how problems can be understood and dealt with. Yet the two concepts are often conflated because they overlap within the university frame, where disciplinary authority is used to control what counts as specialization, and who can have access to it.

By virtue of their position within these relations, graduate students and young professionals come face-to-face with multiple manifestations of top-down authority, which become so normalized and ubiquitous that they appear totally natural. Yet, tensions remain: between aspirations to address real-world issues and the narrow measures of success imposed by disciplines; between the proliferation of "new" research approaches and their containment within standardized academic forms of community; between promoting a set of conceptual ideals versus the material basis that currently provides the support and employment for the proponents of those ideals; and between what graduate students and professionals have become accustomed to in terms of training versus genuinely new approaches that may be more rewarding in the long term. The question that must be asked is what happens to graduate students and young professionals subjected to these conditions over time? What happens to the issues that originally motivated part of the interest in discovering new approaches to graduate training and research, the longer these conditions persist?

What can be seen in the diversity of interviewee experiences is a general process of internalization, whereby the tensions embedded in the context of graduate training and research become accepted as part of the normal development of consciousness. There is 
little room for discussing these tensions within the formal channels of graduate training and research, leaving interviewees to deal with them largely on an individual basis, where the incentive structures push toward conformity with the status quo. Some form of internalization is an inevitable part of interviewee encounters with the real, concrete world that presents itself to them in the form university departments and programs whereby students compete with each other to see who fits better within the established measures of success. What success means is taken for granted as moving through the existing structures as quickly and efficiently as possible, which ultimately boils down to getting the job done as it has been prescribed. Yet, as the experience of interviewees documented here demonstrates, this process of internalization is by no means linear, direct or without contradiction. On the contrary, interviewees are engaged in a constant struggle to define themselves and their work on terms that are meaningful to them, despite having to fit themselves into the institutional design of a world that has already been setup.

Institutions by definition tend to outlive those who must work through their arrangements. On the one hand, this can be a tremendous help for building upon past efforts without having to start from scratch; on the other hand, it can pose a huge challenge if the dominant institutional order is part of what allows problems to persist or develop in the first place. For example, by creating "new" training and research programs, it may appear that issues of ecological sustainability and human health are now being dealt with by the appropriate authorities, yet the dominant order remains in place, largely unchanged, and perhaps even strengthened by the addition of a new legitimacy that the 
labels of this training and research promote. In this way, institutionalizing a new label may only ensure that hegemonic patterns can reproduce themselves while making the whole situation appear so natural that it is seemingly inevitable-yet the outcomes are so frustrating because of the inevitable mismatch between titles and actions.

For those attempting to move through the established institutional channels under these new labels, attention is immediately turned away from the initial problem (e.g. ecological sustainability and human health), as a new problem becomes more immediate, which is the problem of playing by the institution's established rules to rise through its ranks (or even to just keep your job). Those committed to participation, transdisciplinarity, and social/gender equity find themselves working within institutional patterns and contexts that reinforce the exact opposite. In concrete terms, the job of graduate students and young professionals quickly shifts from addressing real problems in the world to (primarily) producing dissertations, journal articles, funding proposals, and reports—and while some of this work will have a meaningful impact, most of the energy initially intended to make research meaningful becomes absorbed in the normal activities supporting the prevailing institutional context. At some level, there are successful cases in which the original thrust of the attempt manages to shift the institutional priorities to better address the issues - this is certainly what many people using the ecohealth approach are trying to do. But right from the beginning, there is a struggle between the extent to which those institutions are becoming part of the solution and the extent to which they are neutralizing attempts at change. 
Issues arise in the world in relation to the organization of the world-this organization and the arising issues cannot be adequately understood as separate phenomena. Yet, this is exactly how the issues are experienced: as isolated occurrences by an individual or a particular group of people. And this is exactly how the issues are treated by the institutional authorities: as isolated incidents that have little bearing on the normal process of work. In between the issues and the established authorities there are the mediators. Pulled between a genuine interest in helping address the problems and their own security within the existing institutional structures, these mediators are trying to find a role for themselves in a world where the pre-defined roles cannot address the problems, yet these roles present themselves as the channels of leadership and success. Interviewee experiences help expose the production process of the institution in which their experiences are subsumed, since they make up the "raw material" of training and professionalization. Along with realizing their wider aspirations, interviewees are also interested in validating themselves within the channels of academic and professional certification and employment, which means that graduate students and young professionals - much like any group subjected to top-down authority - are expected to submit themselves to the dominant terms of success and adopt them as their own, thus imposing on their ability to become subjects of their own knowledge.

What the example of ecohealth training and research points toward is the genuine interest in a more integrated, less fragmentary approach to science—-but how to sustain this interest without becoming usurped into the same material base that supports current norms and practices? The question has a double meaning. In one sense, the position of 
graduate students and young professionals is constituted by their graduate and professional training, with the purpose of producing a particular type of specialist within the existing material base; therefore, without this base it becomes impossible to sustain ecohealth training and research. In another sense, however, interviewee aspirations go beyond simply adding ecohealth to the university curriculum, toward changing the role of research in the world; here the problem in the question can be taken at face value since it really is about sustaining an interest that not only goes beyond the current material base, but also demands replacing that base with something else.

Although it might appear that all that is missing is greater resources, reputation, and the establishment of ecohealth as its own field, the more ecohealth becomes institutionalized into existing university and government structures, the more it acquires exactly the same features of those structures-some of the very norms it initially sought to define itself against. And, while an ecohealth department within the university would make the approach feel more real to those with access to it, nothing much else would change except that the aims of the approach would become further contained within the dominant order of knowledge production. One thing is for certain: the full-range of interviewee aspirations can never be completely fulfilled within the norms of the current design of academic research or professional practice. Thus, while born out of needs arising in the world as it currently exists, the development of the full range of aspirations associated with ecohealth depends on the realization of another world, a world that is presumably possible but that is far from being able to exist under the current conditions, 
which provide the administrative base for activities and employment. The only way to realize these aspirations is to transform the context itself.

\section{Navigation and Transformation: Confronting the backdrop of employment relations}

In theory, the difference between navigation and transformation is that the former leaves the situation's basic structure intact whereas the latter implies a more fundamental change. In practice, navigation can be part of transformation, but as Rosa Luxemberg (1900) argued in relation to party politics, meaningful reform requires a view toward the possibility of total revolution. In the context of this dissertation, the challenge and value of these two terms rests in how they might help bring interviewee insights together in a single comprehensive strategy for consciously directing change. Interviewees have tried to use ecohealth to open space for research outside the narrow limits imposed by their own disciplinary departments; however this strategy had at least two downfalls. First, it was still necessary to fit into what the dominant mode of knowledge production viewed as successful, so the more interviewees used ecohealth to move in the direction of a radically different approach to research, the more they would find themselves at odds with the norms of their own departments and disciplines. Secondly, and conversely, the more interviewees could make ecohealth compatible with the dominant mode of knowledge production, the more they felt short-changed on achieving the wider aspirations that approaches like ecohealth promised.

Everyone I spoke to was working within an institutional context with employeremployee relations. But while these relations inevitably came up, they tended to arise as a 
backdrop, not as the main object of discussion. Why might this be so? Most people come to universities and professional careers with certain goals pertaining to desired accomplishments, yet they do not necessarily take the reorganization of the institution itself as part of their concern. This disconnect between work and its institutional context is part of how discipline works: it teaches its disciples to submit themselves to making their efforts relevant to its perpetuity without democratically organizing themselves to steer the direction. Rather than being based on the full self-directive capacity of the group, the "right" direction becomes fragmented into the pursuit of individualized success within the established order. Any "collective" decision making tends to be done by a small group of more senior people whose job in essence is to discipline the rest of the workforce to fit within what they believe will be a competitive business plan.

At first this disconnect may not appear as too much of an obstacle to accomplishing personal goals. While the established administrative structure may impose certain constraints, these are often spontaneously accepted as simply par for the course, part of what each individual is expected to deal with alone. But upon analyzing a wider breadth of experiences it becomes clear that no individual effort could ever lift such constraints and, therefore, any individual definition of "success" must ultimately learn to accept these constraints even if they compromise the aspirations that originally inspired the work. In the end, the original premise that personal goals can be divorced from the institutional context of work turns out to be false, and it starts to become clear that simply following the program set up is the biggest obstacle to realizing a more participatory, transdisciplinary and equitable approach to research. 
One of the assumptions that currently underpins the institutionalization of the ecohealth approach is that its adoption by universities and governments is the first step to its proper application. How will this happen? Universities present themselves as society's institutions for education and training, and as such they equip students with certain capacities and competencies. Instead of churning out graduates who know nothing about ecohealth, all of a sudden these institutions would start processing and producing ecohealth graduates_-as if what was really missing all this time was the value-added by the ecohealth approach. In the case of government ministries, the idea is similar: the first step is to get ecohealth into official state policy and from there it will spread to the populations at large. In both scenarios, the emphasis is on equipping the official institutions with the ecohealth approach, so that the subjects (people and topics) of those institutions get what they supposedly were lacking. But neither scenario offers a way of understanding why "ecohealth" has been missing all this time. Furthermore, in adding the ecohealth approach now, the core problem remains, since whether through training or policy, ecohealth becomes something done to the population from the top-down. Another assumption that goes along with this top-down approach is that the reason ecohealth is not currently practiced is that people are not familiar enough or committed to the approach. Without the bottom-up element driving the whole process, training and policy continue to model the idea that institutional leaders already have the answers, whereas students and the rest of the population are simply there to absorb or respect this authority. In short, education becomes about putting you in the right place (giving you the right 
concepts, the right credentials, the right contacts) rather than supporting the development of your capacity to transform yourself through transforming the context of your work.

Despite all the good will behind the pillars of the approach, the end product winds up being a watered down version of the original hopes and dreams because of the obstacles imposed by current norms and structures at every step along the way. But rather than condemn the approach to failure or, conversely, pretend that the application has been totally successful, what seems most useful is to begin working on the obstacles that currently get in the way of a better application. The wider political economic conditions that shape state policy and North-South relations, the lack of coordination between projects in areas of high research traffic, and the disciplinary norms that continue to pervade how group processes unfold stand out in interviewee experiences as key obstacles to realizing some of the fundamental aspirations associated with ecohealth. Although these obstacles may appear to exist in separation from each other, they remain connected within one world in on-going historical development (see Wolf 1982). By better understanding how the current institutional arrangements at once make a certain kind of research possible while at the same time imposing significant constraints on what projects can actually look like, it becomes possible to see how new institutional arrangements are needed to advance how ecohealth happens in practice.

What hopes do graduate students and young professionals have of practicing a genuinely participatory approach given their own position within the authority of wider disciplinary relations? The first step is to create space where graduate students and young professionals can become subjects of their own knowledge-where they can begin to 
question the setup of the context itself, without feeling as much pressure to conform to its already internalized assumptions. In essence, there is a need to question the constraints within which the ecology of knowledge is currently contained, and who is better positioned to lead this questioning other than the graduate students and young professionals subjected to said constraints? At this point willpower, dedication, and resources do become key factors in confronting the disciplinary authorities, which otherwise direct all energies away from such self-organizing efforts, towards conformity and reproduction of the status quo. But more importantly, it is alliances between different ways of knowing against top-down authority that can move the institutional parameters within which everyone is expected to operate-and this is why ecological consciousness matters. Graduate students and young professionals may be able to change the institutional constraints to which their work is subjected by mobilizing as a group and confronting the structures of authority that enforce the terms of work-in other words it would mean bringing a participatory approach to the institutions of research and training themselves, and ultimately democratizing the structure of the state. ${ }^{12}$

One implication for graduate students and young professionals involved with the communities of practice is that collectively acting upon the administrative structure that organizes the communities is probably the most direct path to realizing the ideals

\footnotetext{
12 Of course, at some level, the institutional context will always be something larger than what can be meaningfully controlled, and therefore there will always be a need to negotiate within imposed constraints. But the more steering capacity exercised by workers, the more the form of action will feel rewarding, whereas simply accepting a prescribed role as if this were the only option (or the most politically neutral option) only guarantees a widening disconnect between ideals and actions. Thus meeting personal objectives starts with becoming involved in the reorganization of the institutional context of work. But this kind of active role in institutional reorganization is not the lesson that institutions systematically teach. On the contrary, the lesson systematically taught is that of the obedient and disciplined worker, making anything else seem to be about trouble-making or failing to play by the rules.
} 
associated with ecohealth. Interviewee experiences suggest a mixed bag of results in terms of how to confront this challenge. While the interactions between members of the community of practice are generally supportive and offer a kind of comfort zone compared to most university departments or other employment settings, graduate students and young professionals—-not to mention the non-academic and non-professional communities_-remain largely excluded from the core decision making and organizational work of the communities, though there may be ways of challenging this through bringing those trained in ecohealth together to pool their insights and make recommended changes. Furthermore, while the CoPEHs transcend nation-state boundaries to include entire regions and while such networks may represent new forms of organizing, they also remain tied to universities within a global nation-state framework. The advantage of this is that the CoPEHs can begin to map the existing global state infrastructure and develop networks that mirror that infrastructure, perhaps forcing it to be more accountable to concerns about health and the environment. A potential weakness, however, is a tendency to legitimize and even mimic the nation-state form and its disciplining authority. In general, I believe the former advantage is much better understood than the latter disadvantage, even if the feelings expressed by interviewees suggest that at the affective level, interviewees know that the CoPEHs do not yet fulfill their longing for meaningful social change. 


\section{The ambiguous potential of peer relations}

The unique character of peer relations is that, although they take place within certain power-relations, peers encounter each other on a more even playing field compared to, say, a student and a supervisor whose roles are already positioned at different places within an established hierarchy. In essence, as peers it is up to students to define for themselves what kinds of support they can provide each other, whereas the institution formally prescribes to a much greater extent the supervisor-student relationship. This kind of open-ended possibility built into peer relations creates some intriguing options.

One option is to work out how peer relations might support individuals' abilities to better meet the institutional requirements to which they are collectively subjected. In this case, formal institutional supports and informal peer networks can work together toward fulfilling mutual interests. For example, with respect to the isolation that many interviewees experienced, peer networks seemed to play a fundamental role in providing support to continue working on the formal requirements of their degrees. Peers often play a role in keeping each other informed about upcoming deadlines, program requirements, job opportunities, and administrative loop-holes—in essence, by sharing their experiences peers can learn all kinds of useful information about how to better navigate the existing institutional channels and in this way peer relations can help prevent individual students from falling through the cracks, thereby heightening institutional success.

Another option, however, is to use this same information as grounds for questioning and redesigning the institutional channels, which in many cases have been operating the same way for years and years. By virtue of having to move through these channels from 
the bottom up, students' understanding of how they actually work may in fact surpass in some areas the understanding of those administering them. When this happens, more options open up. For example, now there is the possibility for students and administrators to work together in improving the existing channels, in which case formal and informal supports can continue to play a mutually supportive role. If, however, the administration is not interested in listening to student experiences, students can seek other means of pressuring for change, for example, by comparing practices at different institutions and making a case for why their own institution ought to keep up with certain trends. Or, students might decide to withhold paying their tuition until the administration agrees to make certain changes.

Moreover, peer relations can actually play a fundamental role in making participatory processes possible. By virtue of occupying a similar position within a wider set of power-relations, peers experience the world on more or less equal footing, which means that peer experiences are in a precise sense comparable. Each one's experience actually adds to a more complete understanding of the world as a whole, which means that if peers were to share their experiences with each other, their own understandings of the world would be augmented in a cumulative way. The reason for this is that the subjective experiences of peers take on an objective quality in relation to the world. Thus different experiences can be added together to produce a greater understanding of the whole context, a more complete picture of the objective circumstances in which those different experiences are produced. This quality of peer relations lends itself to a meaningful participatory process in the sense that peers can genuinely learn from each 
other real knowledge about the world as it exists, knowledge that can actually serve to transform the conditions of the world, should peers find a way of leveraging it.

Of course, peer relations also take place within the context of wider influences, norms, imagined communities, and competition within imposed measures of success. But the unique advantage of peer relations over employer-employee relations is that peers can establish their own rules to meet their own needs, whereas employer-employee relations are predefined through pay and the hierarchical structure of employment. While it is certainly possible for peers to ignore each other, to be so busy that making time for each other just seems like an additional burden, or to view each other strictly as competitors for limited resources, this possibility is also largely in their own hands and it is up to them to decide what to do with it. What would it mean to help each other in this context? Peers are put in charge of this question almost naturally since no one else can really answer it for them; it is up to them to figure out the potential of their own relationship, and this potential can be applied to both navigation and transformation. Thus, peer-relations contain a wide range of options, and what is to be gained or lost through these relationships is entirely up for grabs.

Mediation is a role that graduate students and young professionals are set up to play, since they find themselves pulled between established institutional success and the wider successes required to actually make a difference in the world. As peers or near-peers, graduate students and young professionals have the opportunity to turn and face each other as part of their navigation through the terms dictated by graduate and professional training. While they are on the path to becoming institutionalized, graduate students and 
young professionals have not yet become entirely absorbed into the institutional channels. By building on their own collective knowledge they can both confront the university's administration with certain demands as well as lend their support to wider social movements, thereby pressuring the university to stay true to its claim of valuing the graduate student experience, supporting democracy, and making a positive impact on society.

But the extent to which the ecohealth approach actually supports the mediating role that peer relations can play within the struggle against conforming to the dominant model of knowledge production remains questionable. Despite significant successes on many fronts, the official version of ecohealth continues to promote itself as a newly emerging academic field seeking to institutionalize itself within university curriculum and government policy. Most interviewees did not see themselves playing a direct role in leading this process, unless being paid as an employee of one of the communities of practice. It may be that ecohealth training is currently set up to legitimize the reputation of ecohealth much more than to build capacity to confront the constraints built into the norms of academic or professional work. This does not mean that there have not been efforts on the part of graduate students and young professionals to take ownership and redirect the approach themselves. On the contrary, most of the interviewees had initiated attempts to organize meetings, presentations, events, gatherings, etc. But these efforts have not been systematically supported from the top or in some cases they have been designed more to legitimize the approach than to respond to actual needs of those at the bottom. 
Alternatively, by supporting informal peer networks the ecohealth approach could move much further toward building people's capacity to name the official program in their own terms, based on their own experiences with it. There is a yearning for this work, but also much confusion: is the ecohealth approach a new discipline or just a platform for exchanging ideas? Do you have to be trained in the approach to be able to practice it? Are academic or non-academic communities in charge? Compared to more traditional scientific approaches, is the ecohealth approach too different (thereby making it unpractical and unfeasible) or is it too much alike (thereby not really changing anything)? Rather than try to find the right answer in theory, it would be more practical to develop an answer in practice through the work of peer networks. ${ }^{13}$ Peers can help each other survive and navigate the existing system, for example, through discussion, providing feedback on each other's work, sharing conceptual insights, forming study groups, sharing knowledge of study places and upcoming events, establishing study schedules, etc., and through this work peers discover broader contextual insights and strategies for leveraging change within dominant group processes. Following the processes of the established order will not lead to fundamental change (at least not in the short-term), so the real challenge is working out a new process, a new method for working together. What is at stake is not just the research results, as typically defined, but also the production of the researcher. The question is whether there is a common position that would take into account the range of interviewee experiences, while still leading to the possibility for a fuller

\footnotetext{
${ }^{13}$ I have been fortunate to have had the opportunity to explore this work with two groups of transdisciplinary graduate students and professionals, see Feagan (2014) for a description of the process and discussion of what has been learned.
} 
realization of collective aspirations in terms of ecohealth? In other words, what would it look like to struggle against the current institutional conditions for a better realization of collective aspirations?

Over time graduate students and young professionals are drawn into disciplining tendencies even as they push back against them, as ideals cannot continue to be divorced from the material context of work. But if workspaces inhibit the realization of certain ideals, then it is the workplaces that must be re-appropriated and transformed by democratizing the employer-employee relations that define them. Only institutions based on democratic collective steering capacity will be able to support the type of work-and the type of people-that workers aspire toward. Knowledge production, self-production, and the context of work are interdependent, even though they may appear completely isolated one from the other: by collectivizing experiences the underlying themes that structure them become visible. Suddenly, the same conditions that produced isolated individual competition can begin to push students into deeper peer relations, as students become fed up with decisions made by the top administrators, which tend to limit the role of students to that of consumers of a product in a pre-ordered world. No matter how much institutions discourage peer interactions (whether intentionally or unintentionally), there always remain cracks in the institutional structure where peer relations can form, and once groups begin to form around common interests and issues they can create important ways of pressuring the institution to be more accountable to something other than its own reproduction. 
The challenge for peer relations is to mediate between the formal institutional supports and the actual lived experiences of those relying on them, with the aim of making the former relevant to the latter. Without maximizing this mediating role, education remains something that is imposed on students, rather than something that students can do to themselves. This is why peer relations hold important lessons: they teach how to practice autonomy. But there will always be a tension between living up to existing measures of success and transforming them. The more this tension is confronted collectively, the better the chances of actually transforming the present conditions (rather than simply navigating through them and internalizing them as inevitable facts, thereby mystifying their true nature as products of specific social processes, over which there is a struggle for control).

It is through these complex interactions between formal and informal supports that interviewees experience the central tension that I am exploring in this thesis: between how we produce ourselves and how we are produced through existing channels. Although elements within ecohealth communities of practice push back against certain parts of the dominant educational training model (for example, by using a team-based approach as well as certain activities that encourage strong peer relations), the overall frame continues to take for granted many academic norms that in turn pose significant constraints on the core aspirations associated with ecohealth.

The approach thus far has been to fund and train young researchers to try and do research differently, in line with the pillars of ecohealth. But while the direction of this model offers certain opportunities, it will never be enough in and of itself, since its 
relevance remains controlled by the current terms of academic success. On paper, the idea of a community of practice based on the principles of ecohealth may sound like exactly what is needed, but in practice disciplinary norms do not go away by themselves-rather they continue to dictate who is in charge and push toward their own established measures of success, which according to the business of field-building means organizing funding, publications, conferences, etc. As a result, part of the intended aim of the CoPEHs is quickly hijacked by processes already in-place for justifying academic work. Rather than an open-ended community, the CoPEHs become largely inaccessible groups (except through the channels of graduate training and research) working toward ever more standardized language, norms, etc. to fit with the institutional aims of whomever is providing the funding for the approach. Rather than expanding through the transformations that other knowledges demand of them, the communities impose more and more constraints on who is a "member" and what members of the CoPEHs can say, write, do, etc.

While there is potential for transformation, it can remain locked within isolation, competition, and the terrifying comfort of the status quo-and while individualized approaches to navigating existing norms can lead to some individual successes, no widerscale transformation of the conditions is possible without a collective effort that connects issues within the channels of graduate and professional training to broader issues that transcend well beyond the walls of the university. Balancing a tension between navigating the existing norms and working toward their transformation involves learning how to work 
on fundamentally contradictory terrain—and graduate students and professionals are uniquely positioned to play this mediating role.

Young researchers face the odd situation whereby knowledge is being shut down and made to fit within the dominant order and, on top of this, the present order that dominates pretends that this is normal. By establishing such absurd conditions of "normal" life and work, this order teaches graduate students and professionals to ignore what they already know, to ignore themselves for the sake of fitting into something that they do not even entirely agree with in the first place. By naming this situation, it becomes possible to develop strategies for fitting in and sticking out all at once, to show that the whole apparatus propping up this absurd normality is not the reality that must be perpetuated and, instead of bowing in submission, it is possible to organize a response from within the workplace that supports the goals of social movements outside. By connecting internal and external struggles, a new reality can be produced, one that supports the development of a wider diversity of ways of knowing. In effect, I have come to believe that the apparent background status of employment relations and the shutting down of different ways of knowing (in part by their inclusion as slogans in the dominant order) are deeply intertwined phenomena — and the pursuit of a more ecological consciousness is therefore necessary as a way of transforming this context. In bringing together the experiences of interviewees it starts to become clear that despite the apparent background status of the employer-employee relations, these relations systematically weigh down on just about every aspect of interviewees' experiences. These relations can no longer remain relegated to a taken-for-granted backdrop—just furniture in the room. On the contrary, they must be 
named directly and brought from the corner of peripheral vision into the centre of the gaze. Without this focus, it becomes difficult to address interviewees' frustration about the gap between talking about different kinds of expertise working together versus actually following a group process built from the contributions of all participants. But if the dominant channels could be appropriated by those moving through them, and turned into something that better meets their needs, then the position of graduate students and professionals would reveal a tremendous transformative potential.

At times, interviewees believed that they could continue being the kind of researcher that they wanted to be, even if the established norms were pushing them to be someone else; at other times, interviewees felt that the current conditions severely limited the types of roles they might play. Many interviewees talked about experiencing considerable isolation, hoping that ecohealth would provide them a network of support. Although many interviewees had developed strong peer relations alongside the formal institutional supports, their struggles to realize their aspirations still remained largely within the frame of an individual or personal pursuit of a successful career. These experiences cannot be adequately understood on an individual, case-by-case basis, since they emerge in relation to the underlying structures in which interviewee experiences are embedded. Isolation can make the various departments, disciplines, and divisions of work seem completely separated one from the other, when in fact all of them are structured by the same (increasingly) anti-democratic employer-employee relations. The separations between the disciplines and the closed-mindedness that this breeds must be addressed together, otherwise we fall victim to the trope that the problem is in the people themselves, as they 
appear "naturally" closed-minded. Even the ecohealth approach, when it takes on a disciplinary form, pushes its promoters toward this trope, as suddenly all those outside of the approach become seen as the problem, and the task turns into convincing them to adopt the approach.

But the barriers imposed by isolation can only be turned into an opportunity if spaces can be made for sharing different experiences. This has been one of the biggest successes of the current organization of the ecohealth communities of practice: they provide space that is sufficiently different from the confines of normal, everyday disciplinary and professional work. In such shared spaces the limitations of individual work experiences suddenly have the opportunity to become the missing puzzle pieces for a more complete understanding of the underlying structures that at once connect and separate our collective experiences. Once it is seen that the conditions of isolation are not accidental but rather by design, attention can be directed to the disciplinary structures that produce and necessitate such fragmented experiences for the maintenance of their own authority. The challenge, therefore, is to develop a form of expertise that is not based upon disciplinary authority. It would have to be an expertise developed by the people themselves, though it could and should draw on available specialized knowledge. It would have to be an expertise developed in relation to an actual problem that the people themselves face, though that problem may be connected to wider scales and situations that go well beyond the peoples' experiences. It would have to be an expertise based on a different group process from the one that is currently producing the problem, otherwise no meaningful change could be expected. Removing disciplinary authority from the 
ecohealth approach is the first step to a more complete realization of the ideals of ecohealth. Disciplinary experts can play a role, but they cannot be the ones in charge of the process because they themselves are not in charge of the discipline-the discipline is in charge of them.

While a deeper level of politicization is necessary to realize certain aspirations associated with ecohealth, the process of politicization cannot come from above, though people at all levels of hierarchy can support its development; it can only emerge through a struggle in line with those at the bottom. The position of graduate students and young professionals occupies an in-between location, with the world's established order on one side and wider aspirations more closely aligned with non-academic communities on the

other. Some interviewees may find themselves even more committed to a larger vision of change, as they experience the contrast between what is expected of them as researchers and the actual complexity of real-world issues that must be confronted. Others may come to realize that they will be more "successful" staying within the dominant norms of knowledge production. In either case, adequate room for discussing the range and complexity of different experiences remains hampered by the reality of the present conditions. The risk is that discussion is in fact shut down and confronting the complexity of real-world issues never happens.

\section{General Implications for Ecological Consciousness, Graduate Training and Research}

1) The position of young researchers characterized by interviewees in this dissertation reveals a tension within the production of consciousness that pulls between self-directed 
development and conformity to the demands that existing structural incentives make on thought and action. This tension cannot be addressed solely by attempting to stick to one's own values and beliefs without changing the context in which thought and action occurs, since over time a certain congruence (though not without contradictions) will re-establish itself between ideas in the mind and the shape of the surrounding world. Within the context of those seeking meaningful careers through graduate training and research, the implication is that the current organization of the training and research process should not only be scrutinized by those subjected it, it requires their actions guided by their own mobilized knowledge to steer it in more productive directions, i.e. directions that better support the development of trainees' experience addressing pressing issues. At this level of trainee experiences, ecological consciousness means collectivizing the diversity of knowledge that graduate students and young professionals carry with them to open up and deepen the training and research process. An ecological consciousness approach thus turns the normal graduate training model on its head by using the tension between existing trainee knowledge and existing training content to push the whole training process somewhere new. Rather than pass along a fixed set of answers or preset specialized awareness, the training becomes about the ongoing development of the trainees' own knowledge and ability to act on that knowledge collectively.

2) Without recognizing and supporting this collective developmental process within the trainees themselves, ecological consciousness becomes reduced to the individual insights transmitted by those in positions of authority, but this deformed version of ecological consciousness generally serves (a) to further the illusion that the problem linking 
ecological sustainability and human health arose solely out of a general lack of individual people's understanding of the connections between health and the environment and (b) to naturalize the authority of the existing training process, which assumes itself to be the most appropriate "answer" to the "problem." The naturalized message within the training process is to assume that those who have not undergone the training cannot lay claim to the specific outputs that that training offers. Thus the "problem" is multiplied by the number of people who cannot (officially) lay claim to this expertise and, at the same time, the solution becomes the expansion of the training process, that is, its institutionalization within existing channels of authority. By framing the problem largely in terms of a lack of specialized training, this form of institutionalization reinforces the authority built into existing institutional hierarchies while ensuring that the problem will persist, since graduate training and research is by definition only accessible to a tiny group of the "top" specialized experts.

3) Containing consciousness within a standardized approach governed by existing authorities leads to a dehumanizing and distorted version of ecological consciousness. A more genuinely useful version of ecological consciousness would harness the possibilities opened up by different ways of knowing, thus supporting a process of transversal thinking and action that cuts across the existing structural organization of society and allows new forms of self-organized communities to emerge. In theory, peer-to-peer relations hold the promise of opening space for new self-organizational capacities that put graduate students and young professionals in charge of steering their own futures. This potential, however, needs to be developed in practice. 
More generally, the argument advanced in this dissertation lends support to two broad hypotheses about why, so far, efforts have not changed the overall path of the global ecological crisis and how young researchers might intervene more successfully. First, throughout much of the scholarly work examining the link between consciousness, educational training, and the global ecological crisis, there has been a tendency to posit consciousness as a kind root cause of the crisis, and I argue that this tendency distorts our understanding of the actual process through which consciousness develops in relation to existing hierarchies and social relations. In turn, the response has been to advocate for the "right" type of consciousness resting on so-called ecological values, principles, and forms of awareness, as if once enough people were trained with this specific consciousness, problems of ecological sustainability and human health would magically be fixed. However, this tendency seems to have led to the present situation whereby there is more emphasis than ever on valuing the environment—and now corporations, governments, universities, and people in general say they do value the environment-yet the rate of ecological destruction on the whole continues to increase. My main claim regarding this first point is that an over-emphasis on consciousness as resting on the right values assumes a kind a-historical base for human action and awareness, which ignores the fact that consciousness is co-produced with the world as it is currently designed. The "problem" of consciousness does not originate in consciousness itself, but rather in the process of its production. Rather than seeing people's consciousness as the problem (even if it surely is part of the problem—and solution), the real challenge is working out how consciousness 
came to be produced in a particular way, and this necessarily has to do with changing the structure of experience. If, however, the focus remains only on consciousness as an isolated thing in the mind, then the tendency to ignore the structural dimension of experience also remains intact, and with the passage of time the structures continue to reshape consciousness to fit into their unchanged form. A more useful approach would be to support consciousness' capacity to intervene in the context of its own production - to change the design of the world - rather than continue to reinforce the idea that respecting existing authority will lead to improvement.

Secondly, while young researchers have a critical role to play, this role is not exactly the one presented to them, which remains contained within the same general social organization co-produced with the global ecological crisis itself and which, therefore, cannot serve to transform it in any fundamental way. In essence, those looking to play a leadership role must question the measures of success that define today's leaders, so that new types of leadership can emerge. While achieving positions of leadership within dominant institutions can be turned into useful leverage points, the category of "leadership" cannot be limited from the outset to such positions, which are themselves built upon the history of domination and subordination that characterizes the world's current social order. Leaders are not necessarily chief executive officers, directors, or presidents; rather they are people who support the range of other people's needs around them. Instead of finding a place within today's recognized canons of expertise, tomorrow's leaders can fulfill their aspirations much more completely by transforming the canons of expertise themselves, for example, by mobilizing a wider range of ways of knowing than 
what is typically recognized within the dominant institutions of knowledge production. My main claim regarding this second point is that improvements in the global ecological crisis will only take place when the full range of human ways of knowing are in charge of developing their own formal and informal institutional supports. The struggle for ecological consciousness cannot be contained wholly within existing canons of expertise, nor should these canons be entirely dismissed, as this would mean abandoning the institutional capacity distributed therein. Trainees thus have a critical role to play in getting to know each other, collectivizing their own knowledge, and using it to influence the training process itself. Young researchers have a responsibility toward the conditions of their own production, as such conditions shape who they can be and what they can do. If they do not claim this responsibility, then an increasingly larger part of their work will cease to be truly their own.

In so far as ecohealth training and research has - at a minimum - opened a space in which a layer of graduate students and young professionals can encounter each other partially outside the disciplinary norms of their departments and programs and begin to analyze what it might mean to confront health and sustainability issues as real-world problems embedded within real-world contexts, a new potential has been created, and this approach to research and training should continue to offer a basis for further analysis, discussion, and capacity building. Perhaps the most significant results of ecohealth training and research have yet to be experienced, as they depend upon the agency of actors to pick up the pieces of their experiences and decide what to make of them collectively. The promises of ecohealth will never be met if this is seen as someone else's 
job, but if a new generation can take up in small working groups a process that models what the group believes ecohealth means, then it becomes possible to transform the context of the group.

The ecological consciousness framing that I am proposing in this dissertation may be useful in helping to pick up the different pieces of people's experiences and connect them to a larger struggle against a mode of production that effectively seeks to make all forms of consciousness conform to the logic of a single production process. Theoretically, this cannot happen within a single discipline, therefore, I have brought together works that draw on a range of different ways of knowing, including Indigenous, systems, and historical materialist traditions. Rather than a single or final solution, ecological consciousness lives in processes that support self-direction, self-discovery, and the development of autonomous capacity on a collective level. It is only by gaining control over the production process that we can ultimately change ourselves as, in part, its products and, in part, its producers. The solution begins with naming the problem, and to name the problem is to work on it collectively, and to work on it collectively does not mean involving all of the stakeholders, rather it means that those faced with the problem must fight back using as many allies as possible, and fighting back means constructing a new material base that supports human autonomy in its diverse expressions: because there is no better way to know ourselves than to produce ourselves and this production cannot take place until the means of production are in the control of the people. For this to happen, general patterns like the ones I have uncovered in this dissertation need to be named and worked on. 


\section{Appendix 1}

This list of participants is organized by the community of practice where ecohealth training occurred (names have been replaced with pseudonyms to protect confidentiality).

\begin{tabular}{|l|l|l|}
\hline \multicolumn{1}{|c|}{ Canada } & West \& Central Africa & \multicolumn{1}{c|}{ Central America } \\
\hline Janet & François & Daniel \\
\hline Daryl & Abriana & Felipe \\
\hline Marlo & Gilles & Gabriel \\
\hline Caroline & Olaitan & Cecelia \\
\hline Mitch & Alain & David \\
\hline Denise & Djibril & Lucia \\
\hline Alicia & Azim & Carla \\
\hline Jonathan & & \\
\hline Julian & & \\
\hline Beatrice & & \\
\hline Vincella & & \\
\hline Nancy & & \\
\hline
\end{tabular}

Total: 26 graduate student and/or young professional participants (11 female and 15 male)

\section{The interview questions}

The following questions were posed in English, French or Spanish according to the language preference of the interviewee:

1) How did you first get involved with ecohealth?

a. What enticed you to become involved?

b. What has your involvement looked like?

c.What has been most rewarding for you so far in your involvement with ecohealth?

2) What does ecohealth mean to you?

a.How does ecohealth fit into your wider aspirations?

b. How has your understanding of ecohealth shifted over time?

3) What are the challenges of navigating different institutional contexts (e.g. as a graduate student, professional, researcher etc.) in seeking to address issues of ecological sustainability and/or health?

a. How does ecohealth fit (or not) with the rest of your work?

b.What support networks have you found to be most helpful?

c.What about the role of peers, online communities, mentors, other organizations, etc.?

4) What opportunities do you see for the development of ecohealth communities of practice?

a.What role do you see yourself playing therein?

5) What questions do you have for me? 


\section{Bibliography}

Adams, W.K., K.K. Perkins, N.S. Podolefsky, M. Dubson, N.D. Finkelstein, and C.E. Wieman. (2006). "New instrument for measuring student beliefs about physics and learning physics: The Colorado Learning Attitudes about Science Survey" in Physical Review Special Topics - Physics Education Research 2, 010101. DOI:

10.1103/PhysRevSTPER.2.010101

Akpo, C and Baba-Moussa, A. (2010). Rapport Final: Institutionnalisation de I'approche ecosante en Afrique de l'Ouest et du Centre. Cotonou. Accessed June 132014 : http://idl-bnc.idrc.ca/dspace/bitstream/10625/45417/1/131881.pdf

Alfred, Taiaiake. (2009 [1999]). Peace, Power, Righteousness: an Indigenous Manifesto. Don Mills: Oxford University Press.

Armstrong, Jeannette. (1998). "Land Speaking" in Simon J. Ortiz (ed.) Speaking for the Generations: Native Writers on Writing. Tucson: U of Arizona Press.

Armstrong, Jeannette. (2007). "Indigenous Knowledge and Gift Giving: Living in Community" in Genevieve Vaughan (ed.), Women and the Gift Economy: a Radically Different Worldview is Possible. Toronto: Inanna Publications and Education.

Barnett, Ronald. (2011). Being a University. Abingdon: Routledge.

Battiste, Marie (2001). "Decolonizing the University: Ethical Guidelines for Research Involving Indigenous Populations" in Len M. Findlay \& Paul M. Bidwell (eds.), Pursuing Academic Freedom: "Free and Fearless"? Saskatoon, SK: Purich Press.

Bateson, Gregory. (2000 [1972]). Steps to an Ecology of Mind. New York: Ballantine Books.

Bebbington, Anthony. (2004). "Theorizing participation and institutional change: ethnography and political economy" in Samuel Hickey and Giles Mohan (eds.), Participation: from tyranny to transformation? Exploring new approaches to participation in development. New York: Zed Books.

Berkes, Fikret and C. Folke (eds.). (1998). Linking Social and Ecological Systems: Management practices and social mechanisms for building resilience. Cambridge: Cambridge University Press.

Berkes, Fikret, Johan Colding and Carl Folke. (2000). "Rediscovery of Traditional Ecological Knowledge as Adaptive Management" in Ecological Applications, Vol. 10, No. 5 (Oct, 2000), pp. 1251-1262. 
Biesanz, Mavis Hiltunen, Richard Biesanz, and Karen Zubris Biesanz. (1999). The Ticos: Culture and Social Change in Costa Rica. Boulder, CO/London: Lynne Rienner Publishers.

Bookchin, Murray. (1990). The philosophy of social ecology: essays on dialectical naturalism. Montreal/New York: Black Rose.

Bowers, C.A. (2003). Mindful Conservatism: Rethinking the Ideological and Educational Basis of a Sustainable Future. Oxford: Rowman and Littlefield.

Bowers, C.A., and F. Apfel-Marglin (2005). Rethinking Freire: Globalization and the Environmental Crisis. Mahwah, N.J.: Lawrence Erlbaum.

Brundtland, GH, and World Commission on Environment and Development. (1987). Our common future: report of the World Commission on Environment and Development. Oxford University.

Cajete, Gregory. (2000). Native Science: Natural Laws of Interdependence. Sante Fe: Clear Light Publishers.

Cajete, Gregory. (1994). Look to the mountain: an ecology of Indigenous education. Skyland, NC: Kivaki Press.

Campbell, Marie and Frances Gregor. (2004). Mapping Social Relations: A Primer in Doing Institutional Ethnography. Walnut Creek, CA: Altamira Press.

Capra, Fritjof. (2002). The Hidden Connections: A Science for Sustainable Living. New York: Anchor Books.

Carden, Fred. (2000). "Giving evaluation away: Challenges in a learning-based approach to institutional assessment" in Marisol Estrella (ed.) Learning from Change: Issues and experiences in participatory monitoring and evaluation. London: Intermediate Technology Publications.

Catalyst. (2014). Catalyst Quick Take: Women's Earnings and Income. New York: Catalyst. Accessed 6 August 2014: http://www.catalyst.org/knowledge/womens-earnings-andincome

Charron, Dominique. (2012). Ecohealth Research in Practice: Innovative Applications of an Ecosystem Approach to Health. New York/Ottawa: Springer/IDRC.

Churchill, Ward (ed.). (1983). Marxism and Native Americans. Boston: South End Press.

Cole, Donald, C.C. Crissman \& A.F. Orozco. (2006). "Canada's International Development Research Centre's Eco-Health Projects" in Canadian Journal of Public 
Health; Nov/Dec 2006; 97, 6; Research Library pg. 18.

Cooke, Bill and Uma Kothari. (2001). Participation: The New Tyranny? New York: Zed Books.

Corbin, J and Strauss AL. (2008). Basics of Qualitative Research: Grounded Theory Procedures and Techniques. 3rd edition. Thousand Oaks, New Delhi, London, Singapore: Sage.

Cronon, William. (1995). Uncommon ground: toward reinventing nature. New York/London: W.W. Norton \& Company.

Dakubo, Crescentia Y. (2010). Ecosystems and Health: A critical approach to ecohealth research and practice. New York: Springer.

Dakubo, Crescentia Y. (2004). "Ecosystem approaches to community health planning in Ghana" in EcoHealth (1), pp. 50-59.

Davis, Mike. (2006). Planet of Slums. London: New Left Books.

Davis, Lynne (ed.). (2010). Alliances: Re/Envisioning Indigenous-non-Indigenous Relationships. Toronto/Buffalo/London: University of Toronto Press.

De Guerre, DW and Taylor, MM. (2004). "Graduate Leadership Education in a SocioEcological Perspective: Working at the Paradigmatic Interface" in O'Sullivan and Taylor (eds.) Learning Toward an Ecological Consciousness: Selected Transformative Practices. New York: Palgrave MacMillan.

Denzin, Lincoln, \& Smith. (2008). Handbook of Critical and Indigenous Methodologies. Los Angeles, London, New Delhi, Singapore: Sage.

De Plaen, R. and C. Kilelu. (2004). "From Multiple Voices to a Common Language: Ecosystem Approaches to Human Health as an Emerging Paradigm" in Ecohealth 1 (Suppl. 2), 8-15.

Dewey, John. (1997 [1938]). Experience and Education. New York, NY: Touchstone.

Dewey, John. (1958). Experience and Nature. Mineola, N.Y.: Dover Publications.

Dei, George J. Sefa, Budd L. Hall, and Dorothy Goldin Rosenberg (eds.). (2000). Indigenous Knowledges in Global Contexts: Multiple Readings of Our World. Toronto: OISE/UT book published in association with University of Toronto Press.

Dei, George Sefa. (2012). “Indigenous anti-colonial knowledge as 'heritage knowledge' 
for promoting Black/African education in diasporic contexts" in Decolonization: Indigeneity, Education \& Society, Vol. 1, No. 1, 2012, pp. 102-119.

Dirlik, Arif. (2006). "Introduction: Our Ways of Knowing-and What to Do About Them?" in Arif Dirlik (ed.), Pedagogies of the Global: Knowledge in the Human Interest. Boulder, CO: Paradigm.

Eagleton, Terry. (2000). The Idea of Culture. Oxford: Blackwell.

Esbjorn-Hargens, Sean and Zimmerman, Michael. (2009). Integral Ecology: Uniting Multiple Perspectives on the Natural World. Boston \& London: Integral Books.

Fanon, Frantz. (1968). The Wretched of the Earth. New York: Grove Press.

Feagan, M., Koné, B., Brou, N., Houenou, Y.A., Kouassi, E. and Spiegel, J. (2014). "Réflexion critique des approches écosystémiques de la santé sur la base des expériences des jeunes chercheurs au Canada, en Afrique Occidentale et Centrale et en Amérique Centrale," in Vertigo (Hors-série).

Feagan, M. (2014). Exploring a New Model With the Next Generation of Transdisciplinary Researchers: Peer-to-Peer Action Research in Canada and Latin America. A report presented to the International Development Research Centre, December 2014.

Foster, John Bellamy. (2001). Marx's Ecology: Materialism and Nature. New York: Monthly Review Press.

Freire, Paulo. (1972). Pedagogy of the Oppressed. New York, NY: Herder \& Herder.

Gadamer, Hans-Georg. (1975). Truth and Method. New York: Continuum.

Gans, Herbert (1999). "Participant Observation in the Era of "Ethnography" in Journal of Contemporary Ethnography, Vol. 28, No. 5.

Garfinkel, Harold. (1967). Studies in Ethnomethodology. Englewoods Cliff, NJ: PrenticeHall.

Geertz, Clifford. (1973). The Interpretation of Cultures: Selected Essays. New York: Basic Books.

Gibney, Elizabeth. (2013). "A different world" in Times Higher Education. 31 January 2013. Accessed 25 July 2014. http://www.timeshighereducation.co.uk/features/a-differentworld/2001128.article

Gibson-Graham, J.K., Jenny Cameron, and Stephen Healy. (2013). Take Back the 
Economy: An Ethical Guide for Transforming Our Communities. London: University of Minnesota Press.

Giroux, Henry A. and Susan Searls Giroux. (2008). "Challenging Neoliberalism's New World Order: The Promise of Critical Pedagogy" in Denzin, Lincoln, \& Smith, Handbook of Critical and Indigenous Methodologies. Los Angeles, London, New Delhi, Singapore: Sage.

Gordon, Todd. (2010). Imperialist Canada. Winnipeg: Arbeiter Ring Publishing.

Gordon, Tuula, J. Holland, and E. Lahelma. (2001). "Ethnographic research in educational settings" in Paul Atkinson et al (eds.) Handbook of ethnography. London: Sage.

Gramsci, Antonio. (1971). Selections from the Prison Notebooks. New York, NY: International Publishers.

Grande, Sandy. (2008). "Red Pedagogy: The Un-Methodology" in Denzin, Lincoln, \& Smith (eds.), Handbook of Critical and Indigenous Methodologies. Los Angeles, London, New Delhi, Singapore: Sage.

Guattari, Felix. (2000 [1989]). The Three Ecologies. London: Athlone Press.

Harding, Sandra (ed.). (2004). The Feminist Standpoint Theory Reader: Intellectual \& Political Controversies. New York / London: Routledge.

Hartsock, Nancy. (2004). "The Feminist Standpoint: Developing the Ground for a Specifically Feminist Historical Materialism" in Sandra Harding (ed.), The Feminist Standpoint Theory Reader: Intellectual \& Political Controversies. New York / London: Routledge.

Hickey, Samuel and Giles Mohan. (2004). Participation: from tyranny to transformation? Exploring new approaches to participation in development. New York: Zed Books.

IPCC. (2013). Climate Change 2013: The Physical Science Basis. Contribution of Working Group I to the Fifth Assessment Report of the Intergovernmental Panel on Climate Change [Stocker, T.F., D. Qin, G.-K. Plattner, M. Tignor, S.K. Allen, J. Boschung, A. Nauels, Y. Xia, V. Bex and P.M. Midgley (eds.)]. Cambridge University Press, Cambridge, United Kingdom and New York, NY, USA, 1535 pp.

Jackson, Michael C. (2000). Systems Approaches to Management. New York/London: Kluwer Academic/Plenum Publishers. 
Jameson, Frederic. (2004). "History and Class Consciousness as an 'Unfinished Project'," in Sandra Harding (ed.), The Feminist Standpoint Theory Reader: Intellectual \& Political Controversies. New York / London: Routledge, pp. 143-152.

Johnson, Richard. (2008). “University Challenge: Neoliberal Abstraction and Being More Concrete" in Canaan and Schumar (eds.) Structure and Agency in the Neoliberal University. New York: Routledge.

Kay. J., Regier, H., Boyle, M. and Francis, G. (1999). "An Ecosystem Approach for Sustainability: Addressing the Challenge of Complexity" Futures Vol 31, \#7, Sept. 1999, pp.721-742.

Kay, J. (1994). "The Ecosystem Approach, Ecosystems as Complex Systems and State of the Environment Reporting", prepared for North American Commission for Environmental Cooperation, State of the North American Ecosystem meeting, Montreal, Canada. 8-10 December, 1994, 42 pages.

Kay, J, Schneider, E.D,. (1994). "Embracing Complexity, The Challenge of the Ecosystem Approach", Alternatives Vol 20 No.3 pp.32- 38

Kovel, Joel. (2007 [2002]). The Enemy of Nature: the End of Capitalism or the End of the World? New York: Zed Books.

Koné B, Feagan M, Houenou YA, Brou N, Houenou PV, Fayomi B, Ngnikam E, Cissé G, Spiegel J, et Kouassi E. (2011). "Facilitating the Relationship Between Researchers and Policy-Makers: Experiences from Three Ecohealth Projects in West and Central Africa," in EcoHealth (8), pp. 413-417.

Kuhn, Thomas. (1962). The Structure of Scientific Revolutions. Chicago and London: The University of Chicago Press.

Laiken, Marilyn E. (2004). "The Ecology of Learning and Work: Learning for Transformative Work Practices" in O'Sullivan, Edmund and Mary Taylor (eds.) Learning Toward an Ecological Consciousness: Selected Transformative Practices. New York: Palgrave MacMillan.

Lazerson, Marvin. (1998). "The Disappointments of Success: Higher Education After World War II" in Annals of the American Academy of Political and Social Science, Vol. 559, The Changing Educational Quality of the Workforce, September 1998, pp. 64-76.

Lebel, J. (2003). In Focus: Health - An Ecosystem Approach. Ottawa: International Development Research Centre.

Lebel J, Mergler D, Lucotte M, Amorim M, Dolbec J, Miranda D, Arantes G, Rheault I and 
Pichet P. (1996). "Evidence of early nervous system dysfunction in Amazonian populations exposed to low-levels of methylmercury". Neurotoxicology, 17: 157-167. Leopold, Aldo. (1949). A Sand County Almanac: and sketches here and there. New York/Oxford: Oxford University Press.

Luxemburg, Rosa. (1900). Reform or Revolution. Transcription: A. Lehrer. [accessed April 4, 2011]: http://www.marxists.org/archive/luxemburg/1900/reform-revolution/index.htm

Marcuse, Herbert. (1964). One-Dimensional Man: Studies in the Ideology of Advanced Industrial Society. Boston: Beacon Press.

McCullagh S, Hunter B, Houle K, Massey C, Waltner-Toews D, Lemire M, Saint-Charles J, Surette C, Webb J, Beck L, Parkes M, Woollard R, Berbés-Blázquez M, Feagan M, Halpenny C, Harper S, Oestreicher S, Morrison, K (Eds.) (2012). Ecosystem Approaches to Health Teaching Manual. Canadian Community of Practice in Ecosystem Approaches to Health.

McHarg, lan. (1969). Design with nature. New York: Natural History Press.

McNally, David. (2011). Global Slump: The Economics and Politics of Crisis and Resistance. Oakland: PM press.

Midgley, G. (2000). Systemic Intervention: Philosophy, Methodology, and Practice. New York: Kluwer Academic/Plenum Publishers.

Millennium Ecosystem Assessment. (2005). Ecosystems and Human Well-Being: General Synthesis. Washington, DC: Island Press.

Moeller, DW., Pahl, HB., Hammond, PB. (1979). "Trends in university environmental health research and training" in American Journal of Public Health, 69 (2), February, pp. 125-9.

Muirhead, B. \& R.N. Harpell. (2010). IDRC: 40 years of ideas, innovation, and impact. Waterloo: Wilfrid Laurier Press.

Nguyen, V. (2011). Understanding the Concept and Practice of Ecosystem Approaches to Health in the Context of Public Health. Master's thesis. University of Guelph.

Nyamnjoh, Francis B. (2012). "'Potted Plants in Greenhouses': A Critical Reflection on the Resilience of Colonial Education in Africa" in Journal of Asian and African Studies, 47(2), pp. 129-154. 
O'Sullivan, Edmund and Mary Taylor. (2004). Learning Toward an Ecological Consciousness: Selected Transformative Practices. New York: Palgrave MacMillan.

Parkes, Margot, Charron, D. and Sanchez, A. (2012). "Better together: Field-Building Networks at the Frontiers of EcoHealth Research" in Charron (ed.) Ecohealth Research in Practice: Innovative Applications of an Ecosystem Approach to Health. New York/Ottawa: Springer/IDRC.

Peet, Richard and Michael Watts (eds.). (2004). Liberation Ecologies: Environment, Development, Social Movements. London: Routledge.

Poteete, Janssen, \& Ostrom, E. (2010). Working Together: Collective action, the commons, and multiple methods in practice. Princeton and Oxford: Princeton University Press.

Readings, Bill. (1996). The University in Ruins. Cambridge, Mass: Harvard U Press.

Rebick, Judy. (2009). Transforming Power: From the Personal to the Political. Toronto: Penguin.

Reyes-Cruz, Mariolga. (2012). "Ni con dios ni con el diablo: Tales of survival, resistance and rebellion from a reluctant academic" in Decolonization: Indigeneity, Education \& Society, Vol. 1, No. 1, pp. 141-157.

Reynolds, H. E.S. Brondizio and J.M. Robinson. (2010). Teaching Environmental Literacy Across Campus and Across the Curriculum. Bloomington: Indiana U Press.

Rose, Hilary. (2004). "Hand, Brain, and Heart: A Feminist Epistemology for the Natural Sciences" in Sandra Harding (ed.), The Feminist Standpoint Theory Reader: Intellectual \& Political Controversies. New York / London: Routledge.

Rosenberg, Charles E. (1997 [1976]). No Other Gods: On Science and American Social Thought. Baltimore/London: John Hopkins University Press.

Santos, de Sousa Boaventura. (2009). "A non-occidentalist West? Learned ignorance and ecology of knowledge" in Theory, Culture \& Society (SAGE, Los Angeles, London, New Delhi, and Singapore), Vol. 26(7-8): 103-125.

Santos, de Sousa Boaventura (ed.) (2008). Another Knowledge Is Possible: Beyond Northern Epistemologies. London/NewYork: Verso.

Scott, W. and S. Gough. (2003). Sustainable Development and Learning: Framing the Issues. London/New York: Routledge. 
Sibbel, Anne. (2009) "Pathways towards sustainability through higher education" in International Journal of Sustainability in Higher Education, Vol. 10 Iss: 1, pp.68 - 82.

Simpson, Leanne. (2008). Lighting the Eighth Fire: the Liberation, Resurgence, and Protection of Indigenous Nations. Winnipeg: Arbeiter Ring Publishing.

Smith, Dorothy E. (2004 [1974]). "Women's Perspective as a Radical Critique of Sociology," in Sandra Harding (ed.), The Feminist Standpoint Theory Reader: Intellectual \& Political Controversies. New York / London: Routledge.

Smith, Dorothy E. (2005). Institutional Ethnography: a Sociology for People. Toronto: Altamira Press.

Smith, Linda T. (1999). Decolonizing Methodologies: Research and Indigenous Peoples. New York/London: Zed Books.

Spiegel, Jerry M, Jaime Breilh, Efrain Beltran, Jorge Parra, Fernanda Solis, Annalee Yassi, Alejandro Rojas, Elena Orrego, Bonnie Henry, William R Bowie, Laurie Pearce, Juan Gaibor, Patricio Velasquez, Miriam Concepcion, and Margot Parkes. (2011). "Establishing a community of practice of researchers, practitioners, policy-makers and communities to sustainably manage environmental health risks in Ecuador." BMC Int Health Hum Rights. 2011; 11(Suppl 2): S5. Published online Nov 8, 2011. doi: 10.1186/1472-698X-11-S2-S5: http://www.ncbi.nlm.nih.gov/pmc/articles/PMC3247836/

Suzuki, David. (2012). "The fundamental failure of environmentalism." David Suzuki Foundation Blog Accessed June 14, 2014: http://www.davidsuzuki.org/blogs/sciencematters/2012/05/the-fundamental-failure-of-environmentalism/

Uhl, Christopher. (2003). Developing Ecological Consciousness: Path to a Sustainable World. Toronto: Rowman and Littlefield Publishers.

Uhl, Christopher. (2013). Developing Ecological Consciousness: The End of Separation (Second Edition). Lanham, MD: Rowman and Littlefield.

United Nations. (1973). Report on the United Nations Conference on the Human Environment. Stockholm, 5-16 June 1972. New York: United Nations. Accessed 16 August 2014: http://www.un.org/en/ga/search/view_doc.asp?symbol=A/CONF.48/14/Rev.1

United Nations. (1992). Report of the United Nations Conference on Environment and Development. Rio de Janeiro, 3-14 June 1992. Accessed 16 August 2014: http://www.un.org/documents/ga/conf151/aconf15126-1annex1.htm

United Nations. (1997). Outcome document: General Assembly resolution S-19/2 of 27 June 1997, Programme for the Further Implementation of Agenda 21. Accessed 16 August 
2014: http://www.un.org/en/ga/search/view_doc.asp?symbol=A/RES/S-19/2

United Nations. (2002). Report of the World Summit on Sustainable Development. Johannesburg, South Africa, 26 August- 4 September, 2002. New York: UN. Accessed 16 August 2014: http://www.un.org/en/ga/search/view_doc.asp?symbol=A/CONF.199/20

United Nations. (2012). Report of the United Nations Conference on Sustainable Development. Rio de Janeiro, Brazil, 20-22 June 2012. New York: UN. Accessed 16 August 2014: http://www.un.org/en/ga/search/view_doc.asp?symbol=A/CONF.216/16

Vaughan, Genevieve (ed.). (2007). Women and the Gift Economy: a Radically Different Worldview is Possible. Toronto: Inanna Publications and Education.

Volosinov, V.N. (1973). Marxism and the Philosophy of Language. New York and London: Seminar Press.

Vygotsky, L.S. (1962). Thought and Language. Cambridge, Mass: MIT Press.

Wallerstein, Immanuel. (2004). World-Systems Analysis: An Introduction. Durham and London: Duke University Press.

Waltner-Toews, David, Kay, James, and Lister, Nina-Marie. (2008). The Ecosystem Approach: Complexity, Uncertainty, and Managing for Sustainability. New York: Columbia University Press.

Webb, Jena, D. Mergler, M. Parkes, J. Saint-Charles, J. Spiegel, D. Waltner-Toews, A. Yassi and R. Woollard. (2010). "Tools for Thoughtful Action: The Role of Ecosystem Approaches to Health in Enhancing Public Health" in Canadian Journal of Public Health, November/December 2010, pp439-441.

White, Jessica. (2006). Ecohealth Research Awards Program Tracer Study: Final Draft. International Development Research Centre.

Wilson, Shawn. (2008). Research Is Ceremony: Indigenous Research Methods. Halifax, NS: Fernwood.

Wolf, Eric. (1982). Europe and the People Without History. Berkeley: University of California Press.

Yip, Julianne. (2013). "An Anthropology of 'Avian Flu': Beyond the Nature-Culture Divide", A thesis submitted to McGill University in partial fulfillment of the requirements of the degree of Master of Arts in Anthropology. 
Zizek, Slavoj. (2007) "Censorship Today: Violence, or Ecology as a new Opium for the Masses." Accessed 26 February 2010:

http://nosubject.com/Censorship_Today:_Violence,_or_Ecology_as_a_New_Opium_for_th e_Masses 